\title{
SEEDLING RECRUITMENT OF THE \\ INVASIVE SPECIES BERBERIS DARWINII \\ (DARWIN'S BARBERRY): WHAT \\ CONTRIBUTES TO INVASION SUCCESS?
}

\author{
by \\ Katherine (Kate) Grace McAlpine
}

A thesis submitted to Victoria University of Wellington in fulfilment of the requirements for the degree of Doctor of Philosophy in Science

Victoria University of Wellington

2005 


\section{ABSTRACT}

Berberis darwinii is an invasive tree species that is considered a serious threat to indigenous ecosystems and biodiversity conservation throughout New Zealand. I examined the recruitment dynamics of this species in order to identify traits contributing to invasion success, and thus pinpoint critical stages for management. In order to do this, I measured patterns of both spatial and temporal seed dispersal, and compared rates of germination and seedling survival across a range of light environments. I also measured patterns of growth, biomass allocation, photosynthetic performance, leaf morphology, and water use efficiency across different light environments. In most of these experiments I compared the performance of $B$. darwinii to four ecologically similar, co-occurring native species. Berberis darwinii produced large quantities of viable seed that were widely dispersed by birds. Almost all viable seeds germinated in the spring following dispersal, indicating that $B$. darwinii does not form a persistent seed bank. Rates of germination and seedling survival were significantly higher in $B$. darwinii compared to the native species, although seedling establishment of all species was limited to high-light environments. Berberis darwinii also had approximately twice the photosynthetic capacity of the native species, but this advantage was limited to high-light environments. Berberis darwinii does not vary significantly in proportional biomass allocation across light environments, suggesting that this type of plasticity does not contribute to invasion success. Berberis darwinii was more water use efficient in sun compared to shade, but the same pattern was evident in four of the five native species. The critical stage of recruitment for $B$. darwinii was first-year seedling establishment. Rates of mortality were highest at this stage, and were largely associated with seedling density and low light availability. Seedling mortality was near $100 \%$ beneath the parent canopy, indicating that seed dispersal is critical to $B$. darwinii recruitment. These results suggest that $B$. darwinii is not shade-tolerant as a seedling, and that management practices should be concentrated on the removal of fruiting adult plants and seedlings growing in open sites. 


\section{ACKNOWLEDGEMENTS}

Many, many thanks to my two supervisors from Victoria University: Don Drake for getting me started, and Linley Jesson for guiding me, supporting me, and generally getting me to the end point. I am also grateful to Victoria University for a postgraduate scholarship grant. And a special thanks to the Department of Conservation, especially Susan Timmins, for allowing me to turn this project into a (paid!) job.

For extra guidance, feedback, support, and/or assistance in the field, thanks also to Chris Boorman, Lindsay Eaton, Chris Edkins, Richard FitzJohn, Harshi Gamage, Phil Garnock-Jones, Rod Hay, Clayson Howell, Mark Kearney, Dave Kubien, Tony Lawson, Shona Mackay, Carol McAlpine, Grant McAlpine, Rachel McAlpine, Leeann Peden, Shirley Pledger, Ian Popay, Susan Timmins, Justine Ward, Sue Wilkins, and the wonderful staff at the Karori Wildlife Sanctuary. For technical and administrative support, thanks to Victoria University staff, particularly Lesley Milicich, but also Mary Murray, Peter Watson, and Alan Hoverd. 


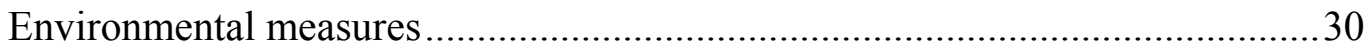

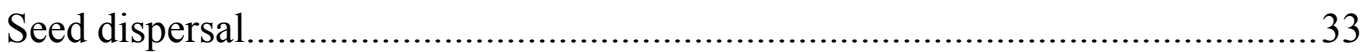

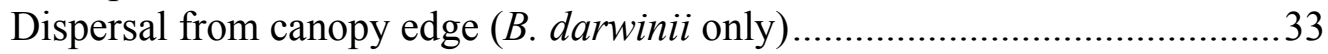

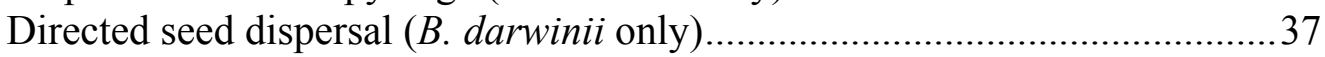

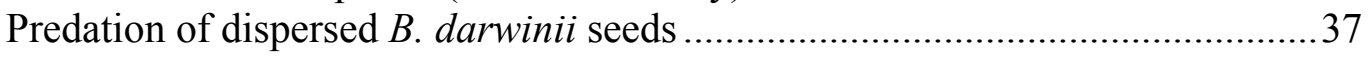

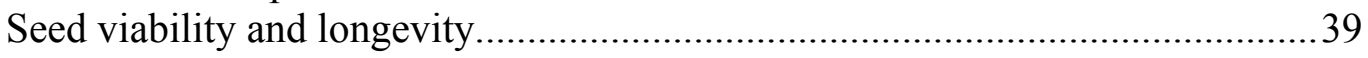

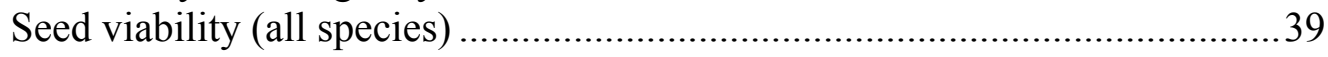

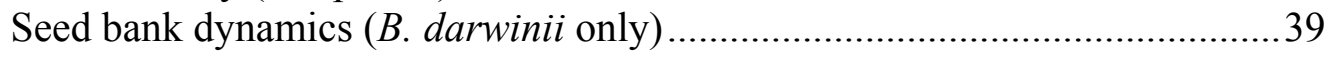

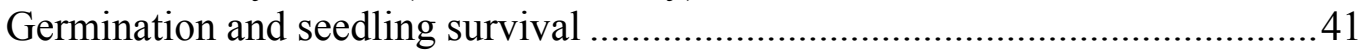

Germination and survival of seeds sown in the field (all species)..................41

Natural seedling establishment (B. darwinii only) ......................................45

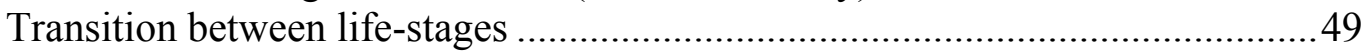

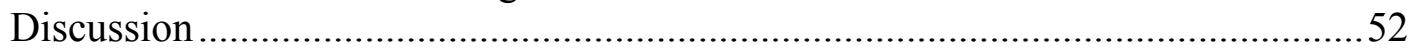

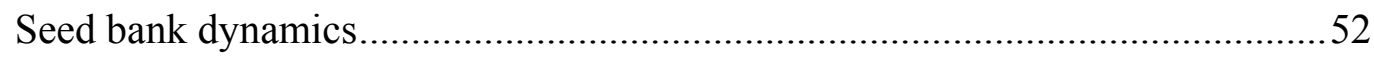

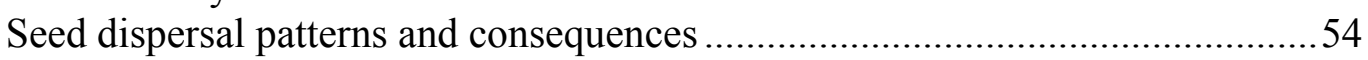

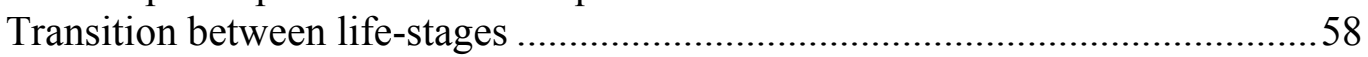

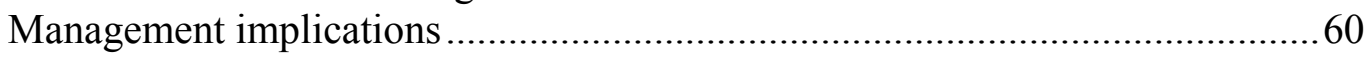

\section{CHAPTER THREE. PATTERNS OF BIOMASS ALLOCATION DO NOT} APPEAR TO CONTRIBUTE TO INVASION SUCCESS IN BERBERIS

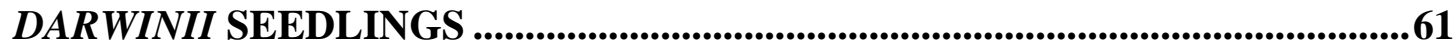

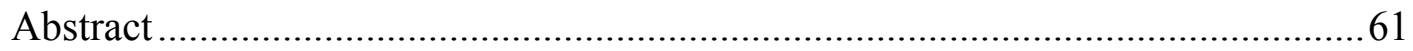

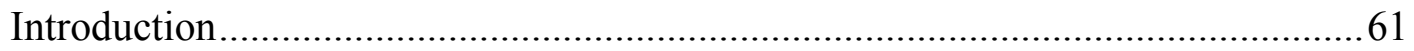

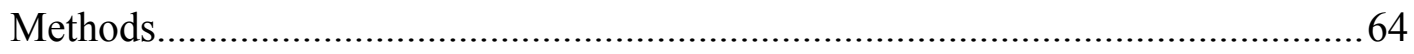

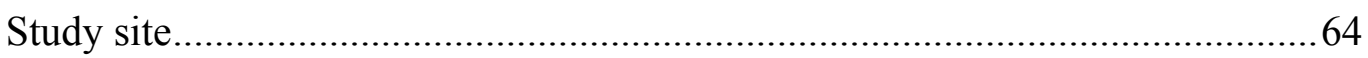

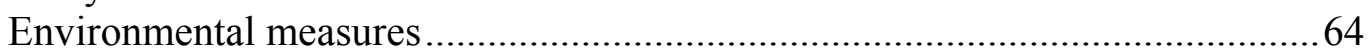

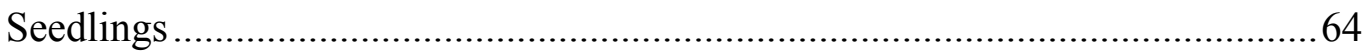

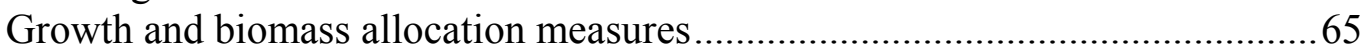

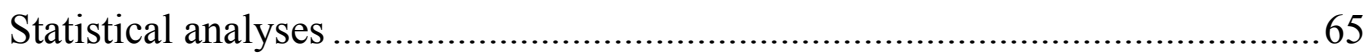

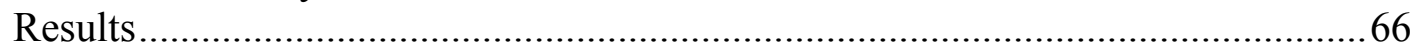

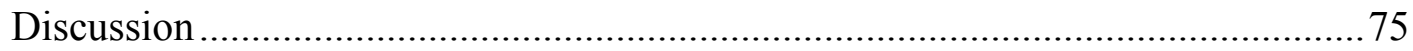

CHAPTER FOUR. PHOTOSYNTHESIS AND WATER USE EFFICIENCY: A COMPARISON BETWEEN INVASIVE AND NATIVE SPECIES .....................79

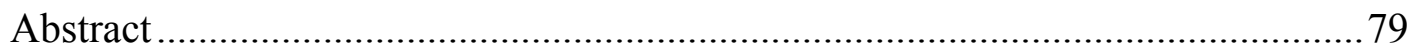

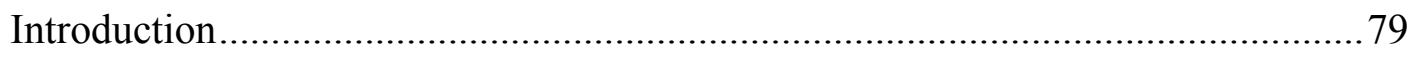

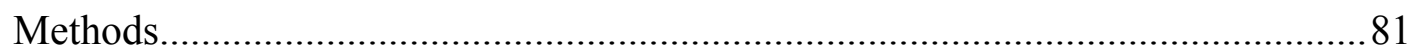

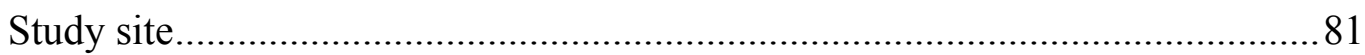

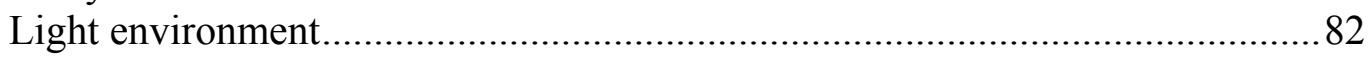

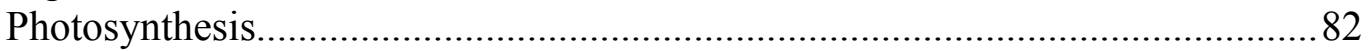

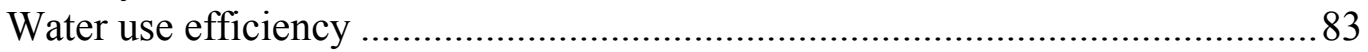

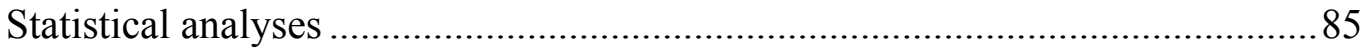

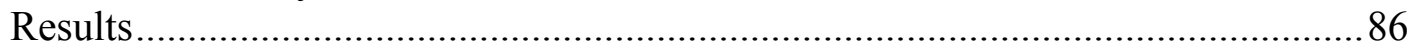

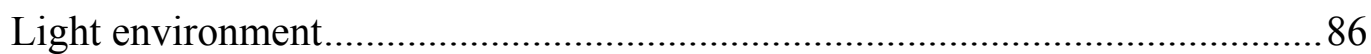

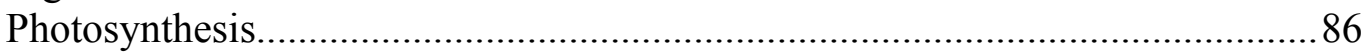

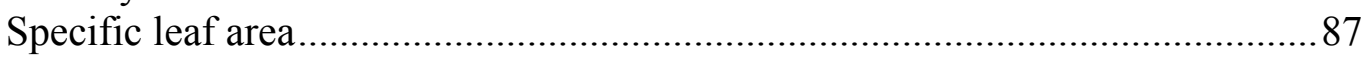

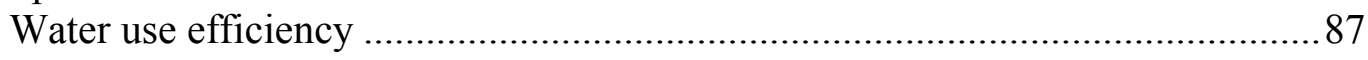

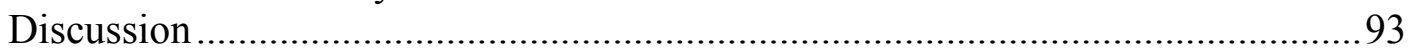


CHAPTER FIVE. WHY IS BERBERIS DARWINII SUCH A SUCCESSFUL ENVIRONMENTAL WEED? ........................................................................96

Factors contributing to invasion success..............................................................96

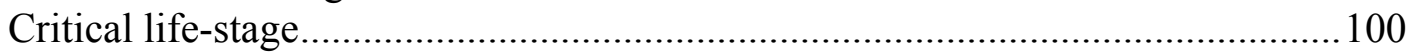

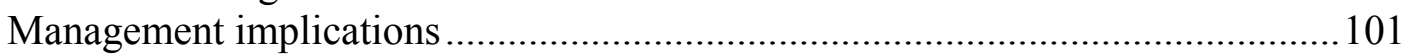

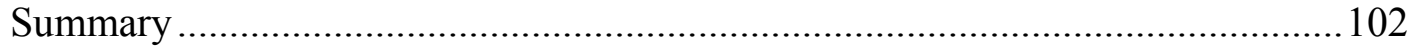

REFERENCES..............................................................................................................103 


\section{LIST OF TABLES}

Table 2.1. ANOVA of response variables canopy openness, litter depth, and soil moisture by site (both seed sowing and sampling station sites).

Table 2.2. ANOVA of Berberis darwinii seed dispersal by distance from source population and by year.

Table 2.3. Linear mixed-effects model of germination of the five study species by location, canopy openness, soil moisture, litter depth, and site.

Table 2.4. Linear mixed-effects model of seedling survival of the five study species by location, canopy openness, soil moisture, litter depth, and site.

Table 2.5. Generalized linear model of survival of two cohorts of naturally-occurring Berberis darwinii seedlings by seedling density, year, canopy openness, and distance from source population.

Table 2.6. Transition ratios between life-stages (seed rain: seed bank, seed bank: seedling, and seed rain: seedling).

Table 2.7. Generalized linear model of survival of one cohort of naturally-occurring Berberis darwinii seedlings by seed rain density, seed bank density, seedling density, canopy openness, and distance from source population.

Table 3.1. ANOVA using linear mixed effects model of growth and biomass allocation parameters of Berberis darwinii seedlings by light environment, site, and plot. . .66

Table 3.2. Multivariate analysis of variance of biomass proportions (root, stem, leaf) of Berberis darwinii seedlings by light environment, site, and plot. .66 
Table 4.1. Generalized linear model of photosynthetic and leaf parameters by light environment and species, and linear mixed effects models of water use efficiency by light environment and species. ........................................... 87 


\section{LIST OF FIGURES}

Figure 2.1. Map of study site (Karori Wildlife Sanctuary) and sampling locations...20

Figure 2.2. Layout of experimental plots associated with treefall gaps.

Figure 2.3. Boxplots of a) canopy openness, b) litter depth, and c) soil moisture in different light environments associated with seed sowing experiment.

Figure 2.4. Boxplots of canopy openness at sampling stations located at increasing distance from source Berberis darwinii population.

Figure 2.5. Total number of Berberis darwinii seeds dispersed to ten sites increasing in distance from the source population over two fruiting seasons.

Figure 2.6. Average number of Berberis darwinii seeds dispersed per $\mathrm{m}^{2}$ per month, to ten sites increasing in distance from the source population over two fruiting seasons.

Figure 2.7. Berberis darwinii seedling emergence beneath, and away from, hinau and Fuchsia trees.

Figure 2.8. Germination of Berberis darwinii seeds. a) Fresh seeds collected and sown monthly during the fruiting season of 2000-01, b) seeds buried then retrieved periodically over 19 months, and c) seed bank samples collected periodically over the 12 months following the fruiting season of 2000-01. 39

Figure 2.9. Average percent germination and seedling survival of Berberis darwinii and four co-occurring native species, in a range of light environments.

Figure 2.10. Comparison of natural Berberis darwinii seed rain, seed bank, and seedling establishment per $\mathrm{m}^{2}$ relating to two summers of seed production. 45 
Figure 2.11. Survival of naturally occurring Berberis darwinii seedlings at increasing distances from source population, five months after germination.

Figure 3.1. Total leaf, stem, and root biomass of Berberis darwinii seedlings grown for 6 months in different light environments.

Figure 3.2. Boxplots of leaf and stem measurements of Berberis darwinii seedlings grown for 6 months in different light environments: a) stem length, b) total number of leaves, and c) total leaf area. .68

Figure 3.3. Boxplots of root: shoot ratios of Berberis darwinii seedlings grown for 6 months in different light environments. .69

Figure 3.4. Proportion of biomass allocated to roots, stem, and leaves in Berberis darwinii seedlings grown for 6 months in different light environments.

Figure 3.5. Boxplots of leaf characteristics of Berberis darwinii seedlings grown for 6 months in different light environments: a) specific leaf area, b) leaf area ratio, and c) leaf mass ratio.

Figure 3.6 Boxplots of percent survival of Berberis darwinii seedlings grown for 6 months in different light environments.

Figure 4.1. Photosynthetic measurements from wild plants growing in sun and shade:

a) $A_{\max }$, b) quantum yield, and c) dark respiration. . .86

Figure 4.2. Light response curves from wild plants growing in sun and shade. .88

Figure 4.3. Specific leaf area of leaves on which photosynthesis was measured. .....89

Figure 4.4. Carbon isotope composition $\left(\delta^{13} \mathrm{C}\right)$ of wild plants growing in sun and shade as a measure of water use efficiency 


\section{CHAPTER ONE. SEEDLING RECRUITMENT OF BERBERIS DARWINII: WHAT FACTORS MIGHT CONTRIBUTE TO INVASION SUCCESS?}

\section{Introduction}

A species can be defined as invasive if it a) has been introduced (usually by human action) to an area where it did not previously occur naturally, b) successfully reproduces and/or spreads in the new location without further intervention by humans, and c) becomes a pest in the new location, threatening the local biodiversity or ecosystems in some way. Invasive weed species can profoundly alter the structure and function of natural ecosystems (Shimizu and Tabata 1985; Hobbs and Mooney 1986; Braithwaite and Lonsdale 1987; Vitousek et al. 1987; Braithwaite et al. 1989; Vitousek 1990; D'Antonio et al. 1999; Bellingham et al. 2005), and are currently considered one of the most serious threats to global biological diversity (Heywood 1989; Stone et al. 1992; Lodge 1993a; Cronk and Fuller 1995; Luken and Thieret 1997; Schmitz et al. 1997; Adair and Groves 1998). Accordingly, ecologists have long been searching for a universal set of biological and ecological attributes that define - and thus predict — "weediness" in plants (Baker 1965; Barrett and Richardson 1986; Bazzaz 1986; Lodge 1993b). However, weeds as a group display many combinations of weedy and non-weedy attributes (Kornberg and Williamson 1986; Newsome and Noble 1986; Roy 1990; Binggeli 1996) and competitiveness is often highly habitat-dependent (Thompson et al. 1995; Daehler 2003). Consequently, there is rarely a simple answer to the question of what determines invasion success. Nevertheless, detailed studies of recruitment dynamics continue to build on this growing body of knowledge, and, perhaps more importantly, provide valuable information for the management of invasive species. (e.g. Wiser et al. 1998; Ehrenfeld 1999; Lavergne et al. 1999; Almasi 2000; Radford et al. 2002; Aragón and Groom 2003). In this thesis I take this approach, and examine the recruitment dynamics of the invasive species Berberis darwinii Hook. (Berberidaceae). Berberis darwinii is a woody, evergreen, bird-dispersed shrub, native to southern Chile and Argentina. First recorded as naturalised in 1946 (Sykes 1982), it has since invaded a wide range of 
environments throughout New Zealand (Webb et al. 1988). It is recognised as a serious threat to indigenous ecosystems and biodiversity conservation in many areas of New Zealand, and accordingly is included in the regional pest management plans of five regional councils (Waikato, Taranaki, Manawatu, Wellington, and Southland). It has also been declared an unwanted organism by the Department of Conservation, which means that it is illegal to propagate, sell, or distribute it within New Zealand. The aims of this thesis are to a) identify factors contributing to invasion success in this species and, b) identify the ideal time (e.g. life stage) and place (e.g. light environment) to implement control measures.

Case studies of invasion success evince many different factors that contribute to invasion success. For example, differences in reproductive efforts (Callaway and Josselyn 1992; Vilà and D'Antonio 1998), seed dispersal (Richardson et al. 1987; Sallabanks 1993; Lavergne et al. 1999), germination and establishment requirements (Honig et al. 1992; Aragón and Groom 2003), phenotypic or physiological plasticity (Williams and Black 1994; Williams et al. 1995; Schweitzer and Larson 1999; Stratton and Goldstein 2001), biomass allocation (Baruch et al. 2000), carbon fixation and growth rate (Pattison et al. 1998; Durand and Goldstein 2001a), and susceptibility to seed predation (Richardson et al. 1987; Yamashita et al. 2003), herbivory (Schierenbeck et al. 1994), and pathogens (Goergen and Daehler 2001; Mitchell and Power 2003) have all been shown to give invasive species an advantage over competing indigenous species. Conversely, in a recent review of 79 independent native-invasive plant comparisons, the invasive species were not found to be statistically more likely to have higher growth rates, competitive ability, or fecundity, and under some conditions were less competitive than natives (Daehler 2003). The probability of invasion also depends on the "invasibility" of the recipient environment - for example environmental conditions, the level of disturbance, and the composition and diversity of the local plant community may render it more or less likely to be invaded (Burke and Grime 1996; Tilman 1997; Woitke and Dietz 2002; Burns and Miller 2004). In any case, it seems likely that factors contributing to invasion success in any given species may vary both spatially and temporally. Detailed case studies on the ecology of individual species will continue to shed light on these processes and contribute to the growing body of knowledge on invasion biology. 
Many such studies of invasion success are essentially studies of the seed and seedling stages, because without seed and seedling survival, there can be no recruitment (Harper 1977; Cavers 1983; Fenner 1987; Drake et al. 1989; Jones and Sharitz 1998; Ellison and Parker 2002; Hille Ris Lambers and Clark 2003). As per John Harper's (1977) maxim, in plant ecology the action is in the transition of seeds to seedlings; what comes later is history. In other words, the structure and composition of a forest community may be largely determined at early life history stages. An understanding of recruitment dynamics - and thus invasion success - requires an understanding of the many interacting processes operating at these early stages. This study examines seed and seedling traits in Berberis darwinii from the time mature seeds are released from the parent plant, to the time seedlings emerge and become photosynthetically self-sufficient: i.e. the stages of seed dispersal, seed bank characteristics, germination, first-year seedling survival, seedling growth and biomass allocation, and photosynthesis. The role these traits play in seedling establishment, and their potential contribution to invasion success are discussed in more detail below.

\section{Seed dispersal}

Seed dispersal can be a crucial component of recruitment, and thus invasion success. In many cases there can be no invasion without dispersal, because seed arrival is a necessary first step of recruitment. Dispersal is also vital to many species because density-dependant mortality beneath the parent plant can be as high as $100 \%$, usually due to factors such as sibling competition, increased predator, pathogen and herbivore activity (Janzen 1970; Connell 1971; Augspurger 1983b; Augspurger and Kelly 1984; Howe 1993; Hulme 1998), and possibly also because of parental allelopathic effects (Rice 1983; Friedman 1994).

Spatial patterns of seed dispersal determine the initial template upon which subsequent recruitment takes place. Patterns of seed deposition usually decline exponentially with increasing distance from the source population, regardless of the dispersal vector, but seed dispersed by animals can also be concentrated around preferential perching, nesting, or hoarding sites (Willson and Crome 1989; McClanahan and Wolfe 1993; Herrera 1995; Verdú and García-Fayos 1996). If the 
dispersal vector deposits seeds disproportionately to sites favourable for germination and survival, recruitment is likely to be enhanced. Knowing where seeds are likely to be deposited enables managers to search effectively for new individuals or populations, and also to accurately assess the likelihood of reinvasion following control. However, this also requires knowledge of where seeds are likely to germinate and survive as seedlings. In some cases, the pattern of seedling establishment is very similar to the initial pattern of seed deposition, which suggests that most seeds germinate and establishment wherever they land-hence recruitment is limited largely by seed availability (e.g. Herrera et al. 1994; Ackerman et al. 1996; Ehrlén and Eriksson 2000; e.g. Traveset et al. 2003). If, however, patterns of seedling establishment do not reflect patterns of seed deposition, this suggests that microsite availability is the main limitation on recruitment; germination and seedling establishment occur only in 'safe sites' (sensu Harper 1977) that offer favourable environmental conditions (e.g. Houle 1992; Houle 1995; Jordano and Herrera 1995; Houle 1998; Russell and Schupp 1998; Lavergne et al. 1999). The consequences of dispersal, and the likely pattern of invasion, thus depend on whether recruitment is seed- or microsite-limited.

\section{Seed bank}

Seeds can also be dispersed in time if they persist in the soil for more than a few months. This too can contribute to invasion success, particularly if coupled with effective spatial dispersal, because a persistent seed bank allows an individual to "lie in wait" for future regeneration opportunities. This ability is particularly advantageous in environments where germination opportunities are infrequent, or unpredictable (Harper 1977; Grime 1989; Parker et al. 1989). There are three main types of seed bank (c.f. Bakker et al. 1996): i) transient, where seeds persist for less than one year, ii) short-term persistent, where seeds persist for 1-5 years, and iii) long-term persistent, where seeds persist for more than 5 years. Invasive species with persistent seeds are more difficult to manage, because monitoring and control must continue for at least as long as the life of the seed bank (Panetta 2004).

Persistent seeds are often — but not always — dormant (Thompson et al. 2003), and so require certain environmental cues and/or processes to occur before germination can 
take place, for example a change in the temperature regime, light environment, or water relations, or the gradual decay of a hard seed coat (Egley 1994; Baskin and Baskin 1998). Dormancy may be one of five general types (c.f. Baskin and Baskin 1998): i) physiological (physiological inhibiting mechanism of germination in the embryo), ii) physical (seed coat is impermeable to water), iii) combinational (both physiological and physical), iv) morphological (embryo is undeveloped), or v) morphopysiological (embryo is undeveloped, plus physiological inhibiting mechanism of germination in the embryo). Seed longevity can also be affected by the presence of seed predators and pathogens (Augspurger 1983b; Louda 1989; Fenner 1994), and may vary with seed condition, depth of burial, and the level of disturbance (Wilson 1988; Bekker et al. 1998; Christian and Stanton 2004). Information about the type of seed bank and dormancy mechanisms an invasive species possesses is necessary for the effective management of current populations - and also the prediction of where and when future populations might emerge.

\section{Germination}

Germination requirements can have a major impact on patterns of recruitment-and thus invasion success - because they dictate where and when seedlings emerge (Venable and Lawlor 1980; Fenner 1985; Figueroa 2003). As mentioned above, requirements may be broad, for example in non-dormant seeds that only require sufficient moisture, temperature, and oxygen to germinate (Baskin and Baskin 1989). These seeds have the potential to germinate wherever they land, providing those conditions are met while seeds remain viable. On the other hand, persistent, dormant seeds that require light to germinate may emerge only in canopy gaps and other disturbed areas (Vázquez-Yanes and Orozco-Segovia 1993; Figueroa 2003). In both cases, germination requirements interact with patterns of dispersal to influence the number and location of potential new recruits to the population (Horvitz and Schemske 1994; Houle 1996; Rey and Alcàntara 2000; Hille Ris Lambers and Clark 2003).

Timing of germination also plays a critical role in seedling establishment, particularly in relation to competing species (e.g. Streng et al. 1989; e.g. Bush and Van Auken 1991; Miller et al. 1994; Mandák 2003). Early germination may enable seedlings to 
capture a disproportionate share of environmental resources earlier, and for a longer proportion of the growing season than late germinators (Ross and Harper 1972; Bush and Van Auken 1991; Jones et al. 1997; Seiwa 1997; 1998). This 'head start' may be accelerated further because seedlings start life early in the season, at a time of low competition and reduced pathogen and predator loads (Seiwa 1997; 1998). Invasive species are often early colonisers that germinate quickly in response to disturbance (Baker 1965; Hobbs 1989; Burke and Grime 1996; Jesson et al. 2000), so this alone may be enough to increase the chances of invasion success. On the other hand, early germination has a number of inherent risks associated with it, such as germinating at a time or place when conditions are unfavourable, so any advantage is likely to be context-dependent.

\section{Seedling establishment}

Seedling establishment is the next critical phase in the process of regeneration from seed. A myriad of biotic and abiotic factors interact at this stage, so patterns of recruitment may vary considerably, both spatially and temporally (Burton and Bazzaz 1991; Bazzaz and Wayne 1994; Shibata and Nakashizuka 1995; Houle 1998; Clark et al. 1998b; Kobe 1999; Rey and Alcàntara 2000; Hille Ris Lambers and Clark 2003). Rates of seedling mortality are usually high, so there can be significant selective pressures acting at this stage (Fenner 1987; Grime and Hillier 1992; Kitajima and Fenner 2000). Light quantity and quality, litter characteristics, soil moisture content, nutrient levels, herbivore and pathogen presence, seedling competition, and physical disturbance can all be important influences on seedling survival and establishment (De Steven 1991a; Schmitt and Wulff 1993; Tinoco-Ojanguren and Pearcy 1995; Davis et al. 1999; Milberg et al. 1999; Case and Crawley 2000; Jesson et al. 2000; Packer and Clay 2000; Drake and Pratt 2001; Dzwonko and Gawroński 2002). A break in the otherwise continuous canopy can change all these factors in ways that are beneficial to seedling establishment (Augspurger 1983b; Augspurger and Kelly 1984; Augspurger 1984a; Vitousek and Denslow 1986; Denslow 1987; Uhl et al. 1988; Braker and Chazdon 1992; Ballaré 1994; Wenny 2000), and in fact many species rely on canopy gaps for successful regeneration (Bazzaz and Pickett 1980; Vázquez-Yanes and Orozco-Segovia 1984; Brokaw 1985a; Popma et al. 1988). 


\section{Critical life-stages}

Overall patterns of regeneration are determined by the number and location of individuals surviving through the stages from seed arrival to germination to seedling survival. An integrated view of recruitment must consider each stage sequentially, and identify the factors and processes influencing survival at each stage. This helps to identify which life-stage transition is most critical to population growth. Several previous studies identify the most critical life stage for a particular species by pinpointing critical factors limiting population growth and estimating transition probabilities between life stages. For example, Traveset et al. (2003) found recruitment of the rare shrub Rhamnus ludovici-salvatoris to be most limited by postdispersal seed predation and water stress at the early seedling stage, but that transition probabilities varied according to microhabitat. Variation in transition probabilities according to microenvironment was also found by Jordano \& Herrera (1995): recruitment of Phillyrea latifolia was limited at the seed stage in scrubland, but postgermination events were more important in forest sites. Seedling mortality due to water stress had the greatest impact on recruitment of the shrub Olea europaea, (Rey and Alcàntara 2000), whereas post-germination processes were the critical stage for the herb Helleborus foetidus (Garrido et al. 2005). Schupp (1990) found that annual variation in recruitment could be largely explained by seed fall and seed predation, but that environmental conditions could modify that pattern. Recruitment dynamics are obviously highly complex and variable, both within and between species and environments, but all of these studies illustrate a critical stage of recruitment, and/or critical factors influencing survival, where mortality is high and few individuals make it to the next stage. This critical stage is essentially the "weak spot" of a species, and may, therefore, be an important focus of management efforts.

\section{Seedling growth and biomass allocation}

Seedlings that do survive the hazardous first year continue to face competition from other seedlings, and continue to be challenged by both biotic (e.g. herbivores and pathogens) and abiotic (e.g. water or light stress, nutrient deficiency) factors. Light conditions in particular can have a strong bearing on whether seedlings live or dieindeed plant species are commonly classified according to the light environment they 
regenerate in, for example pioneer vs non-pioneer, early-succession vs latesuccession, and shade-tolerant vs shade-intolerant species (e.g. Connell and Slatyer 1977; Bazzaz 1979; Fenner 1987; Grubb 1987; Zangaro et al. 2003). Most species occur in a relatively restricted range of light conditions, but some cope with a broad range of light conditions, surviving in both high and low light environments (e.g. Kitajima 1994; Broncano et al. 1998; Poorter 1999). One of the ways plants achieve this is by increasing carbon allocation to the tissue-type (i.e. above- or below-ground tissue) required to capture limiting resources (Grime 1977). For example many species are able to increase leaf area in low-light environments, and/or increase root production in moisture- or nutrient-limited environments (e.g. Chapin 1991; King 1991; Wang et al. 1994; Canham et al. 1996; Poorter and Nagel 2000; Ryser and Eek 2000). Invasive species that can adjust patterns of biomass allocation in this way may be able to occupy a broader range of habitats than a less flexible species, and thus gain a competitive advantage.

\section{Photosynthesis and water use efficiency}

Invasive species may also gain a competitive advantage by being more efficient at photosynthesis. Plants with high photosynthetic capacity generally exhibit high rates of biomass accumulation and growth (Lambers and Poorter 1992), and this may enable them to out-compete slower-growing species (Grime and Hunt 1975). Specific leaf area (SLA, leaf area per unit leaf mass) also tends to be positively related to growth rate (Lambers and Poorter 1992; Reich et al. 1997), and has been shown in several cases to be higher in exotic species compared to natives (Jones and McLeod 1990; Baruch and Goldstein 1999; Smith and Knapp 2001). However, both photosynthetic capacity and SLA vary according to environmental conditions (Boardman 1977; Givnish 1988), so species rankings may change with habitat (e.g. Walters and Reich 1996; Zipperlen and Press 1996; Agyeman et al. 1999). This is commonly seen in shade-tolerant versus shade-intolerant species; each is most efficient - and thus out-competes the other-in the light environment it is adapted to (Grime 1965). Other species may have a more flexible physiology, and can, therefore, acclimate to a broader range of light environments (e.g. Bazzaz and Carlson 1982; Strauss-Debenedetti and Bazzaz 1991; Valladares et al. 2000; Niinemets et al. 2003). 
As is always the case, however, any strategy has its costs and associated tradeoffs, and a competitive advantage gained in one area may be lost in another.

Differences in water-use efficiency (WUE, the ratio of carbon fixed per unit water transpired) can be another factor determining the outcome of inter-species competition. In order for plants to fix carbon, they must open their stomata and take in carbon dioxide. However, stomatal opening also results in an increase in transpiration, so there is a trade-off between the gain in $\mathrm{CO}_{2}$ and the loss of water (Cowan 1977; Cowan and Farquhar 1977). Plants that manage this trade-off most effectively may gain a competitive advantage, particularly when water is a limiting resource (Fischer and Turner 1978; Gordon et al. 1999). High WUE may be particularly advantageous in plants that photosynthesise rapidly, because of this associated water loss. The ability to maintain net carbon gain at low soil water availability has been shown, in some cases, to give invasive tree species an advantage over natives (e.g. Kloeppel and Abrams 1995; Stratton and Goldstein 2001).

\section{Aims and objectives of thesis}

This study examines various ecological traits of the invasive species Berberis darwinii and four co-occurring, ecologically-similar native species: Coprosma grandifolia (Rubiaceae), Melicytus ramiflorus (Violaceae), Pseudopanax arboreus (Araliaceae), and Schefflera digitata (Araliaceae). The aims of the study are to a) identify factors contributing to invasion success in $B$. darwinii, and b) determine whether $B$. darwinii has a critical life-stage during which weed control is likely to be most successful. In Chapter Two I examine patterns of seed dispersal and seed bank characteristics of $B$. darwinii, and compare seed viability, germination, and seedling establishment patterns of $B$. darwinii and the four native species. I also identify the critical life-stage for $B$. darwinii by comparing the number of individuals surviving thorough each stage: seed rain, seed bank, newly-germinated seedlings, and 5 monthold seedlings. In Chapter Three I examine how patterns of biomass allocation and survival in $B$. darwinii seedlings vary according to light environments. And finally, in Chapter Four I compare leaf traits, water-use efficiency and photosynthetic responses to high and low irradiance in wild populations of $B$. darwinii and the four native species. Chapters are written as stand-alone papers so duplication in some instances is 
unavoidable. In particular, environmental measures such as canopy cover, soil moisture, and litter depth are relevant to several experiments. 


\title{
CHAPTER TWO. FACTORS CONTRIBUTING TO INVASION SUCCESS IN BERBERIS DARWINII: SEED DISPERSAL, GERMINATION, AND SEEDLING ESTABLISHMENT
}

\begin{abstract}
Seedling recruitment in plant populations is a multiphase, sequential process that has the potential to substantially affect community composition and dynamics. I examined recruitment patterns in the environmental weed Berberis darwinii in order to identify traits that may contribute to invasion success, and thus pinpoint critical stages for management. I measured the spatial patterns of seed rain generated by frugivorous birds, and compared them with seed bank densities, germination and subsequent seedling survival. To estimate the life of the seed bank, I tested seed longevity under both natural and artificial conditions. To compare germination and seedling survival of $B$. darwinii and four co-occurring native species, I sowed seeds in a range of natural light environments in the field. Seed dispersal was extremely widespread, with seeds regularly detected up to $450 \mathrm{~m}$ from the source population. Dispersal was essential to seedling establishment, as few seedlings survived beneath the parent canopy. While the number of dispersed seeds decreased according to the inverse power law with increasing distance from source population, there was also evidence that birds dispersed seeds disproportionately to favoured perch sites. Seed banks of $B$. darwinii were relatively short-lived under both field and glasshouse conditions, with few seeds surviving for more than one year. In the seed-sowing experiment, Berberis darwinii germinated successfully across all light environments, but seedling establishment was limited to high light environments. In natural populations, patterns of newly-emerged seedlings largely reflected patterns of seed rain, but seedling survival was significantly affected by distance from source population, seedling density, and by light environment. Native species germinated and survived most successfully in higher light environments, but at lower rates than B. darwinii. Many of the traits identified have the potential to contribute to invasion success, but the most vulnerable stage appears to be seedling establishment.
\end{abstract}




\section{Introduction}

Seedling recruitment is a multi-faceted process ranging from seed production and dispersal, through to germination, seedling establishment and subsequent survival. The likelihood of a seed surviving through each stage may vary both spatially and temporally, and will depend on a multitude of factors (Augspurger 1983a; Schupp 1988a; Lamont et al. 1993; Houle 1998). Accordingly, it can be difficult to "map" the recruitment process, and thus identify mechanisms underlying seedling establishment (but see Augspurger 1983b; Howe et al. 1985; Jordano and Herrera 1995; Dalling et al. 1998a; Clark et al. 1998b; Rey and Alcàntara 2000; Wenny 2000; Garrido et al. 2005). Nevertheless, this information is a crucial component of population dynamics, and is particularly pertinent to the study of invasive species. Knowledge of where seedlings are likely to emerge and under what conditions they are most likely to survive and out-compete natives can be of considerable value to weed managers.

The initial stage of seedling recruitment (following seed production) is seed dispersal. Seed dispersal has a major influence on recruitment because it determines the physical environment that seeds and seedlings experience, which in turn influences survival (Harper 1977; Schupp 1988a; Wenny 2001). It is of particular interest when examining the success of invasive species, because biological invasion often begins with seed dispersal (Hobbs 1989; Brothers and Spingarn 1992; Wiser et al. 1998; Parendes and Jones 2000; Richardson et al. 2000b). Weed species are frequently welladapted for the efficient dissemination of their seed (Amor and Piggin 1977; Glyphis et al. 1981; McEvoy and Cox 1987; Timmins and Williams 1987; Binggeli 1996), and dispersal by any vector (e.g. birds, mammals, wind, or water) can result in widespread and prolific seed-deposition, and thus enhance the chances of invasion success (Loyn and French 1991; Lonsdale 1993b; Cronk and Fuller 1995; Williams and Karl 1996; Panetta and McKee 1997; Richardson et al. 2000a; Allen and Lee 2001).

Dispersal is generally considered an adaptation to increase the probability of survival of offspring, but causative factors can be difficult to identify. The three main hypotheses that seek to explain the selective advantage of dispersal are: i) escape from density-dependent competition and sources of parental-associated mortality (escape hypothesis: Janzen 1970; Connell 1971), ii) colonization of new sites that are 
unpredictable in time and space (colonization hypothesis: Howe and Smallwood 1982), and iii) dispersal to microsites particularly favourable for seedling establishment (directed dispersal hypothesis: Howe and Smallwood 1982; Howe 1986; Bazzaz 1991). These hypotheses are not mutually exclusive, and all may apply with different degrees of importance in some situations (Howe and Smallwood 1982). Numerous studies provide evidence both for (e.g. Howe and Primack 1975; Platt 1976; Salmonson 1978; Clark and Clark 1981; Howe et al. 1985; Coates-Estrada and Estrada 1988; Schupp 1988b; Harms et al. 2000), and against (e.g. Silander 1978; Hubbell 1979; Schupp 1988a; Houle 1992; Houle 1995; Houle 1998; Chauvet et al. 2004) the escape and colonization hypotheses. However, it is often difficult to find support for one hypothesis over the other, and to identify causative factors (Howe 1986). Furthermore, a complicating factor is that juveniles are often more likely to be found near parents than farther away, simply because so many more seeds fall near the parent (Hubbell 1979; Hubbell 1980; Russo and Augspurger 2004).

The directed dispersal hypothesis has been less widely tested, but there is mounting evidence that some species of birds, mammals and ants deposit seeds non-randomly in microsites that favour germination and seedling survival in some way (Livingston 1972; Stapanian and Smith 1978; Culver and Beattie 1980; Fleming and Heithaus 1981; Davidar 1983; Debussche and Isenmann 1994; Wenny and Levey 1998). Birds, which are the dispersal agent of interest in this study, disperse seeds effectively when they consume and digest fruits in such a way that seed viability is retained, and deposit (by defecation) the seeds some distance from the parent plant. Most defecation occurs when birds are perched or immediately after they take off (McDonnell and Stiles 1983; Charles-Dominique 1986; Stiles and White 1986; Thomas et al. 1988; Gorchov et al. 1993), so patterns of seed deposition can be strongly clumped around favoured roosting sites such as trees, shrubs, and man-made structures (Glyphis et al. 1981; McDonnell and Stiles 1983; McDonnell 1986; Guevara and Laborde 1993; McClanahan and Wolfe 1993; Chavez-Ramirez and Slack 1994; Ferguson and Drake 1999; Toh et al. 1999; Dean and Milton 2000). There is also evidence for roost selection on the basis of nest-site availability (Schmidt and Whelan 1999; Kitamura et al. 2004), proximity to forest edge (Thompson and Willson 1978; Hoppes 1988; Restrepo et al. 1999), and fruit availability on both heterospecific and conspecific trees (Levey et al. 1984; Stiles and 
White 1986; Bronstein and Hoffmann 1987; Murray 1988; Masaki et al. 1994;

Slocum and Horvitz 2000). When seedling survival is higher at these sites than away from them, the directed dispersal hypothesis is supported.

Following dispersal, seeds either germinate, die, or are incorporated into the soil seed bank where they can remain dormant for months, years, or even decades (Harper 1977; Baker 1989; Thompson et al. 1997). Seed longevity in the soil is affected by the presence of seed predators, pathogens, and allelopathy (Augspurger 1983b; Augspurger 1984a; Louda 1989; Fenner 1994; Friedman 1994), and depends on temperature, soil moisture, seed condition, depth of seed burial, and the level of disturbance (Wilson 1988; Simpson et al. 1989; Bekker et al. 1998; Christian and Stanton 2004). Germination from the seed bank is triggered when dormancy is broken by particular environmental cues, for example a change in day-length, light quality, temperature regime, water relations, and/or levels of oxygen, carbon-dioxide, or ethylene (Egley 1994; Baskin and Baskin 1998). The characteristics of the seed bank and the type of cue that triggers germination varies among species.

Seed banks can be usefully classified into three broad groups (cf. Bakker et al. 1996): i) transient, where seeds persist in the soil for less than 1 year, often much less; ii) short-term persistent, where seeds persist for at least 1 year, and up to 5 years; and iii) long-term persistent, where seeds persist for more than 5 years. Species with transient seed banks tend to be found in environments that provide regular, predictable regeneration opportunities (Thompson and Grime 1979). In contrast, persistent seed banks are often found where environmental conditions are ephemeral or unpredictable and thus the probability of seedling success is low (Harper 1977; Silvertown 1982; Parker et al. 1989). Many invasive species are early colonizers associated with such ephemeral or unpredictable environments (Hobbs and Huenneke 1992; Rejmánek 1995), but not all have persistent seed banks (Timmins and Williams 1987; Clement and Foster 1994). The life of the seed bank has important implications for the management of invasive species, because eradication programmes have to continue for at least as long as the life of the seed bank if they are to succeed (Panetta 2004; Panetta and Timmins 2004). 
The impact of seed dispersal on seedling recruitment is often poorly understood. As mentioned above, the pattern of seed dispersal provides the starting point from which subsequent germination and seedling survival takes place. However, seed and seedling survival are influenced by a virtually infinite array of ecological variables (Harper 1977; Howe 1989), and sites favourable for germination are not necessarily favourable for seedling establishment (Jordano and Herrera 1995; Schupp 1995; Schupp and Fuentes 1995; Rey and Alcàntara 2000; Figueroa and Lusk 2001). By comparing the spatial pattern of the seed rain with emerging seedlings and, later, with surviving seedlings, one can begin to determine the environmental factors influencing final recruitment patterns. For example, Houle (1996) found that the spatial pattern of seeds in the seed bank and that of emerging seedlings were not related to one another for either of two herbaceous species studied, and concluded that spatial patterns of recruitment were largely determined by factors influencing mortality at the germination stage. In a similar study of a shrub species, Rey and Alcàntara (2000) found that frugivore-generated dispersal patterns differed from the final pattern of recruitment because water-stress caused high mortality at the seedling stage. Such information is useful to managers of both invasive and threatened species, because it identifies both the strengths and weaknesses of a population.

The focus of this study is an important environmental weed in New Zealand: Berberis darwinii Hook. (Berberidaceae) (Darwin's barberry). Berberis darwinii is a woody, evergreen, bird-dispersed shrub that grows to approximately $4 \mathrm{~m}$ high, native to southern Chile and Argentina. Initially brought to New Zealand as an attractive garden plant, it was first recorded as naturalized in 1946 (Sykes 1982). It has since invaded many vegetation types throughout the country, including remnant forest stands, scrub, and along roadsides (Webb et al. 1988), but little is known of its seed and seedling ecology. In general, $B$. darwinii flowers in spring (Aug-Nov) and fruits in summer (Dec-Feb) in New Zealand, although both fruits and flowers can be found on plants almost year-round (Webb et al. 1988, pers. obs.). Seed germination occurs in the spring following dispersal (Allen and Wilson 1992). Anecdotal evidence suggests that it has a transient seed bank, but this has not been tested. It is also widely assumed that, since adult plants are shade tolerant, seedlings will be too, but in fact $B$. darwinii is a species of disturbed forest habitats in its native range (Landrum 1999), so this may not be true. In any case, it seems likely that light environment will be a 
significant factor influencing germination and seedling success. Berberis darwinii is dispersed by many species of birds in New Zealand, including silvereye (Zosterops lateralis), blackbird (Turdus merula), song thrush (Turdus philomelos), and the native wood pigeon (Hemiphaga novaeseelandiae) (Allen and Lee 1992; Williams and Karl 1996). Flocks of silvereyes, in particular, which are known to be effective seed dispersers (Stansbury 2001; Stanley and Lill 2002) were regularly seen feeding on $B$. darwinii fruits during the course of this study (pers. obs.). In order to understand the seed and seedling ecology of $B$. darwinii, and to identify possible reasons for its invasion success, I conducted a series of experiments designed to answer the following questions:

i) How does B. darwinii compare to ecologically similar native species in terms of seed viability, germination, and seedling establishment?

ii) What are the temporal and spatial patterns of B. darwinii seed dispersal, and how do they relate to patterns of seedling establishment?

iii) What are the transition probabilities of survival of $B$. darwinii individuals through the life stages from seed rain to seed bank to seedling?

Four common native species were chosen in order to answer the first question: Coprosma grandifolia (Rubiaceae), Melicytus ramiflorus (Violaceae), Pseudopanax arboreus (Araliaceae), and Schefflera digitata (Araliaceae). These species are all woody, bird-dispersed species, potentially capable of establishing and persisting in the shade but also common in high light areas. As such, they are ecologically similar to $B$. darwinii, and so may be the species most at risk of displacement.

I chose two tree species to test the directed dispersal hypothesis: Elaeocarpus dentatus (hinau) and Fuchsia excorticata (Fuchsia). The hinau trees at KWS extend above the general forest canopy and have an open branching structure that may offer a readily accessible perch site to birds. However, environmental conditions beneath hinau trees are unlikely to differ from the rest of the vegetation, so I did not expect any significant variation in seedling survival beneath hinau trees. Fuchsia and B. darwinii fruit concurrently, at a time that is earlier than most other species, so feeding frugivores may be moving - and thus dispersing seeds — between the two species. Fuchsia is one of the few semi-deciduous species in the largely-evergreen New 
Zealand native forest, so the reduction in canopy cover during autumn and winter may be more favourable for seedling survival.

\section{Methods}

\section{Study site}

I conducted this study within the Karori Wildlife Sanctuary (KWS), a 249 ha ecological restoration site in Wellington, New Zealand (41 $\left.{ }^{\circ} 18.3^{\prime} \mathrm{S}, 174^{\circ} 44.8^{\prime} \mathrm{E}\right)$. Mean annual rainfall is $1235 \mathrm{~mm}$, and mean annual temperature is $12.8^{\circ} \mathrm{C}(16.9$ midsummer and 8.8 mid-winter) (Greater Wellington Regional Council 2005; National Institute of Water and Atmospheric Research 2005). The predominant vegetation is regenerating native podocarp/broadleaf forest, with remnant pockets of planted Pinus radiata and other exotic species. Berberis darwinii dominates the western hills adjacent to the KWS, and this is considered the 'source population' for this study. All experiments were conducted at various sites within the KWS (see Fig. 2.1). Berberis darwinii seed dispersal was measured at ten sites increasing in distance (from 0 to $450 \mathrm{~m}$ ) from the source population. Sampling stations were set up at four of these sites $(0,25,250$, and $450 \mathrm{~m})$, where, in addition to seed dispersal, seed bank density and natural seedling establishment were measured. Dispersal was also measured at sites within the surrounding native forest population where either of the native species Elaeocarpus dentatus (hinau) or Fuchsia excorticata (Fuchsia) were present.

To examine germination and seedling establishment I chose five types of sites based on differences in canopy openness: full sun, edge, understorey, sycamore, and deep shade (Fig. 2.1 and Fig. 2.2). Full sun sites were located near the centre of artificial treefall gaps. These gaps were created in 1999 when three to four Pinus radiata trees amongst the native forest were felled within as part of the ecological restoration plan at KWS. Gaps were approximately $200 \mathrm{~m}^{2}$ in size, and were surrounded by regenerating evergreen/broadleaf native forest. Edge sites were located within $5 \mathrm{~m}$ of the sunniest edge (approximately north-facing) of these treefall gaps. Understorey sites were located in areas of undisturbed canopy between gaps. Sycamore sites were located within mature stands of the exotic species Acer pseudoplatanus (sycamore). 
Sycamore is deciduous, so these sites will also be more seasonally variable compared to the evergreen sites in terms of litter depth, soil moisture, and light levels. Deep shade sites were located in the darkest accessible area of KWS, beneath tall native forest, close to the side of a hill. Three replicates of each type of site were located, giving a total of 15 sites. Because the sycamore and deep shade light environments were restricted to relatively small areas within the KWS (see Fig. 2.1), these sites may present a problem of pseudoreplication (Hurlbert 1984). Two of the sycamore sites were approximately $100 \mathrm{~m}$ apart, and the third was $500 \mathrm{~m}$ away (sites in Fig 2.1 are not to scale). Similarly, two of the replicate deep shade sites were within $50 \mathrm{~m}$ of each other, and the third was $400 \mathrm{~m}$ away. Accordingly, results are interpreted-and extrapolated-cautiously.

\section{Environmental measures}

In order to establish the influence of environmental conditions on seed germination and subsequent seedling survival (and on growth and biomass allocation-see chapter three), I measured canopy openness, soil moisture, and litter depth at the microsites where seeds were sown (see below). To quantify percent canopy openness at each microsite I used hemispherical photography and Gap Light Analyzer (GLA) software. I photographed the canopy directly above each microsite using a Sigma fish-eye lens with a $180^{\circ}$ field of view. I scanned the photos and transformed them into digital images, then analysed them with GLA software (Frazer et al. 1999). High mortality of seedlings in the sycamore and deep shade light environments meant that seedlings were harvested from outside prepared microsites, so hemispherical photographs were not directly attributable to particular seedlings. In these cases I averaged percent canopy openness over the three microsites in each site. Canopy cover in both sycamore and deep shade sites was uniform, so variability between sites was likely to be minimal. In order to capture the spring/summer light environment that seedlings experienced for the duration of this experiment I photographed the deciduous sycamore sites in January 2002. Timing was less important for the relatively stable canopy composition of the evergreen forest sites, so I photographed them in August 2001. 
I also measured canopy openness at the sampling stations established at $0 \mathrm{~m}, 25 \mathrm{~m}$, $250 \mathrm{~m}$, and $450 \mathrm{~m}$ from the source $B$. darwinii population, but using a different method due to the difficult terrain. I quantified the degree of canopy cover at these microsites using a crown densiometer (Forestry Suppliers, USA). This instrument is comprised of a spherical, convex mirror which reflects a large overhead area. A grid etched into the mirror is used to estimate the percentage of this overhead area covered by forest canopy (Lemmon 1957). I measured percent open sky overhead to the north, south, east and west and took the average of these four values. I took the readings from $10 \mathrm{~cm}$ directly above each microsite.

I measured soil moisture levels on an overcast day in August 2001 using a Lincoln soil moisture meter. In order to get an average moisture level reading for each microsite, I inserted the moisture-sensitive probe of $3 \mathrm{~cm}$ into the soil in each corner of each microsite. Levels of soil moisture are likely to vary throughout the year, but it is expected that the different sites are likely to vary in a similar way-except for the deciduous sycamore sites, which probably have deeper litter and thus higher soil moisture in winter compared to the other sites. To measure litter depth, I counted the number of leaves pierced by a knife stabbed into the litter just outside each corner of each microsite, and averaged values for each light environment. 


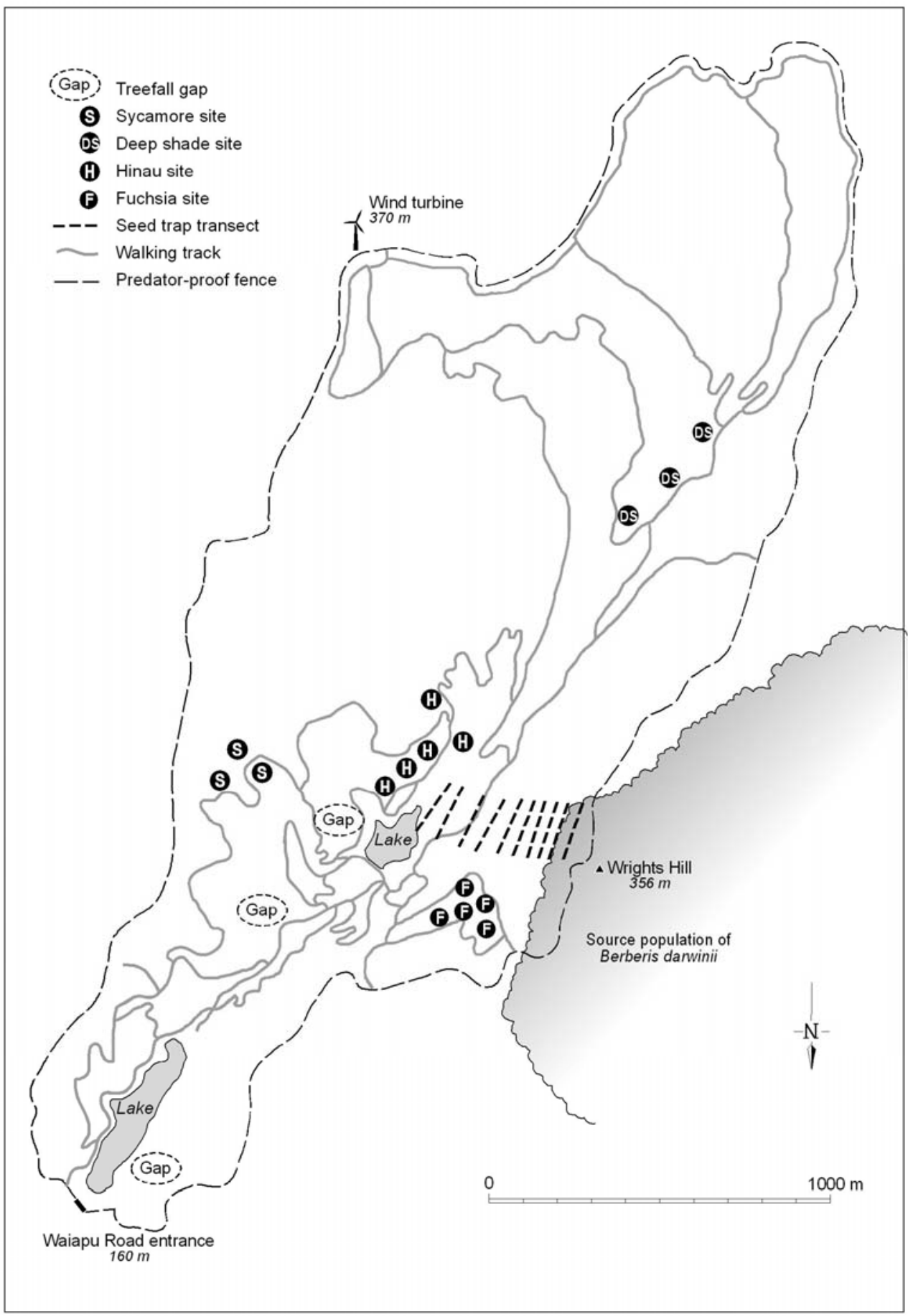

Fig. 2.1. Map of study site (Karori Wildlife Sanctuary) and sampling locations. Gap, sycamore, and deep shade sites are associated with the seed sowing experiment. Within each gap site are the full sun, edge, and nearby understorey plots (see Fig. 2.2), which combine with plots at the sycamore and deep shade sites to comprise the five light environments. Seed trap transects indicate sites at -10, 0, 10, 25, 50, 100, $150,250,350$, and $450 \mathrm{~m}$ away from the edge of the source population of Berberis darwinii, where seed dispersal was measured. Sampling stations are located at the 0 , 25,250 , and $450 \mathrm{~m}$ sites where seed rain, seed bank and natural seedling establishment was measured. Directed seed dispersal was measured at each hinau and Fuchsia site, and at paired non-hinau and non-Fuchsia sites a minimum of $20 \mathrm{~m}$ away (not shown on map). Map used with permission from Karori Wildlife Sanctuary. 


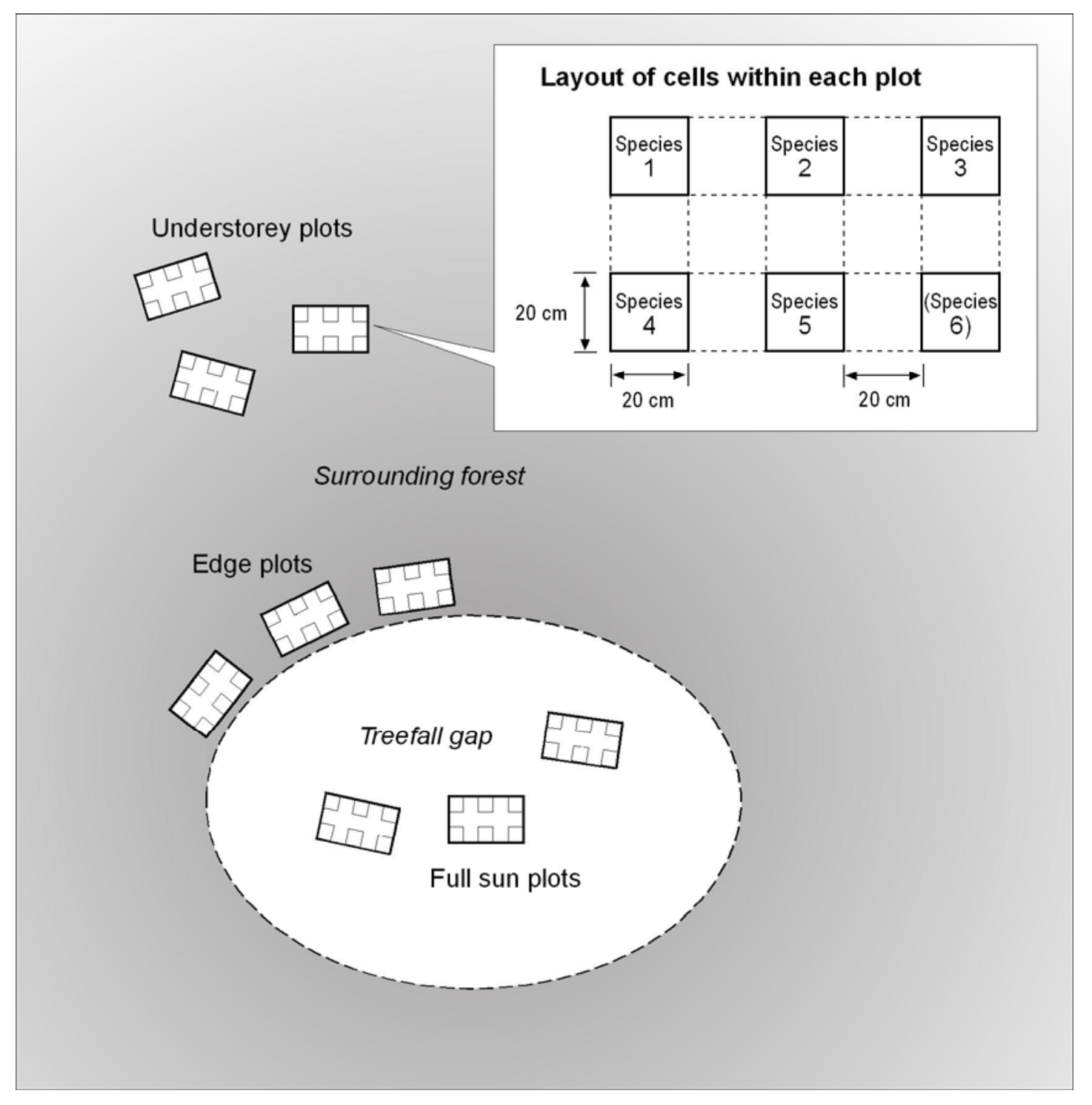

Fig. 2.2. Layout of full sun, edge, and understorey plots around each of the three treefall gaps. Detail indicates the layout of $20 \mathrm{~cm}$ x $20 \mathrm{~cm}$ cells within each plot where seeds of the five study species were sown (species 6 is not included in this thesis). Three plots, with the same cell layout, were also established in each of the three sycamore and three deep shade sites (see Fig. 2.1). This makes a total of three replicate sites of each of the five light environments (full sun, edge, understorey, sycamore, and deep shade), with three replicate plots within each site. 


\section{Seed dispersal}

Dispersal with increasing distance from source population (B. darwinii only)

One hundred seed traps were laid out (and partially buried for stability) in groups of ten at sites beneath and leading away from the source $B$. darwinii population (see Fig. 2.1) for two consecutive summers: 2000-01 and 2001-02. The first group of ten seed traps was distributed randomly beneath the $B$. darwinii canopy. The second group of ten seed traps was spaced along $30 \mathrm{~m}$ of the edge of the source population. The remaining 8 groups of ten seed traps were laid out in lines approximately parallel to the canopy edge, one group of ten per distance from the edge: $10 \mathrm{~m}, 25 \mathrm{~m}, 50 \mathrm{~m}, 100$ $\mathrm{m}, 150 \mathrm{~m}, 250 \mathrm{~m}, 350 \mathrm{~m}$, and $450 \mathrm{~m}$. In all cases, seed traps were placed a minimum of $3 \mathrm{~m}$ apart.

The seed traps were made from plastic flower pots $15 \mathrm{~cm}$ high with a diameter of 20 $\mathrm{cm}$. The base of each pot was replaced with a cotton liner for seed collection. Each seed trap sampled an area of $0.0314 \mathrm{~m}^{2}$, so I multiplied the number of seeds per trap by $31.847(1 / 0.0314)$ to get seed rain density per $\mathrm{m}^{2}$. This was averaged across all replicates. The total area sampled by 100 seed traps was $3.14 \mathrm{~m}^{2}$. The seed traps were set out in November 2000 and 2001 when fruits were beginning to mature. Liners were collected and replaced monthly until the end of the fruiting season (March 2001 and February 2002). Clean seeds that were not contained within an intact fruit were counted as dispersed, while seeds that were still contained within an intact fruit were counted as gravity-dispersed.

\section{Directed seed dispersal (B. darwinii only)}

I measured B. darwinii seed rain beneath and away from hinau trees during the spring and summer of 2001-2002. One hundred seed traps were positioned beneath the intact forest canopy: ten directly beneath each of five hinau trees scattered throughout the KWS (hinau sites - see Fig. 2.1), and ten in each of five areas of medium height forest, at least $20 \mathrm{~m}$ away from any hinau tree (non-hinau sites — not shown in Fig. 2.1). The seed traps were set out in October 2001 when fruits were beginning to mature. Liners were collected and replaced monthly until the end of the fruiting 
season in March 2002. Scattered, lone B. darwinii plants occur throughout KWS, but the source population was at least $500 \mathrm{~m}$ away from the directed dispersal seed traps. No mature plants occurred within $50 \mathrm{~m}$ of any one seed trap, so all seeds caught by these traps were assumed to be dispersed by birds. All seeds caught by these traps were clean and free of fleshy fruit, confirming this assumption.

I also used the presence of naturally-ocurring $B$. darwinii seedlings beneath mature hinau and Fuchsia trees as an additional indicator of directed seed dispersal. This method assumes that all seeds germinate wherever they land, regardless of environmental conditions. Germination experiments will confirm whether this is the case for $B$. darwinii. Newly emerged seedlings were easily distinguished from older seedlings by the presence of healthy cotyledons and the absence of woody tissue. In September 2001, one hundred $0.25 \mathrm{~m}^{2}$ quadrats were surveyed for newly-emerged seedlings: ten at each of the five hinau sites, and ten at each of the five non-hinau sites. I repeated this experiment in the following year (September 2002), but this time at the Fuchsia and non- Fuchsia sites (see Fig. 2.1).

\section{Predation of dispersed B. darwinii seeds}

Within the KWS, mice and weta are potential predators of $B$. darwinii seeds (rats have been eradicated). To estimate the level of predation on $B$. darwinii seeds, three intact fruits were placed in two of the seed traps at each group of ten-not including the sets beneath the canopy and at the edge of the $B$. darwinii population. These sets were excluded because traps beneath and near the $B$. darwinii canopy would likely receive significant amounts of naturally-fallen fruits, thereby making it difficult monitor artificially-placed fruits. Fruits were set out in December and February, and checked for presence and/or damage the following month.

\section{Seed viability and longevity}

\section{Seed viability (all species)}

Seeds were sown in a glasshouse in order to calculate percent viability of the seeds of each species. Seeds were collected during the peak fruiting period of each species (April for S. digitata, February-March for all other species), fruit pulp was removed, 
and the seeds were air-dried for 3-7 days. Seed size is indicated by the length of the longest axis: B. darwinii 2-4 mm, C. grandifolia 5.0-7.5 mm, M. ramiflorus 1.5-2.4 $\mathrm{mm}$, S. digitata 2.0-2.5 mm, P. arboreus 2.9-4.5 mm (B. darwinii measured by author, data for natives sourced from Webb and Simpson (2001)). The number of seeds sown varied among species due to differences in seed availability and/or size. Four replicates of either 20 (B. darwinii and C. grandifolia) or 25 (M. ramiflorus, $S$. digitata, and $P$. arboreus) seeds were sown onto standard potting mix in $115 \times 165 \mathrm{x}$ $65 \mathrm{~mm}$ plastic trays, randomised within a neutrally shaded glasshouse, and kept moist with frequent watering. Seedlings were counted, then removed, for as long as they continued to emerge.

As a further examination of $B$. darwinii viability, 4 replicates of 20 seeds were sown each month for four months following collection of seeds from seed traps in Year 1, giving a total of 16 replicates of 20 seeds sown. Percent viability of $B$. darwinii was thus calculated on 16 replicates of 20 seeds, whereas viability of the other four species was calculated on 4 replicates of either 20 or 25 seeds. In addition, in May 2002, 3 replicates of $50 \mathrm{~B}$. darwinii seeds that had been kept in dry storage for 16 months were sown to estimate their viability. In order to examine whether $B$. darwinii is capable of germinating from intact fruits, three replicate trays, each containing 10 fruits on a layer of potting mix, were placed in the glasshouse and monitored for one year.

Artificially buried seeds (B. darwinii only)

B. darwinii fruits were collected in January 2001. Fruit pulp was removed, and the seeds were left to air-dry for 3-7 days. Twenty-five seeds were placed in each of 44 small mesh bags made from 15 denier black nylon stockings. The bags of seeds were distributed evenly between four sites beneath the intact forest canopy at KWS, where they were buried in the soil to a depth of approximately $5 \mathrm{~cm}$. One bag from each site was retrieved every 3 months from May 2001 until February 2002, and then again 6 months later in August 2002. Once retrieved, seeds from each bag were sown onto 3 $\mathrm{cm}$ of vermiculite, and kept moist in the greenhouse. Four replicates of 25 seeds were also sown fresh in January 2001. Germination was monitored for two germination seasons (spring-summer) following seed sowing. 
Natural seed bank (B. darwinii only)

The density of $B$. darwinii seeds in the seed bank was measured by taking a soil core from each of 40 sampling stations, at three-monthly intervals from March 2001 to March 2002. Ten sampling stations were established at each of four sites increasing in distance from the main $B$. darwinii population: ten directly beneath the canopy $(0 \mathrm{~m})$, and ten each at distances of $25 \mathrm{~m}, 250 \mathrm{~m}$, and $450 \mathrm{~m}$ away from the population (see Fig. 2.1). The ten sampling stations located directly beneath the canopy were scattered randomly within the population, and the other three sets of ten sampling stations were established along transects parallel to the edge of the $B$. darwinii population. All sampling stations were a minimum of $3 \mathrm{~m}$ apart. Soil cores were cylindrical, $5 \mathrm{~cm}$ in diameter and $5 \mathrm{~cm}$ high, giving a total area sampled per core of $0.00196 \mathrm{~m}^{2}$. I multiplied the number of seeds per core by $510.204(1 / 0.00196)$ to get seed bank density per $\mathrm{m}^{2}$. This was averaged across all replicates. The total area sampled by 40 seed cores was $0.08 \mathrm{~m}^{2}$. Core samples included the litter layer plus the top $5 \mathrm{~cm}$ of mineral soil. Samples were sieved through $10 \mathrm{~mm}$ mesh to remove stones and large roots, then spread out to a depth of $3-5 \mathrm{~mm}$ in seedling trays containing a layer of peat. Trays were kept moist and exposed to natural day lengths in a light, neutrally shaded glasshouse. Control trays of sterile soil were used to monitor contamination by seed present within the glasshouse. Berberis darwinii seedlings were counted and removed as they emerged. The first soil cores were taken at the end of the fruiting season, in March 2001. Sites were then covered with untreated cotton material to prevent any further seed input. Samples were last checked for germinated seedlings in January 2003.

\section{Germination and seedling survival}

\section{Seeds sown (all species)}

To examine germination and seedling establishment in the field I sowed seeds in the 15 sites differing in light environment: full sun, edge, understorey, sycamore, and deep shade (three replicates per light environment, giving a total of 15 sites) (see Fig. 2.1). At each of the 15 sites, three replicate plots of approximately $1 \mathrm{~m}^{2}$ were cleared of plants, litter, and other debris, then levelled, and covered with $1 \mathrm{~cm}$ of forest soil 
that had been heat-sterilised to kill any resident seeds. At each plot I sowed the seeds of the five study species, which had been collected from within and around the KWS in February and March 2001 (except Schefflera digitata, which was collected in April), cleaned of fruit flesh and stored dry until required. Seeds were sown in March 2001, except for seeds of Schefflera digitata, which were sown in May. Within each plot, one hundred seeds of each species were sown onto a randomly allocated, 20 x 20 cm cell, except for the larger-seeded Coprosma grandifolia, of which 50 seeds were sown per cell (see Fig. 2.2). An empty cell (also 20 x $20 \mathrm{~cm}$ ) was left between each species to facilitate recovery (see Fig. 2.2). This gave a total of 4500 seeds sown for each of B. darwinii, Melicytus ramiflorus, Pseudopanax arboreus, and Schefflera digitata, and 2250 for Coprosma grandifolia. A single layer of homogenised broadleaf litter, collected from within the KWS, was then placed on top of the seeds in an attempt to replicate the environmental conditions that naturally-dispersed seeds would experience. A sheet of metal mesh with $1 \mathrm{~cm}^{2}$ apertures was placed directly on top of each plot to prevent birds from scratching and displacing seeds. This mesh was removed in July 2001 to avoid damage to the seedlings. Ten cells became overcrowded, so I thinned seedlings to allow a minimum of $4 \mathrm{~cm}$ between any two plants. These ten cells were excluded from survival analyses.

Seedlings were counted in November 2001 to estimate percent germination. Seedlings were counted again in March 2003 to calculate percent survival. To account for naturally dispersed seeds, germination data were adjusted according to the number of seedlings that appeared in the nine cells outside each species' designated sub-plot: $\mathrm{G}_{\mathrm{f}}$ $=\mathrm{G}_{\mathrm{d}}-\mathrm{G}_{\mathrm{o}} / 9$; where $\mathrm{G}_{\mathrm{f}}=$ final germination, $\mathrm{G}_{\mathrm{d}}=$ number of germinated seeds in species' designated cell, $\mathrm{G}_{\mathrm{o}}$ = total seeds germinated in nine other cell. These adjustments had little impact on final germination percentages. Cells where there were no seedlings present for the initial count were excluded from survival analyses.

Natural seedling establishment (B. darwinii only)

Natural seedling emergence and survival was monitored for two seasons in $40 \times 0.25$ $\mathrm{m}^{2}$ quadrats - one at each of the 40 sampling stations (see above). Quadrats were established within the sampling stations in the nearest suitable site adjacent to seed bank sampling sites. Where seed bank sampling stations were not suitable, for 
example because of steep terrain or the presence of a tree trunk, quadrats were established in random directions from the sampling stations, a minimum of $3 \mathrm{~m}$ apart. I counted the emerging seedlings after the peak germination period for each year (November), then counted and removed the number remaining 5 months later. I multiplied the number of seedlings per quadrat by $4(1 / 0.25)$ to get seedling density per $\mathrm{m}^{2}$. This was averaged across all replicates.

\section{Transition between life-stages}

I used the seed dispersal, seed bank density, and natural seedling establishment data collected from the ten sampling stations located directly beneath the Berberis darwinii canopy to calculate the transition ratios through the different life stages: seed rain $\rightarrow$ seed bank $\rightarrow$ newly germinated seedlings. I used these sampling stations because they were the most densely-populated sites, and thus were less variable than the sites at $25 \mathrm{~m}, 250 \mathrm{~m}$, and $450 \mathrm{~m}$ from the Berberis darwinii canopy. The seed rain data was collected in summer, and the seed bank and seedling data was collected the following spring, when germination occurred. I calculated the ratios between life-stages (seed rain:seed bank, seed bank:seedling, and seed rain:seedling) by dividing the number of individuals per $\mathrm{m}^{2}$ in the prior stage by the number in the subsequent life-stage. I measured the seed bank in Year 1 only, so the seed rain:seed bank and seed bank:seedling ratios could be calculated for Year 1 only.

\section{Statistics}

I analysed the data using S-Plus 4 (Mathsoft 1997) and SigmaStat 3.1 (SPSS 2004) statistical software.

\section{Environmental measures}

To examine differences in environmental measures (canopy openness, litter depth, and soil moisture) at seed-sowing sites (full sun, edge, understorey, sycamore, and deep shade), I used one-way ANOVA with site as predictor and environmental measures as predictors, followed by multiple pairwise comparisons. Litter depth data were log-transformed to meet model assumptions. To examine differences in canopy 
openness at sampling stations $(0 \mathrm{~m}, 25 \mathrm{~m}, 250 \mathrm{~m}$, and $450 \mathrm{~m}$ from $B$. darwinii population), I used one-way ANOVA with site as predictor and canopy openness as response variable, followed by multiple pairwise comparisons. $P$-values of all posthoc pairwise multiple comparisons are Bonferroni-corrected (multiplied by the number of tests done). For all ANOVA analyses and pairwise multiple comparisons, results in which $P<0.05$ are reported as significant.

\section{Dispersal with increasing distance from source population}

In order to describe the seed dispersal curves for each year, I fitted two

phenomenological models to the data using least squares regression: the negative exponential (linear in a semi-log plot), and inverse power law (linear in a log-log plot). To examine differences in the number of seeds dispersed to sites increasing in distance from the $B$. darwinii population, in two successive years, I used two-way ANOVA with site and year as predictors and the number of seeds dispersed as response variable.

\section{Directed dispersal}

To compare the number of seeds dispersed to hinau sites with the number of seeds dispersed to non-hinau sites, I used one-way ANOVA with site (hinau and non-hinau) as predictor and the number of seeds dispersed as response variable. To compare the number of seedlings at hinau/Fuchsia sites with the number of seedlings at nonhinau/non-Fuchsia in spring and summer, I used two-way ANOVA with site (hinau/ Fuchsia and non-hinau/non- Fuchsia) and date (spring and summer) as predictors and the number of seedlings as the response variable, followed by multiple pairwise comparisons.

\section{Seed viability}

I used one-way ANOVA to compare seed viability of the five study species, with percent germination as the response variable, and species as the predictor. 


\section{Germination and seedling survival}

In the seed-sowing experiment, I used linear mixed effects models to examine the effect of location (within a gap, sycamore, or deep shade location within the KWS see Fig. 2.1) (random effect), site (i.e. replicates of light environment), canopy openness, litter depth, and soil moisture (fixed effects) on germination and 18-month seedling survival.

I examined factors influencing survival of naturally-occurring seedlings in two ways - both using generalised linear models. Firstly, I tested the effect of seedling density, year, canopy openness, and dispersal distance (predictors) on seedling survival (response variable) of two seedling cohorts (i.e. in two different years). I also added seedling density ${ }^{2}$ and canopy openness ${ }^{2}$ as predictors to check for any nonlinear responses. The order in which predictors are added to the model is important, because they are considered in a stepwise fashion: the variance explained by any one predictor depends on how much variance has already been explained by higher-order predictors. The most conservative approach is to add the predictor of most interest last, because that indicates how much remaining variance is explained by that predictor. The effect of distance from source population was the predictor of most interest, since I was testing the escape hypothesis, so I added it to the model last. Nonsignificant interactions were removed by stepwise removal (none were significant).

Secondly, I tested the effect of seed rain density, seed bank density, seedling density, canopy openness, and distance (predictors) on seedling survival (response variable) of one seedling cohort (since seed bank was only measured in one year). Again, the effect of distance was the variable of most interest, so I added it to the model last. I also added seed rain density ${ }^{2}$, seed bank density ${ }^{2}$, seedling density ${ }^{2}$, and canopy openness $^{2}$ as predictors to check for any non-linear responses. Non-significant interactions were removed by stepwise removal (none were significant). 


\section{Results}

\section{Environmental measures}

There were significant differences $(P<0.001$ in all cases) between light environments for canopy openness, soil moisture, and litter depth at microsites where seeds were sown (Table 2.1, Fig. 2.3). As expected, percent canopy openness was highest in the full sun sites, and lowest in the sycamore and deep shade sites, with intermediate values in the other two sites (Fig. 2.3a). Litter depth was more variable, but was shallowest in the full sun sites (Fig. 2.3b). Soil moisture was significantly lower in the full sun sites, but was similar in all other light environments (Fig. 2.3c).

While sampling stations were selected solely on the basis of distance from source population, there were significant differences in canopy cover between them (Table 2.1, Fig. 2.4). Canopy cover was highest at sites at $0 \mathrm{~m}$ and $450 \mathrm{~m}$ from the source population, and lowest at $25 \mathrm{~m}$ and $250 \mathrm{~m}$ sites (Fig. 2.4).

Table 2.1. Analysis of variance of response variables canopy openness, litter depth, and soil moisture in different sites. Sampling station sites are defined by distance to Berberis darwinii population, and seed-sowing sites are defined by light environment (see methods). Summary table indicates degrees of freedom (df), sum of squares (SS), variance ratios $(F)$, and $P$-values $(P)$.

Environmental measure

df

SS

$F$

Canopy openness

Sampling station site

Residual

3

1093.40

10.14

$<0.001$

Seed-sowing site

36

Residual

4

8293.42

74.05

$<0.001$

Litter depth

Seed-sowing site

40

Residual

Soil moisture

Seed-sowing site

Residual 
a.

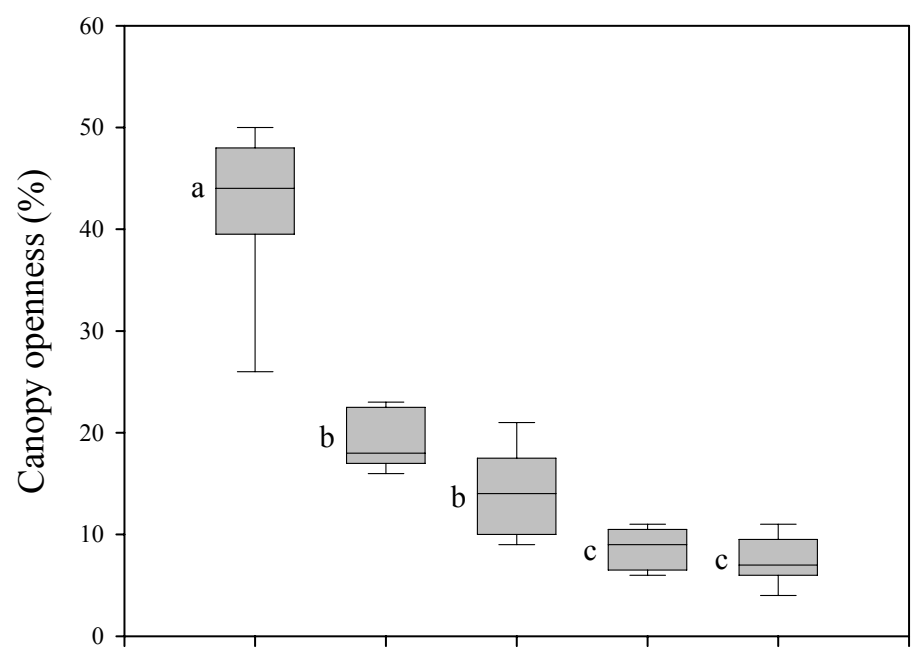

b.

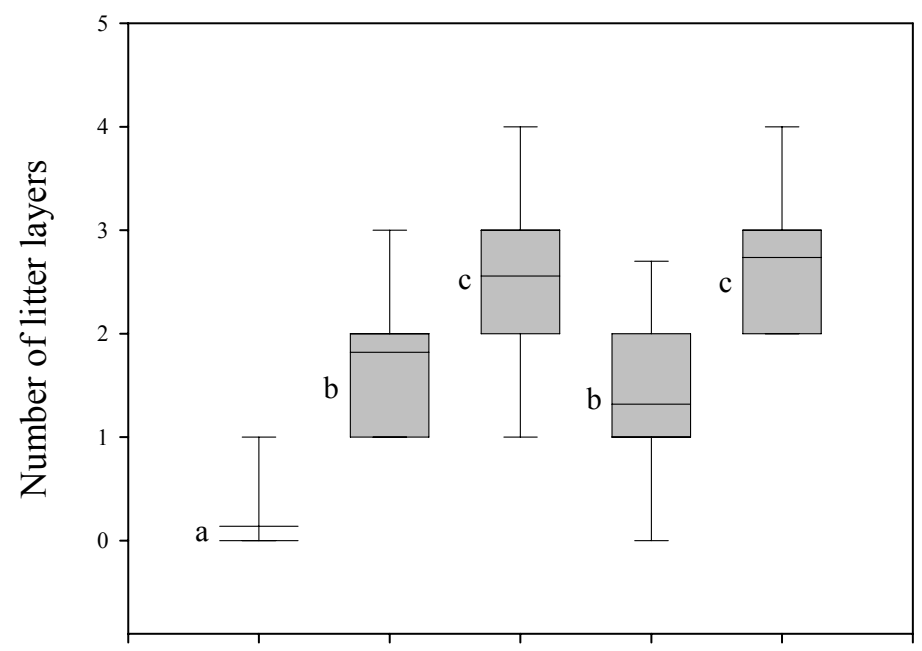

c.

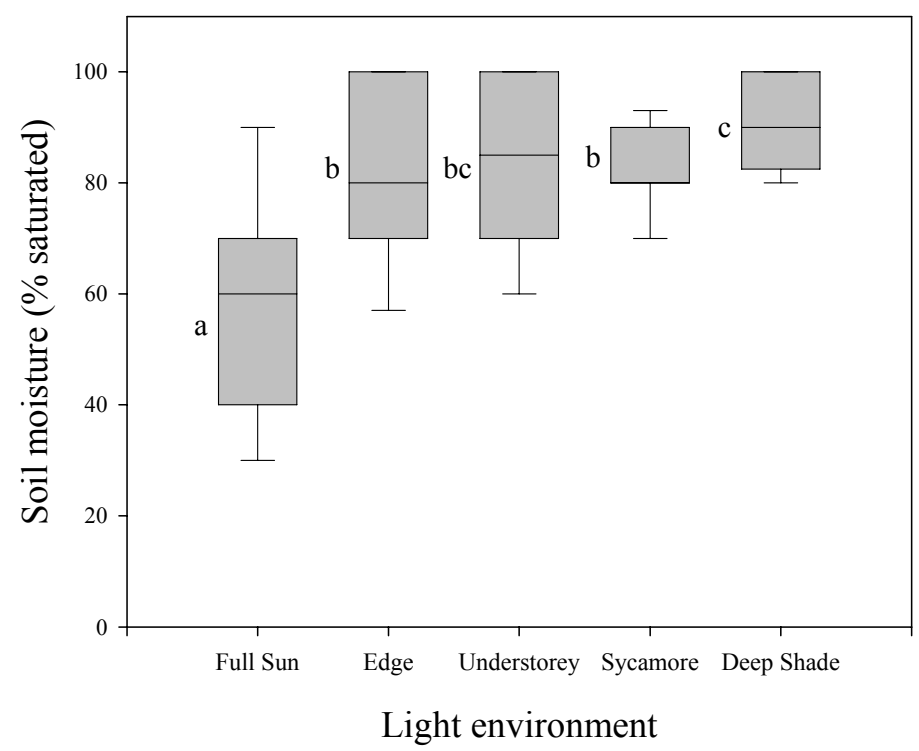

Fig. 2.3. Boxplots of a) canopy openness, b) litter depth, and c) soil moisture in different light environments. The line within the box-plots indicates the median value, the lower and upper side of the box the $25^{\text {th }}$ and $75^{\text {th }}$ percentiles, and the error bars the $10^{\text {th }}$ and $90^{\text {th }}$ percentiles. Within each graph, boxes that share the same letter are not significantly different from each other $(P<0.05)$. See methods section for details on how each variable was measured. 


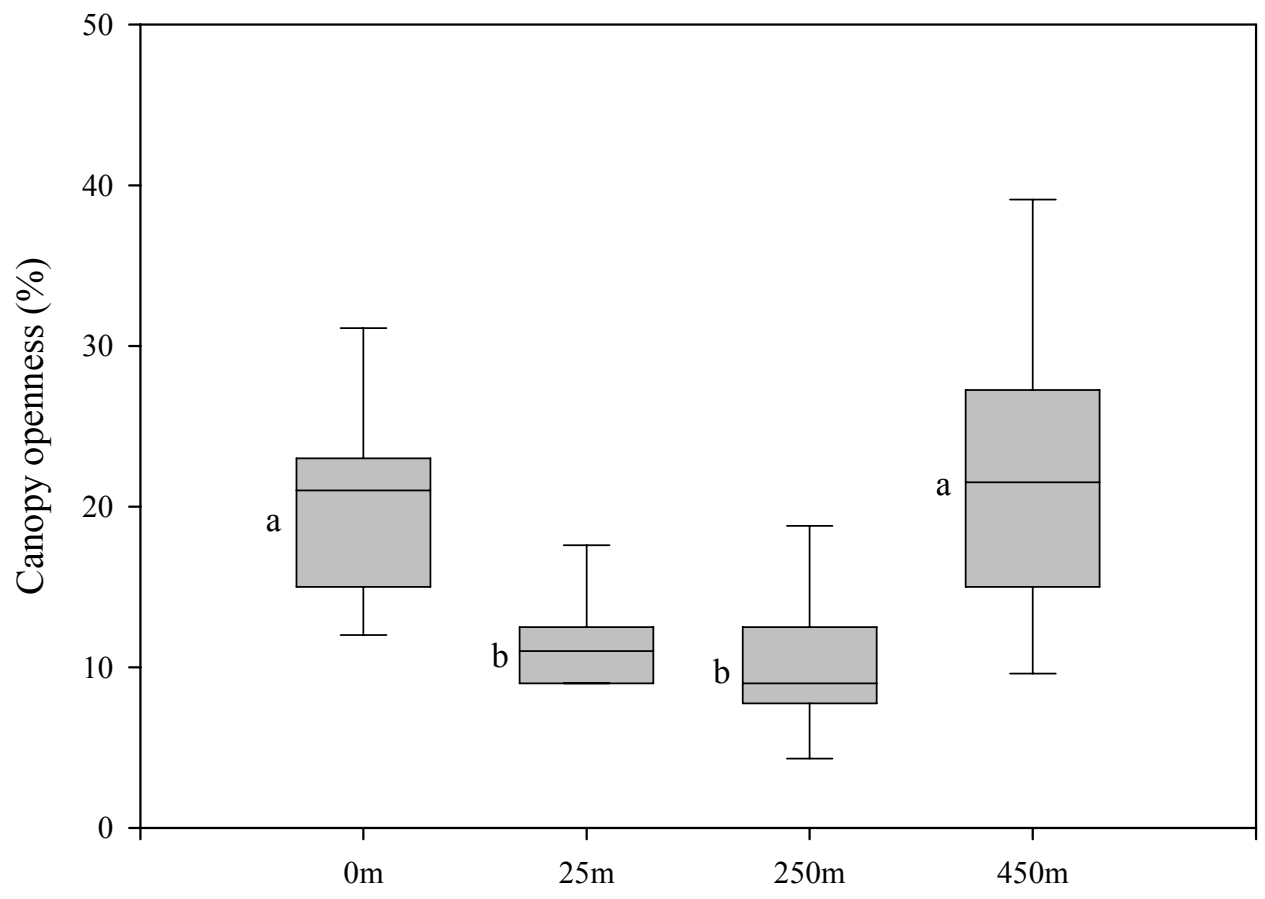

Distance from Berberis darwinii population (m)

Fig. 2.4. Boxplots of canopy openness at sampling stations located at increasing distance from source Berberis darwinii population $\left(\mathrm{n}=10 \times 0.25 \mathrm{~m}^{2}\right.$ per distance). The line within box-plots indicates the median value, the lower and upper side of the box the 25th and 75 th percentiles, and the error bars the 10th and 90th percentiles. Boxes that share the same letter are not significantly different from each other $(P<0.05)$. 


\section{Seed dispersal}

Dispersal from canopy edge (B. darwinii only)

The amount of seed dispersed differed by distance from source population and by year (Fig. 2.5, Table 2.2). There was also an interaction between distance and year (Table 2.2), likely because more seeds were dispersed to middle-distance sites (10$150 \mathrm{~m}$ ) in year 1 (Fig. 2.5). While seed production was higher in Year 1 than Year 2, a greater proportion of the total seeds was dispersed by birds in Year 2 (Fig. 2.5). A total of 6814 seeds were collected from seed traps in Year 1, and 1466 in Year 2. Out of these totals, $21.2 \%$ of seeds collected had been dispersed by birds in Year 1, and $29.7 \%$ in Year 2 (the remainder being gravity-dispersed) (Fig 2.5). Fruiting peaked in January in both years, but length of the season varied, with seeds being dispersed from December until March in Year 1, and from December to February in Year 2 (Fig 2.6). However, the shape of the dispersal curve was similar for both years, with $92 \%$ of seeds falling directly beneath, or at the edge of, the source canopy, 6-7\% dispersed within $100 \mathrm{~m}$ from the source, and the remaining 3-4\% being dispersed up to $450 \mathrm{~m}$ away (Fig 2.5). When only bird-dispersed seeds are considered, these percentages change to $65-76 \%$ of seeds landing directly beneath, or at the edge of, the source canopy, $23-29 \%$ dispersed within 100m from the source, and the remaining 1-5\% being dispersed up to $450 \mathrm{~m}$ away. The dispersal data were best explained by an inverse power law model $\left(\mathrm{r}^{2}=0.76\right.$ in Year $1, \mathrm{r}^{2}=0.59$ in Year 2$)$, which indicates a steep drop off in the curve near the source, but a more gradual drop off in the tail, compared to the negative exponential model $\left(r^{2}=0.56\right.$ in Year $1, r^{2}=0.24$ in Year 2).

Entire fruits were only encountered in seed traps located directly beneath and at the edge of the canopy-except for three occasions when single fruits were found in remote seed traps $(50 \mathrm{~m}, 100 \mathrm{~m}$ and $450 \mathrm{~m}$ away from the $B$. darwinii patch). I counted these seeds as bird-dispersed, as it seems unlikely that the fruits arrived in the seed traps any other way. The number of seeds per $B$. darwinii fruit ranged from 1-13, but $55 \%$ of fruits contained 5,6 , or 7 seeds, and $97 \%$ contained $1-8$ seeds. 

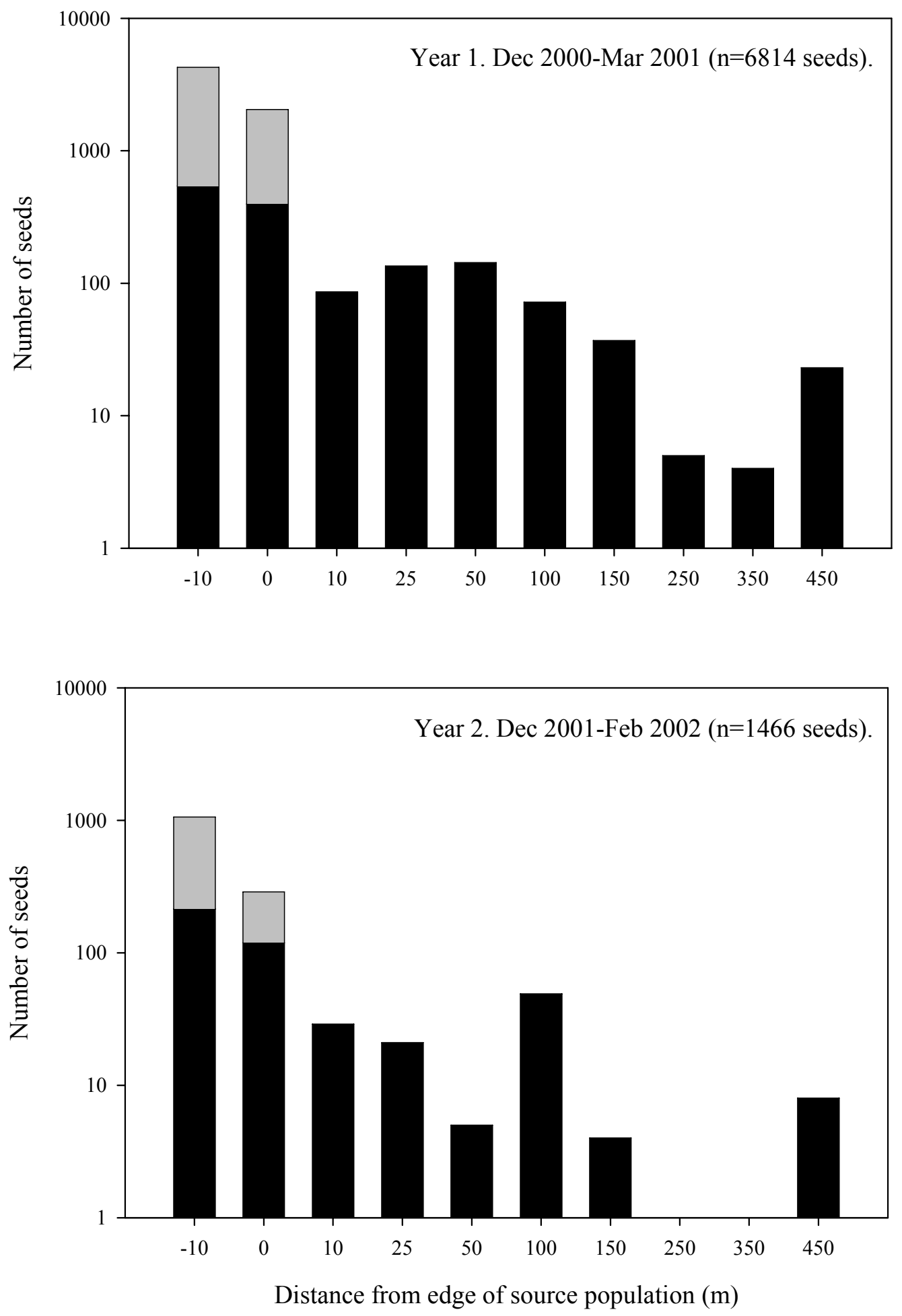

Fig. 2.5. Total number of Berberis darwinii seeds dispersed to ten sites increasing in distance from the source population over two fruiting seasons. Grey bars indicate gravity-dispersed seeds (still contained within a fruit), and black bars indicate bird-dispersed seeds (completely free of fruit pulp). Note $\mathrm{y}$-axis is on a $\log$ scale. 

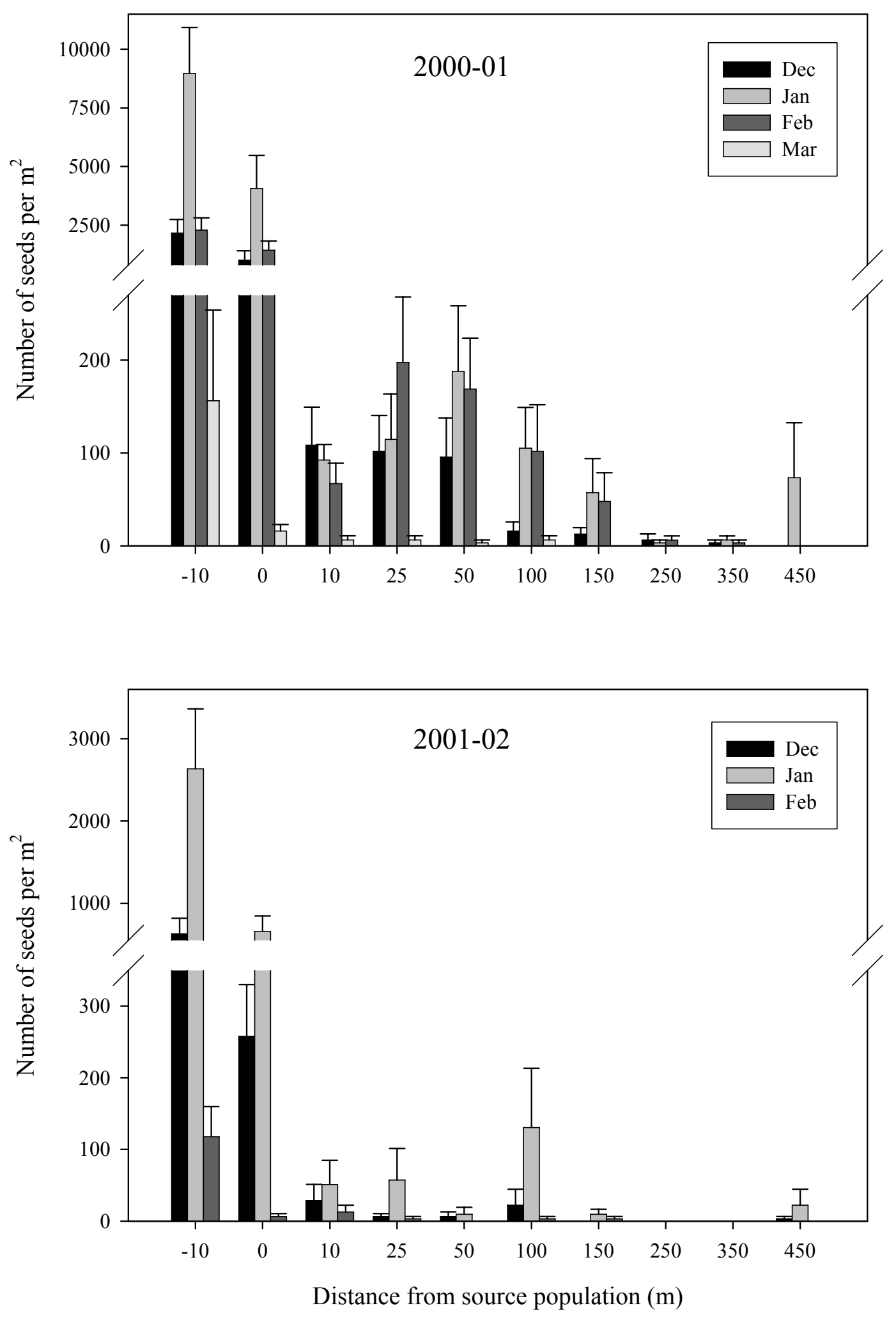

Fig. 2.6. Average number of Berberis darwinii seeds dispersed per $\mathrm{m}^{2}$, per month, to ten sites increasing in distance from the source population over two fruiting seasons. Totals include both gravity- and bird-dispersed seed. Error bars are \pm 1 s.e. of the mean. 
Table 2.2. Analysis of variance of Berberis darwinii seed dispersal by distance from source population and by year. Summary table indicates degrees of freedom (df), deviance (dev), variance ratios $(F)$, and $P$-values $(P)$.

Seed dispersal

df

$\operatorname{dev}$

$F$

$P$

Distance

Year

9

266.72

42.88

$<0.001$

Distance x Year

1

37.97

54.93

$<0.001$

Residuals

199

20.71

3.33

$<0.001$

Directed seed dispersal (B. darwinii only)

There was no significant difference detected $(P=0.810)$ between the number of seeds dispersed to hinau sites compared to non-hinau sites. From the 100 seed traps, 11 seeds were captured at hinau sites, and 9 seeds at non-hinau sites. There was also no significant difference in the number of seedlings at hinau sites compared to non-hinau sites, both initially ( $P=0.294)$, and 5 months later $(P=0.237)$ (Fig. 2.7). The number of seedlings present is assumed to be a valid prediction of the number of seeds present, since Berberis darwinii seeds germinate successfully regardless of environmental conditions (see germination section below). There was a significant difference $(P<0.001)$ in the number of newly-germinated seedlings present at Fuchsia sites compared to non-Fuchsia sites, but five months later there was no significant difference detected $(P=0.169)$ in the number of seedlings at Fuchsia sites compared to non- Fuchsia sites (Fig. 2.7).

\section{Predation of dispersed B. darwinii seeds}

Fruits set out to monitor predation were not damaged at all, so seed loss to predation within KWS is assumed to be minimal (although this may be different at sites where rats are not excluded). It is possible that the seed traps deterred the mice, but weta were frequently observed inhabiting them. 

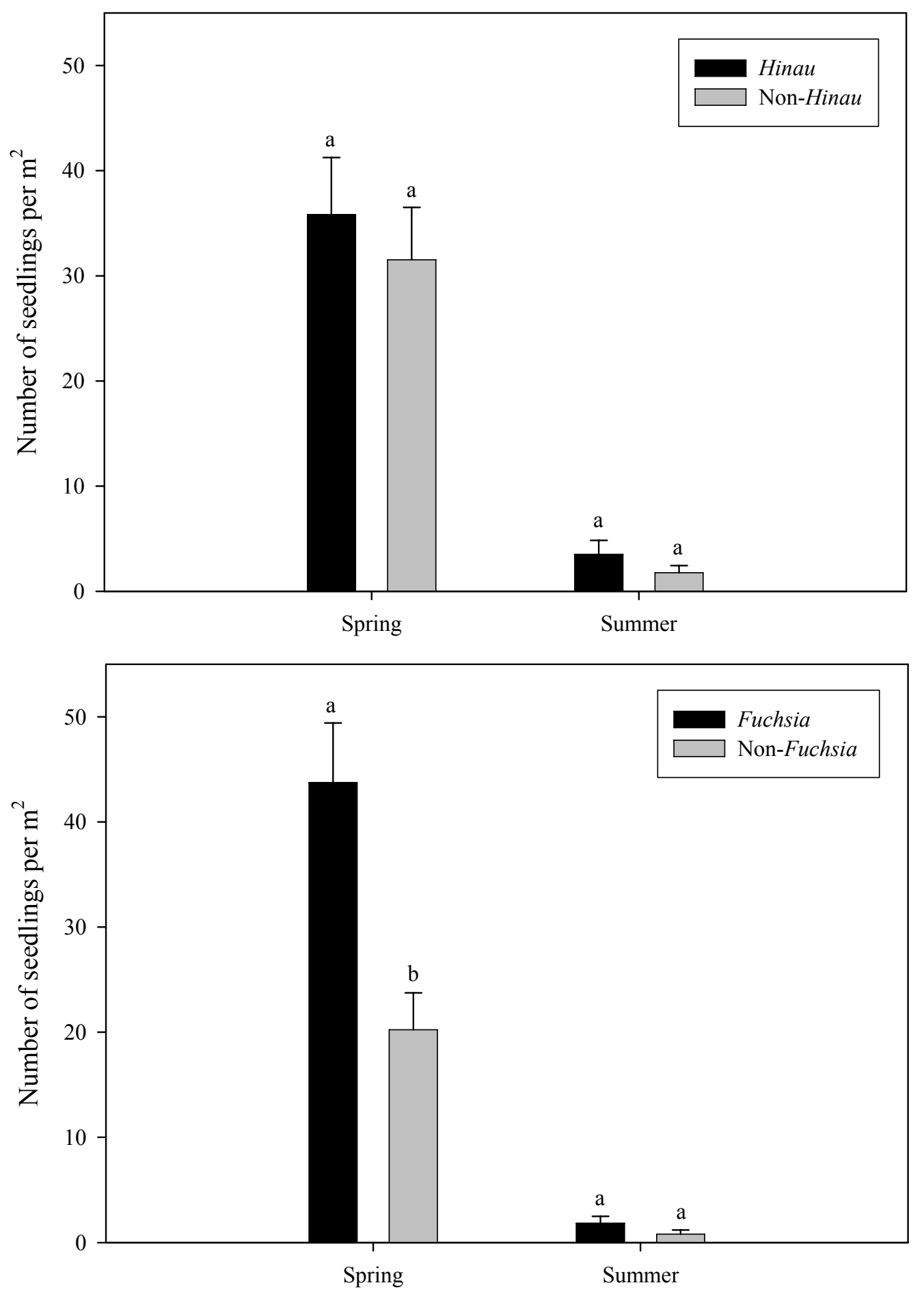

Period of seedling census

Fig. 2.7. Berberis darwinii seedling emergence beneath hinau/Fuchsia trees and beneath canopy that does not include hinau/Fuchsia trees. Seedling emergence was measured in spring and summer over two years: Sept 2001 and Feb 2002 for hinau and Oct 2002 and Mar 2003 for Fuchsia. $\mathrm{n}=50$ quadrats in both hinau/Fuchsia and non-hinau/Fuchsia sites (one quadrat $=0.25 \mathrm{~m}^{2}$ ). Within each season, bars that share the same letter are not significantly different from each other $(P<0.05)$. Error bars \pm 1 s.e. of the mean. 


\section{Seed viability and longevity}

\section{Seed viability (all species)}

For all species, the majority of seeds germinated in the first spring (September to November) following seed production. Seed viability was similar among all species (values indicated are means $\pm 1 \mathrm{se})$ : Berberis darwinii $(70 \pm 2.9 \%)$, Coprosma grandifolia $(60 \pm 4.6 \%)$, Melicytus ramiflorus $(71 \pm 4.1 \%)$, Pseudopanax arboreus $(75 \pm 1.0 \%)$, and Schefflera digitata $(60 \pm 7.1 \%)$. There was no significant difference between these values $(\mathrm{df}=4, \mathrm{SS}=843.20, F=1.889, P=0.165)$. Seeds of $B$. darwinii are capable of germinating from within intact fruits: between 1 and 6 seeds germinated from one third of the fruits.

\section{Seed bank dynamics (B. darwinii only)}

All three experiments investigating seed longevity (fresh seeds sown, seed burial, and seed bank) indicate that only a small number of $B$. darwinii seeds survive for more than one year (Fig. 2.8). By far the majority of viable seeds germinated during the first spring following seed production. As has been reported elsewhere (Simpson et al. 2004), seeds that were stored dry retained viability for much longer: $33 \%$ remained viable after 16 months. However, storage conditions were highly artificial (a dry cupboard inside a heated building) and are unlikely to be encountered by naturally occurring seeds outdoors.

All germination from seed bank samples occurred in the spring following soil core extraction. However, few seedlings emerged from the seed bank samples (Fig. 2.8c). As expected, cores taken from directly beneath the $B$. darwinii canopy elicited the greatest number of seedlings, but this was still generally only between 1 and 3 seedlings per soil core. Sites further away yielded none or very few seeds per core, even from samples taken in March 2001, only two months after peak seedfall (Fig $2.8 \mathrm{c})$. 
a.

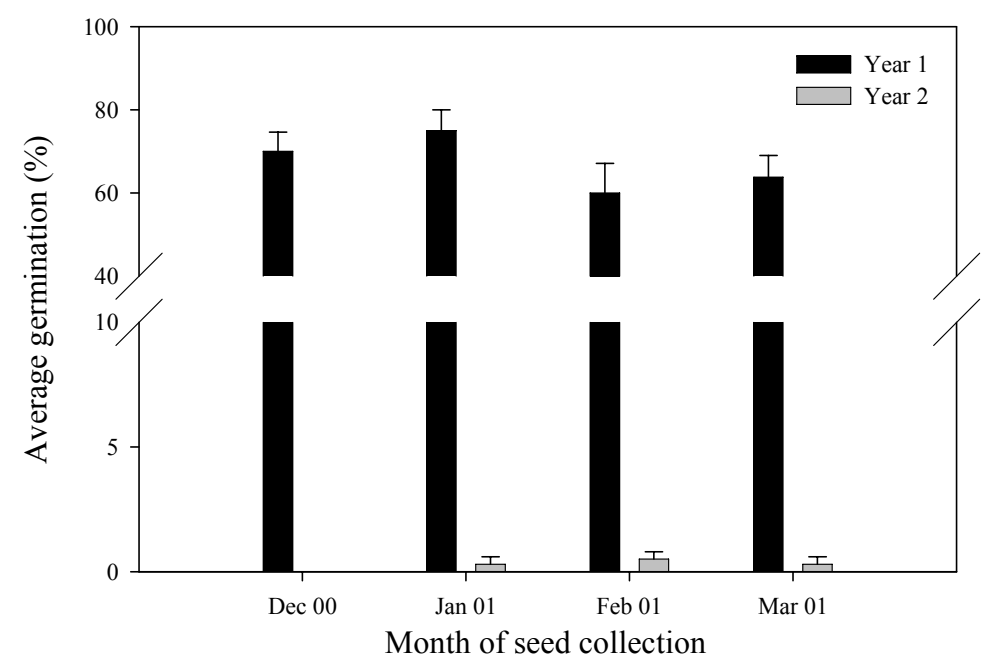

b.

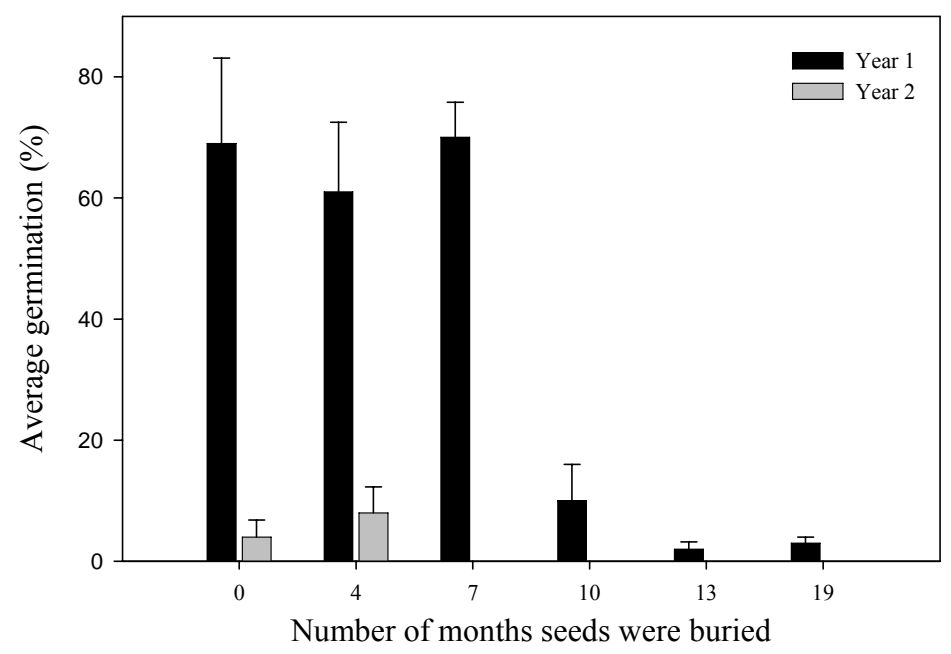

c.

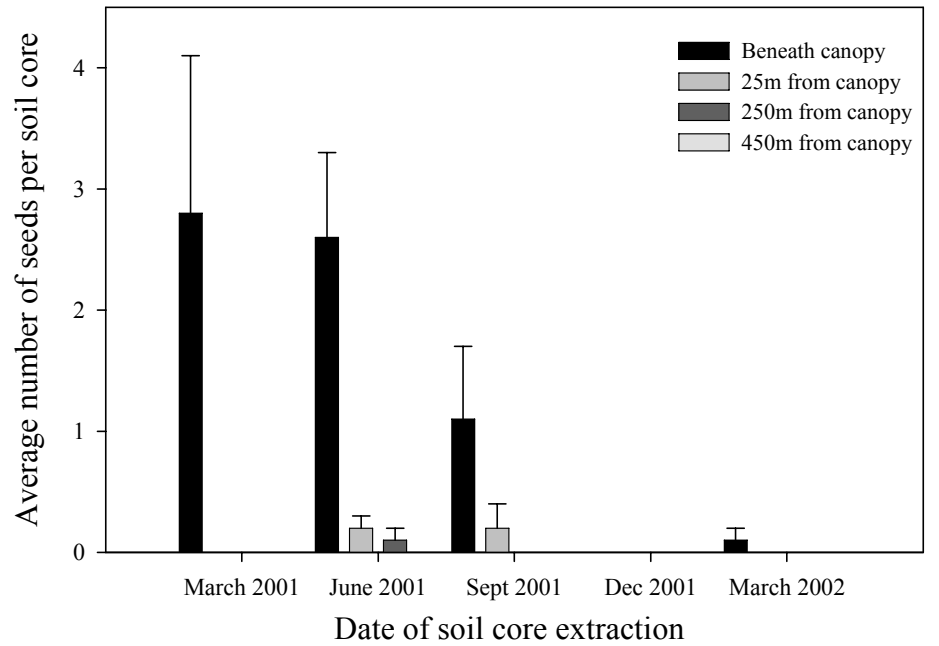

Fig. 2.8. Germination of Berberis darwinii seeds. a) Fresh seeds collected and sown monthly during the fruiting season of 2000-01 ( $\mathrm{n}=4 \times 20$ seeds sown per month), b) seeds buried then retrieved periodically over 19 months ( $n=4$ x 25 seeds collected per date), and c) seed bank samples collected periodically over the 12 months following the fruiting season of 2000-01 $(n=10$ cores per interval, per date). Error bars are \pm 1 s.e. of the mean. 


\section{Germination and seedling survival}

Germination and survival of seeds sown in the field (all species)

Berberis darwinii germinated more successfully across the range of light environments than any of the native species (Fig. 2.9). In general, the native species germinated most successfully in the lightest environments (full sun and edge sites), and all had low germination in the two shadiest environments (sycamore and deep shade sites) (Fig. 2.9). Pseudopanax arboreus, Melicytus ramiflorus, and Coprosma grandifolia all have transient seed banks, but Schefflera digitata has persistent seeds so germination rates may be underestimated for this species (Moles et al. 2000). Percent germination was significantly affected by percent canopy openness for all species (Table 2.3), but the direction of that effect differed among species: moving from open sites to shady sites, germination of $B$. darwinii increased, but germination of native species decreased (Fig. 2.9). Seeds of B. darwinii also germinated successfully whilst buried in the mesh bags, but did not emerge above the soil surface. Litter depth had no effect on germination of any of the species, but an increase in soil moisture had a positive effect on germination of $B$. darwinii and a negative effect on germination of Schefflera digitata (Fig. 2.9 and Table 2.3). There was no effect of site (i.e. replication within light environments) on germination or seedling survival of any of the species (Tables 2.3 and 2.4) when location within the KWS was included as a random effect.

Seedling survival of all species was significantly influenced by canopy openness (Table 2.4). Twelve months after germination there were no seedlings of any species alive in the two shadiest sites (sycamore and deep shade), and only a few B. darwinii seedlings in the understorey sites (Fig. 2.9). Seedlings of all species except Schefflera digitata survived most successfully in the full sun sites (Fig. 2.9). All Schefflera digitata seedlings had died twelve months after germination. Only seedling survival of Pseudopanax arboreus was affected by litter depth, and soil moisture had no impact on seedling survival for any species (Table 2.4). 


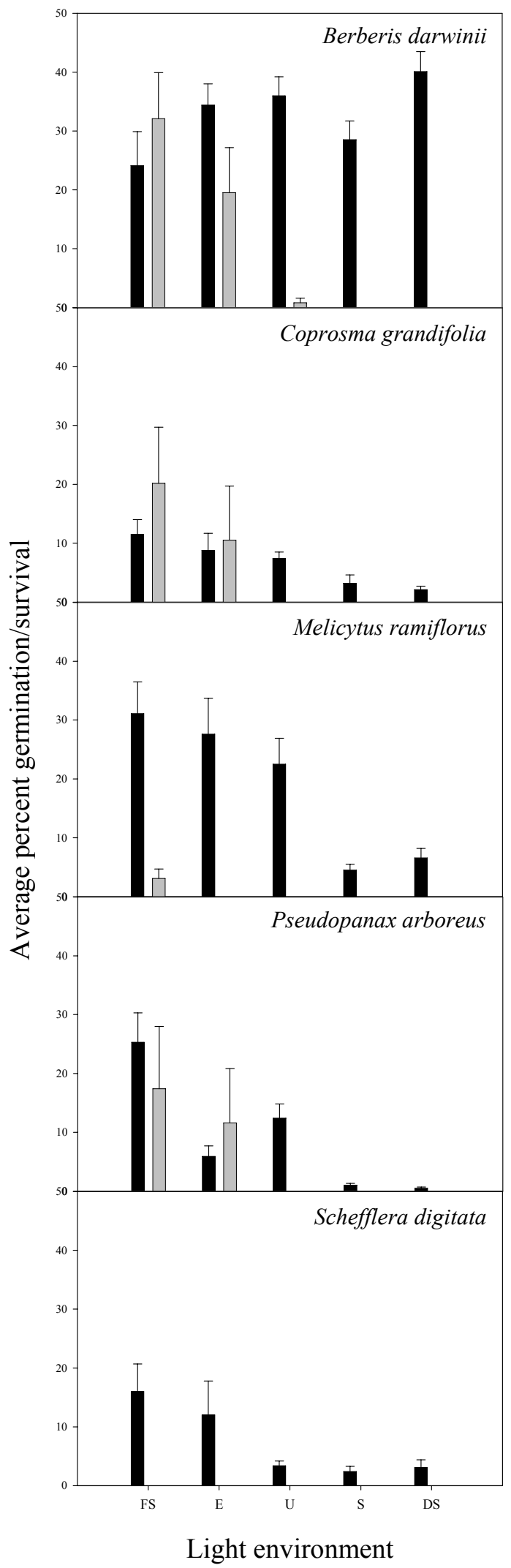

Fig. 2.9. Average percent germination (black bars) and seedling survival (grey bars) of Berberis darwinii and four co-occurring native species, in a range of light environments. Survival data was calculated from the proportion of seedlings alive 18 months after germination. Error bars are \pm 1 s.e. of the mean. 
Table 2.3. Linear mixed-effects model of germination of the five study species by location (random effect), canopy openness, soil moisture, litter depth, and site (fixed effects). Only results for fixed effects are reported. Summary table indicates degrees of freedom (df), variance ratios $(F)$, and $P$-values $(P)$.

Species/predictor

df

$F$

$P$

Berberis darwinii

Canopy openness

Soil moisture

Litter depth

Site

Residuals

$\begin{array}{lll}1 & 3.95 & 0.055 \\ 1 & 9.25 & 0.005 \\ 1 & 0.01 & 0.937 \\ 4 & 0.66 & 0.623\end{array}$

Coprosma grandifolia

Canopy openness

Soil moisture

Litter depth

Site

Residuals

$\begin{array}{ll}8.73 & 0.006 \\ 0.17 & 0.688 \\ 0.23 & 0.636 \\ 2.91 & 0.060\end{array}$

Melicytus ramiflorus

Canopy openness

41

Soil moisture

9.90

0.004

Litter depth

Site

0.20

0.659

Residuals

0.02

0.885

1

2.27

0.083

Pseudopanax arboreus

Canopy openness

Soil moisture

41

Litter depth

Site

Residuals

52.69

$<0.001$

$\begin{array}{ll}1 & 0.15 \\ 1 & 0.01\end{array}$

0.699

0.959

4

2.62

0.053

Shefflera digitata

Canopy openness

Soil moisture

Litter depth

Site

41

Residuals

$\begin{array}{rr}10.31 & 0.003 \\ 4.93 & 0.033 \\ 0.04 & 0.848 \\ 0.69 & 0.607\end{array}$

41 
Table 2.4. Linear mixed-effects model of 18-month seedling survival of the five study species by location (random effect), canopy openness, soil moisture, litter depth, and site (fixed effects). Only results for fixed effects are reported. Summary table indicates degrees of freedom $(\mathrm{df})$, variance ratios $(F)$, and $P$-values $(P)$. There are no results for Schefflera digitata because all seedlings died within 18 months.

Species/predictor

df

F $P$

Berberis darwinii

Canopy openness

Soil moisture

Litter depth

Site

Residuals

$1 \quad 25.37$

$<0.001$

$1 \quad 0.63$

0.432

$1 \quad 1.79$

0.190

4

0.297

Coprosma grandifolia

Canopy openness

41

Soil moisture

Litter depth

Site

1.28

Residuals

5.68

0.023

$1 \quad 0.95$

0.337

1

0.39

0.536

4

0.19

0.943

Melicytus ramiflorus

Canopy openness

Soil moisture

Litter depth

Site

Residuals

16.42

$<0.001$

2.43

0.128

1.69

0.202

0.27

0.893

41

Pseudopanax arboreus

Canopy openness

Soil moisture

Litter depth

Site

Residuals

4.80

0.036

$1 \quad 1.36$

0.025

$1 \quad 0.01$

0.922

4

0.32

0.863

41 
Natural seedling establishment (B. darwinii only)

Patterns of seedling emergence largely reflected patterns of seed dispersal, with density decreasing with distance from source population (Fig. 2.10). However, in the sites directly beneath the parent canopy, the number of emergent seedlings differed among years, and differed in proportion to the number of seeds produced: four times as many seeds, but only twice as many seedlings, were produced in Year 1 compared to Year 2 (Table 2.5). Put another way, the proportion of the seed rain that germinated to produce seedlings was $14 \%$ in Year 1, and 29\% in Year 2. Patterns appear to be similar in sites away from the parent canopy, with a greater proportion of the seed rain emerging as seedlings in Year 2 (Fig. 2.10).

Unlike seedling emergence, patterns of seedling establishment were uncoupled from patterns of seed dispersal, largely because few of the $B$. darwinii seedlings growing directly beneath the $B$. darwinii canopy survived (Fig. 2.11). Results indicate that survival of the two cohorts of naturally-occurring seedlings was affected by all predictors considered: seedling density, year, canopy openness, and distance from parent canopy (Table 2.6), but there were no interactions between variables. Seedling density $^{2}$ was also significant, indicating a non-linear response of survival to seedling density. Seedling density and distance explained the most variance (Table 2.6), but these variables are likely to be highly correlated. Furthermore, the direction of the effect differed between these variables: survival decreased with density, but increased with distance (Fig. 2.11). This probably explains why there was no interaction between density and distance. Interestingly, patterns of survival by distance were not consistent between years (Fig. 2.11, Table 2.5). In Year 1, percent survival was similar in all but the sites directly beneath the source canopy (sites at $0 \mathrm{~m}$ ), but in Year 2, survival was similar in all but the sites $450 \mathrm{~m}$ away from the source canopy (Fig. 2.10). In other words, while there is a positive correlation between survival and distance, the relationship is variable. 

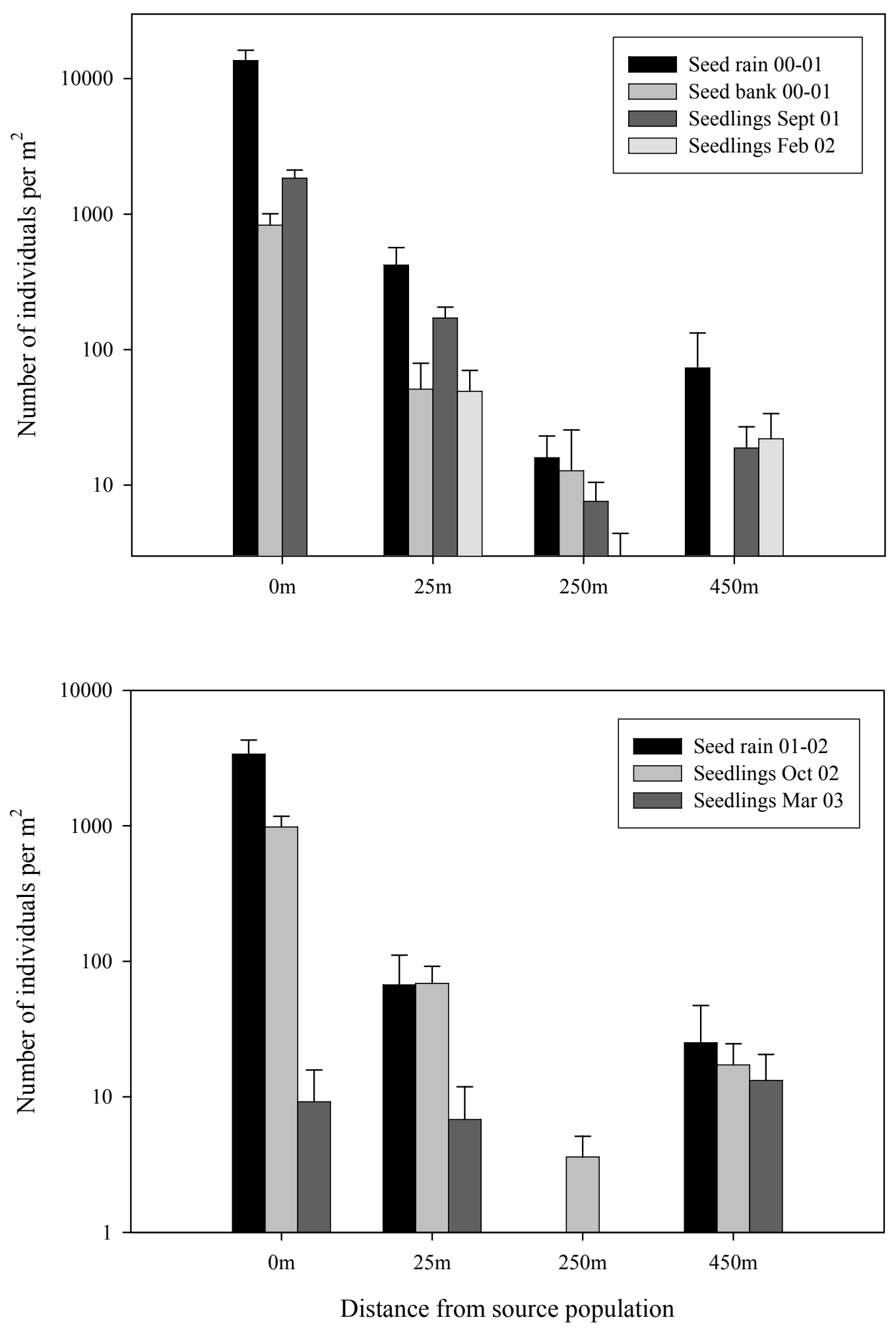

Fig. 2.10. Comparison of natural Berberis darwinii seed rain, seed bank, and seedling establishment per $\mathrm{m}^{2}$ relating to two summers of seed production. The seed bank was measured in Year 1 only, so is not included in the bottom graph. $\mathrm{n}=10$ samples per distance (see methods for total area sampled at each life-stage). Note y-axis is on a log-scale. Error bars are \pm 1 s.e. of the mean. 


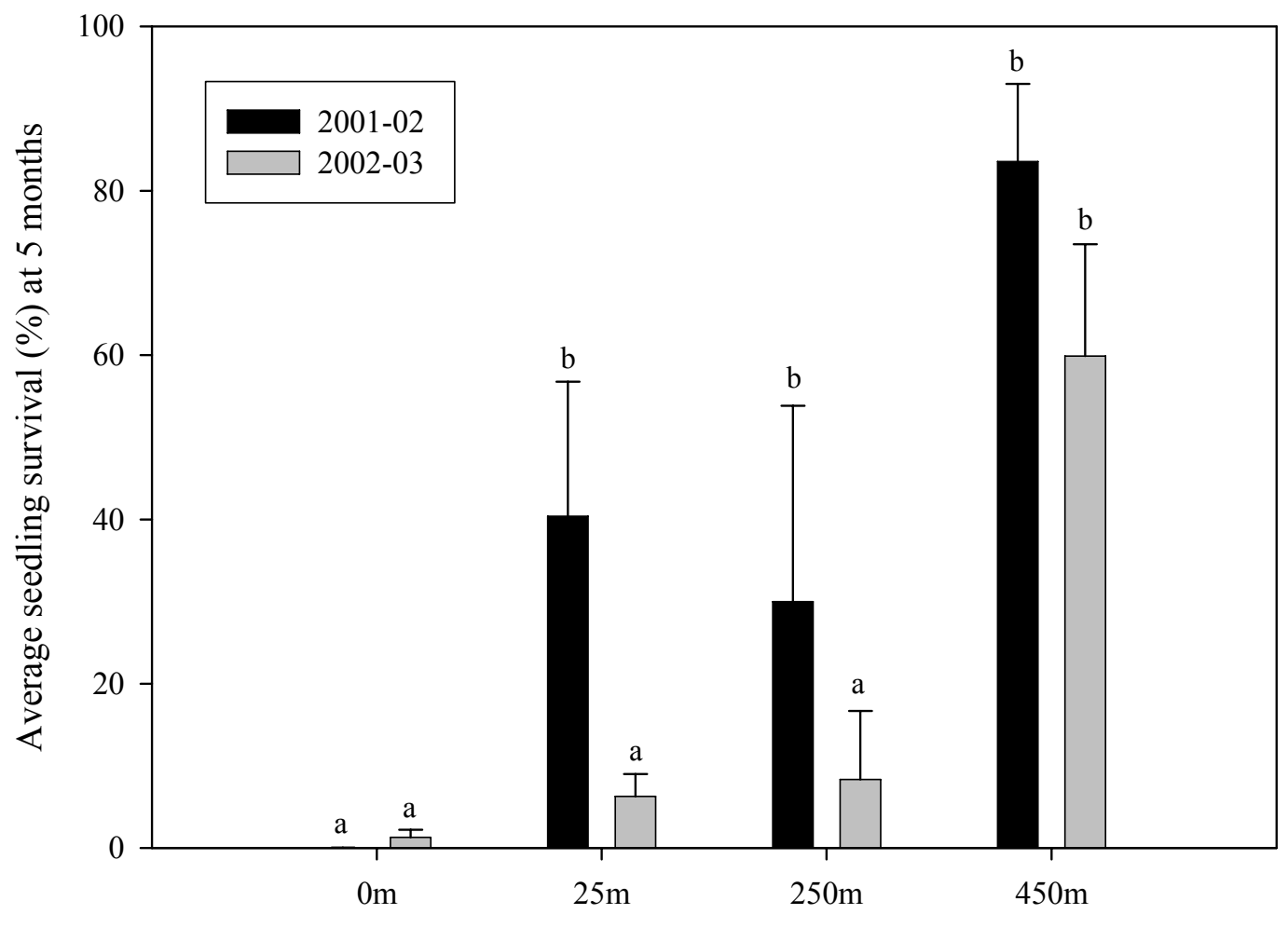

Distance from source population

Fig. 2.11. Survival of naturally occurring Berberis darwinii seedlings at increasing distances from source population, five months after germination. Seedlings were surveyed in $10 \times 0.25 \mathrm{~m}^{2}$ quadrats at each distance.

Within each year, bars sharing the same letter are not significantly different from each other (Tukey posthoc contrasts $P<0.05$ ). No seedlings survived at $0 \mathrm{~m}$ in Year 1 . Error bars are \pm 1 s.e. of the mean. 
Table 2.5. Generalized linear model of survival of two cohorts of naturally-occurring Berberis darwinii seedlings by seedling density, year, canopy openness, and distance from source population. Seedling density and canopy openness were also squared in order to test for a non-linear response of seedling survival to density and canopy. Summary table indicates degrees of freedom (df), deviance (dev), variance ratios $(F)$, and $P$-values $(P)$.

$\begin{array}{lrrrr}\text { Seedling survival } & \text { df } & \text { dev } & F & P \\ & & & & \\ \text { Seedling density }^{2} & 1 & 53.05 & 28.54 & <0.001 \\ \text { Seedling density }^{2} & 1 & 8.10 & 4.36 & 0.041 \\ \text { Year }_{\text {Canopy openness }}^{2} & 1 & 13.19 & 7.10 & 0.010 \\ \text { Canopy openness }^{2} & 1 & 13.79 & 7.42 & 0.009 \\ \text { Distance } & 1 & 0.29 & 0.15 & 0.693 \\ & 3 & 42.24 & 7.57 & <0.001\end{array}$

\section{Transition between life-stages}

There were far fewer individuals detected in the seed bank compared to both the seed rain and natural seedling crop (Fig. 2.10, Table 2.6). A total of 135,796 seeds were detected in the seed rain in Year 1, but only 33,790 in Year 2. However, despite this four-fold difference in the number of seeds produced between years, there were only twice as many seedlings in Year 1 compared to Year 2 (Fig. 2.10, Table 2.6). This means that, on a percentage basis, in Year 1, 13.6\% of the seed rain resulted in seedlings in the field, but in Year 2, this was considerably higher at 29\%. This also means that transition ratios were very different between years: in Year 1, the ratio of seeds to seedlings was 16:1, but in Year 2 it was 3.5:1 (Table 2.6).

In the year that seed bank was measured, seedling survival was affected by seed rain density, seed bank density, and distance (Table 2.7). Distance was the predictor of most interest, and it is interesting that it came out as significant even after the variance explained by all other predictors had been accounted for. This suggests strong support for the escape hypothesis - although again, all predictors tested are likely to be correlated. Seed rain density ${ }^{2}$ was also significant, indicating a non-linear response of seedling survival to seed rain density (Table 2.7). 
Table 2.6. Transition ratios between life-stages (seed rain: seed bank, seed bank: seedling, and seed rain: seedling). Ratios are calculated by dividing the number of individuals per $\mathrm{m}^{2}$ in the prior stage by the number in the subsequent life-stage. Data are from the most densely-populated sites (beneath canopy) only. In Year 1, seed rain data was collected from Dec 01-Mar 01, seed bank samples were collected from Mar 01-Mar 02 (excluding any further seed input after Mar 01), and naturally-occurring seedlings were counted in Sept 01. In Year 2, seed rain data was collected from Dec 01-Feb 02, and seedlings were counted in Oct 02. The seed bank was not measured in Year 2, so only the seed rain: seedling ratios are presented for that year.

\begin{tabular}{lrrrr}
\hline & Seed rain & Seed bank & Seedling & Ratio \\
& & & & \\
\hline Year 1 & 135,796 & 8,418 & & $16: 1$ \\
& & 8,418 & 18,432 & $0.5: 1$ \\
& 135,796 & & 18,432 & $7.4: 1$ \\
\hline & & & 9,796 & $3.5: 1$
\end{tabular}


Table 2.7. Generalized linear model of survival of one cohort of naturally-occurring Berberis darwinii seedlings by seed rain density, seed bank density, seedling density, canopy openness, and distance from source population. All predictors except distance were also squared in order to test for a non-linear response of seedling survival to these variables. Summary table indicates degrees of freedom (df), deviance (dev), variance ratios $(F)$, and $P$-values $(P)$.

\begin{tabular}{lrrrr}
\hline Seedling survival & df & dev & $F$ & $P$ \\
& & & & \\
\hline & 1 & 42.15 & 27.38 & $<0.001$ \\
Seed rain density & 1 & 9.83 & 6.38 & 0.020 \\
Seed rain density $^{2}$ & 1 & 8.42 & 5.47 & 0.030 \\
Seed bank density $^{2}$ & 1 & 0.01 & 0.01 & 0.962 \\
Seed bank density $^{2}$ & 1 & 0.09 & 0.81 & 0.807 \\
Seedling density $^{2}$ & 1 & 3.64 & 0.14 & 0.140 \\
Seedling density $^{2}$ & 1 & 6.36 & 0.06 & 0.060 \\
Canopy openness $_{\text {Canopy openness }}{ }^{2}$ & 1 & 0.34 & 0.64 & 0.642 \\
Distance & 3 & 20.92 & 0.01 & 0.014
\end{tabular}




\section{Discussion}

Berberis darwinii has several traits that may contribute to invasion success. It reaches sexual maturity by 2 years of age (pers. obs.), and produces large amounts of seeds early in the season when competition for dispersers is likely to be low. Birds disperse seeds in significant numbers, many hundreds of metres from the source population. Seed viability is approximately $70 \%$, and seeds germinate in a wider range of light environments, and at higher rates, than the four native species studied. Berberis darwinii also has higher rates of seedling survival than the native species, although none of the species were capable of establishing in shady conditions. The critical stage for recruitment in B. darwinii appears to be seedling establishment. Patterns of seedling emergence are largely determined by patterns of seed rain, but seed bank density, seedling density, light environment, and distance from source population (many of which are correlated) can all have an effect on seedling survival. Dispersal of any distance is likely to increase seedling recruitment because seedling survival is virtually nil beneath the parent canopy. Widespread dispersal, coupled with high germination in all environmental conditions, maximises the chance that at least some seeds will germinate in habitats suitable for seedlings survival. Seedlings are relatively light-demanding, so recruitment into new areas likely depends on disturbance, or dispersal to high light areas. Thus, the scarcity of $B$. darwinii juveniles under canopy reflects poor seedling survival, rather than germination failure. Plants that do occur in shady environments may have established prior to canopy closure, for example soon after gap formation. In this section I will discuss the seed bank dynamics, seed dispersal patterns and consequences for recruitment, and the critical life stage of $B$. darwinii in more detail, and consider the management implications inferred by these results.

\section{Seed bank dynamics}

Long-lived seeds can be advantageous for invasive species, particularly when coupled with effective spatial seed dispersal, because this means seeds are poised to take immediate advantage of conditions favourable for recruitment. However, long-lived seeds are at increased risk of exposure to seed predators and pathogens, and many 
species adopt the alternative strategy of germinating en masse soon after dispersal, thereby increasing the chance that at least some seeds will have arrived in suitable conditions. Long-lived seeds requiring environmental cues to germinate are likely to be more advantageous in environments with low predictability of favourable conditions, whereas early, mass germination is generally more common in stable environments (Venable and Lawlor 1980; Parker et al. 1989; Thompson 2000). All three experiments investigating seed longevity in this study (fresh seeds sown, seed burial, and seed bank sampling) indicate the same result: almost all B. darwinii seeds germinate in the first spring following dispersal, with only a few surviving for more than one year. Both freshly-collected seeds and seeds buried for a short period of time (4 months) and unearthed prior to the time of natural germination (the spring following seed fall) showed a similar pattern of germination: $61-69 \%$ of seeds germinated in the first spring following dispersal, 4-8\% germinated the second spring, leaving a remainder of $27-31 \%$ that was presumably inviable. However, many of the seeds that had been buried for 10-19 months had germinated (but had not emerged) within the mesh bags by the time they were un-earthed. Subsequent germination of these seeds was low (2-10\%), and no further germination took place the following year. All results thus indicate that most seeds germinate during the first year following dispersal, regardless of light environment - including complete darkness beneath the soil surface. While artificial burial bypasses the crucial role of natural mechanisms that can reduce seed viability, and thus provides only a conservative measure of seed longevity (Bakker et al. 1996; Thompson et al. 1997), it is probably safe to say that seeds that are short-lived when artificially buried will likely also be short-lived under natural conditions.

Germination of $B$. darwinii seeds is highly seasonal, occurring mainly in spring between September and December, approximately six months after dispersal. This strategy of delayed germination is common amongst species occurring in climates where potentially adverse seasonal variation is relatively predictable, such as winter in temperate forests, and summer drought in the tropics (Parker et al. 1989; Hille Ris Lambers et al. 2005). Germination following winter dormancy is commonly triggered by a period of low temperatures (chilling), but can also be due to the gradual decay of a hard seed coat which renders the seed permeable to water by the time spring arrives (Vázquez-Yanes and Orozco-Segovia 1993). Seeds sometimes return to a state of 
dormancy if they fail to germinate before the end of spring (Baskin and Baskin 1998), and this may be the case for the $B$. darwinii seeds that remain viable for more than one year. However, it is unlikely that seeds persisting for more than one year play a significant role in recruitment dynamics, given that very few do so.

Few seedlings emerged from the seed bank samples, but this does not necessarily mean that few seeds were present post-dispersal. Many studies have shown that the vast majority of the seed rain is rapidly lost to predation, disease and senescence, with only a small fraction entering the viable seed bank population (e.g. Leck et al. 1989; e.g. Alvarez-Buylla and Martínez-Ramos 1990; Schupp 1990; Dalling et al. 1998b; Cabin et al. 2000; Crawley 2000; Wenny 2000). In this case, however, it could also be due to a problem of sample size. Assessment of seed bank density is often less precise if the total area sampled is low, particularly in areas of low, or patchy, seed density (Mickelson and Stougaard 2003). In this study a total area of $0.08 \mathrm{~m}^{2}$ was sampled on each collection date $\left(0.0196 \mathrm{~m}^{2}\right.$ for each of the four sites increasing in distance from source population), which may be too small for an accurate estimate. In even the most dense areas (directly beneath the source population canopy), seed bank samples picked up only one tenth of the seeds that were captured by the seed traps. Furthermore, in most sites seedling density was more than double the seed bank density, even in areas further away from the source population where fewer seeds arrive at the soil surface. However, given that few seeds survive in the soil for more than one year, it seems safe to conclude that new $B$. darwinii seedlings originate primarily from the current year's seed input, with minimal recruitment from the seed bank.

\section{Seed dispersal patterns and consequences}

Widespread seed dispersal is often considered a key reproductive trait contributing to the success of invasive species (Glyphis et al. 1981; Gleadow 1982; Stansbury 1996; Parendes and Jones 2000; Radford et al. 2001; Stansbury 2001). In this study the number of seeds dispersed long distances may have been underestimated because sampling intensity declined with distance from the source population (see Fenner and Thompson 2005). However, significant numbers of seeds were dispersed up to $150 \mathrm{~m}$ from the parent population, and seeds were also consistently detected at distances up 
to $450 \mathrm{~m}$ away. A seed dispersal curve is generally assumed to be negatively exponential in shape (Howe 1986; Willson 1993), but in this study it was best described by an inverse power function. This implies that the "tail" of the curve was more drawn-out than expected, which, in vertebrate-dispersed species, has previously been attributed to the ability of animals to transport seeds over long distances (Laman 1996; Panetta and Sparkes 2001). Long distance dispersal can accelerate the invasion process by initiating new "satellite" populations (Moody and Mack 1988; Hengeveld 1989; Kot et al. 1996), and is thought to be disproportionately important to a range of recruitment processes (Clark et al. 1998a; Cain et al. 2000). Furthermore, B. darwinii can produce fruit by 2 years of age, and fruits earlier in the season than most other species in New Zealand (Allen and Lee 1992). All of these factors support previous suggestions that $B$. darwinii is a prolific fruit producer with highly effective seed dispersal mechanisms (Allen and Wilson 1992).

Berberis darwinii seeds dispersed away from the source population had a much higher chance of surviving at the seedling stage; almost all naturally-occurring $B$. darwinii seedlings beneath the parent canopy died within the first 5 months following germination, in both study years. Results suggest that both seedling density and distance from source population play a role in this, although these two factors are likely correlated. Seedlings occurring at high densities commonly experience high mortality due to factors such as competition, the presence of pathogens, or allelopathic effects (Augspurger 1983b; Augspurger and Kelly 1984; Howe 1990; Howe 1993; Hulme 1998; Packer and Clay 2000), although there was no obvious cause in this study. The non-linear response of seedling survival to seedling density (Table 2.6) also suggests that there is an upper limit at which point increasing seedling density no longer continues to decrease survival. Interestingly, in this study the relationship between distance and seedling survival was inconsistent between years: survival was significantly higher in all sites away from the parent canopy in Year 1, but in Year 2 only seedlings $450 \mathrm{~m}$ away had higher survival. On the face of it, this seems to indicate that the escape hypothesis explained seedling survival in Year 1, but not in Year 2. However, results were highly variable, and therefore must be interpreted with caution. Other studies too have found seedling survival to be patchy and inconsistently correlated with distance from source population-both within and between years (Wheelwright and Orians 1982; Schupp 1988a; Willson and 
Whelan 1990; Whelan et al. 1991; Houle 1992; Howe 1993). Thus the most favourable sites for seed dispersal are often unpredictable in time and space, and chance may play a significant role in seedling survival.

Seed dispersal combines with patterns of germination and seedling establishment to determine the spatial patterns of saplings and adult trees (Houle 1995; Schupp and Fuentes 1995; Houle 1998; Wenny 2000). Berberis darwinii has a lengthy germination period in its native habitat, ranging from c. 4 to 10 months following dispersal (Figueroa and Armesto 2001). This study illustrates a similar pattern in New Zealand, with germination beginning around August, and continuing through to at least February (pers. obs.). Germination occurred successfully in all light environments (including in the dark, when buried), which has also been found in previous studies both in New Zealand (McAlpine and Drake 2003) and its native habitat (Figueroa and Lusk 2001), so it seems unlikely that B. darwinii has a light requirement for germination. Given that seeds dispersed in summer do not germinate until the following spring, it seems more likely that $B$. darwinii has some form of embryonic dormancy when seeds are fresh, and this is lost over winter. Indeed, Dirr and Heuser (1987) advise that, in the USA, seeds of $B$. darwinii germinate successfully after 2-3 months of cold stratification. This is likely to be the case in New Zealand: $B$. darwinii seeds come out of dormancy following a period of cold winter temperatures and adequate moisture. This is also supported by the fact that seeds stored in warm, dry conditions for 16 months were sowed in autumn, but did not germinate until spring. This strategy of widespread dispersal and mass germination over several months, regardless of light environment, may maximise the chances of a seed germinating in a suitable site.

Sites favourable to germination are not necessarily favourable to seedling establishment (De Steven 1991b; Houle 1992; Herrera et al. 1994; Horvitz and Schemske 1994; Houle 1994; Schupp 1995; Houle 1998; Rey and Alcàntara 2000). In the seed-sowing experiment, germination of $B$. darwinii remained high in shady sites, but 18-month old seedlings were largely restricted to high light environments - i.e. those with approximately $20 \%$ canopy openness or more (edge and full sun sites). Furthermore, average percent canopy openness was significantly higher at sites $450 \mathrm{~m}$ from the parent canopy (20\%) than sites at $25 \mathrm{~m}(11 \%)$ and $250 \mathrm{~m}(10 \%)$, and survival 
of naturally occurring seedlings was high there in both years. On the other hand, canopy openness at $0 \mathrm{~m}$ and $450 \mathrm{~m}$ was similar, but survival was very different between these two sites - possibly because of the negative effect of density, as mentioned above. These results support previous work carried out by Figueroa and Lusk (2001) on B. darwinii in part of its native range (southern Chile), who found that seeds germinated equally well in both gap and understorey environments, but that juvenile plants (0.1-1.0 m tall) required a mean of 20\% canopy openness to survive. The consequences of dispersal appear to be similar for the neotropical tree species Virola surinamensis: seedlings are much more likely to survive if they are dispersed away from the parent population, particularly if they arrive in a high light environment (Howe et al. 1985). Other species of Berberis seedlings are also lightdemanding, including B. vulgaris (Kollmann and Reiner 1996), and B. nervosa (Huffman and Tappeiner II 1997), but B. thunbergii may be more shade-tolerant (Ehrenfeld 1997; Silander and Klepeis 1999). The fact that $B$. darwinii seedlings are relatively light-demanding, coupled with seed longevity of less than one year, suggests that only seeds dispersed to high light environments such as gaps have a chance of making it past the seedling stage. Once past the seedling stage, however, adult plants appear tolerant of relatively shady conditions and are therefore able to persist beneath an intact forest canopy (Allen 1991). Thus, it may be through gap phase recruitment that Berberis darwinii becomes a common component of the forest understorey. Further research would clarify this, and pinpoint the age, or size, at which plants become shade tolerant.

Canopy gaps are frequently associated with high seedling survival, largely due to higher light availability and lower predator and pathogen presence (e.g. Augspurger 1983b; Augspurger 1984a; Brokaw 1985b; e.g. Shibata and Nakashizuka 1995; Kobe 1999). The light environment beneath deciduous Fuchsia trees is potentially more favourable for seedling establishment of $B$. darwinii if the autumn-winter loss of leaves creates the equivalent of a canopy gap. However, while birds do seem to disperse B. darwinii seeds disproportionately to Fuchsia trees, this does not appear to result in greater numbers of seedlings in those sites (although a Type II error is possible here, due to low statistical power). Thus, the directed dispersal hypothesis is not supported by these results. This suggests that the light environment beneath Fuchsia trees is not, in fact, significantly different from that in surrounding areas- 
possibly because the high ratio of canopy height to gap diameter means the sun does not penetrate the "gap" in the canopy and reach the soil surface (Canham et al. 1990). Further research would reveal whether this is true. The directed dispersal hypothesis was also rejected by Hoshizaki et al (1999), who found that although rodents did direct seeds of Aesculus turbinata to particular sites, those sites were not suitable for survival. However, given that birds frequently disperse seeds disproportionately to canopy gaps (Thompson and Willson 1978; Moore and Willson 1982), and given that B. darwinii seedling survival is most successful in high light environments, directed dispersal to a large canopy gap might result in higher recruitment.

Invasive species may also derive a competitive advantage from superior germination and establishment capabilities under certain environmental conditions (Bazzaz 1986; Rejmánek 1996; Ehrenfeld 1999; Jesson et al. 2000; Daehler 2003). Berberis darwinii had both a germination and seedling survival advantage over almost all of the four native species, in almost all of the light environments. Melicytus ramiflorus and Pseudopanax arboreus had similar rates of germination to $B$. darwinii in the sunniest sites, but lower rates of seedling survival. While survival of all five species was low in the three shadiest light environments, $B$. darwinii germinated most successfully in these sites. Thus $B$. darwinii is likely to be best placed to take advantage of a treefall gap occurring in the time between germination and seedling death-which could be as long as 6 months. B. darwinii does not appear to have higher seed viability than the native species, although Schefflera digitata has a persistent seed bank so both viability and rates of germination may be underestimated for this species.

\section{Transition between life-stages}

Prolific seed production alone does not necessarily increase recruitment, because there is likely to be an upper limit on the number of dispersers available, and on the number of seedlings that can emerge per unit area. In the sites directly beneath the parent canopy, there were four times as many seeds in Year 1 compared to Year 2. However, there were only twice as many newly-germinated seedlings in Year 1 compared to Year 2, indicating that a larger proportion of the crop emerged as seedlings in Year 2. This may be because sites were saturated with seed in Year 1, so the number of seedlings was limited by microsite availability. However, a larger 
proportion of the crop in Year 2 also emerged as seedlings in sites less saturated with seed (sites at 25m, 250m, and 450m from source population) (Fig. 2.10), suggesting that either a larger proportion of the crop was dispersed in Year 2, or that weather conditions were more favourable for germination. Several other studies have also shown that proportionally more of the fruit crop is taken by frugivores when a small crop is produced (Jordano 1987; Herrera et al. 1994; Herrera 1998). It seems likely that in the current study dispersal and microsite availability (and probably additional factors) interact to create the germination patterns seen. The relationship between seed rain and seedlings 5 months after germination is even more complex, probably most influenced by density-dependant mortality and light environment. However, overall seedling survival in sites away from the parent canopy was generally higher in Year 1 than in Year 2 (Fig. 2.11), suggesting that higher fruit abundance may increase recruitment under some circumstances. Certainly the quantity of fruit produced can vary significantly between years (Herrera 1998), but only long term research can elucidate what effect this has on seedling recruitment.

There was also discordance between the number of individuals in the seed bank and the seed rain: 16 individuals were counted in the seed rain for every one in the seed bank. The average percent viability of $B$. darwinii seeds was $70 \%$, so theoretically $70 \%$ of the seed rain could germinate in the spring following dispersal-minus the percentage of seeds being lost to predators, pathogens, and other sources of mortality. As mentioned previously, such seed loss can be significant $-90 \%$ or higher in many cases (Howe et al. 1985; Alvarez-Buylla and Martínez-Ramos 1990; Morgan 1995; Dalling et al. 1998b; Cabin et al. 2000; Wenny 2000). In the current study, immediate post-dispersal seed banks represented only $6.2 \%$ of the seed rain, suggesting that approximately $64 \%$ of seeds are being lost between dispersal in summer and germination the following spring. These results may be biased, however, because they are taken solely from the sites directly beneath the parent canopy, where seed density is highest and therefore predator and pathogen activity is likely to be at its most intense-including below the soil surface (Janzen 1970; Connell 1971; Clark and Clark 1984; Dirzo and Domìnguez 1986; Dalling et al. 1998b; Crawley 2000). However, in the current study, results from sites further away from the canopy were highly variable (Fig. 2.7), possibly due to the small area sampled, or to patchy seed distribution. A much higher proportion of seeds germinated in the glasshouse 
experiment: on average $70 \%$ of seeds sown germinated the following spring. This suggests that the factors causing seed loss in the field-for example seed predators and pathogens - were largely absent in the glasshouse and/or potting mix.

Similarly, there were far fewer individuals detected in the seed bank compared to the natural seedling crop, as indicated by the ratio of 0.5 seeds in the seed bank for every seedling (Table 2.5). This seems to imply that seedlings are originating from somewhere other than the seed bank. However, both the seed bank and seedling data are measuring germination from naturally-occurring seeds. The only difference is that the seed bank samples were transferred from the field to the glasshouse. Thus, the fact that germination from seed bank samples was so much lower than germination in the field may be an indication that glasshouse conditions were unfavourable for germination. However, germination from sown seeds (in the seed viability experiment) was high, so this is probably not the case. Another possible explanation is the difference in area sampled for the two experiments. The total area measured from seed bank samples taken from the 10 sites beneath the Berberis darwinii canopy (given that only these sites were used to calculate transition ratios) was $0.02 \mathrm{~m}^{2}$, whereas for seedlings it was $2.5 \mathrm{~m}^{2}$.

\section{Management implications}

Given the ubiquitous nature of $B$. darwinii seed dispersal, removal of the seed source should be the initial management priority. However, this is not always possible, and in many situations the aim of weed control is to prevent further invasion into surrounding territories. In these circumstances, seedling establishment should be the focus of management efforts, given that this appears to be the critical stage for $B$. darwinii recruitment. Berberis darwinii seedlings are likely to out-compete native species in high light environments such as disturbed areas or canopy gaps (Fig. 2.9), so these areas should be the focus of seedling control. Newly-germinated seedlings in shady environments will largely die out naturally, so seedling control in these areas is unnecessary. If seed dispersers are present in the area, managers could expect to find seedlings at least $450 \mathrm{~m}$ away from the source population or plant, in any type of habitat. The seed bank is of minor concern, since most seeds do not last for more than one year. 


\title{
CHAPTER THREE. PATTERNS OF BIOMASS
}

\section{ALLOCATION DO NOT APPEAR TO CONTRIBUTE TO \\ INVASION SUCCESS IN BERBERIS DARWINII \\ SEEDLINGS}

\begin{abstract}
Berberis darwinii is a serious invasive weed in New Zealand, capable of invading a range of different light environments, from grazed pasture to intact forest. According to optimal partitioning models, some plants optimize growth under different environmental conditions by shifting biomass allocation to tissue types (e.g. roots, shoots) to maximise the capture of limiting resources (e.g. water, light). I examined patterns of growth, biomass allocation, and seedling survival in $B$. darwinii in order to determine whether this trait might be contributing to invasion success. Seedlings were grown for 7 months in five natural light environments in the field. Survival was high in the sunniest sites, and low in the shadiest sites. Seedlings grown in full sun were an order of magnitude taller and heavier, had five times as many leaves, and proportionally more biomass allocated to leaves than seedlings grown in other light environments. In the shade, leaves were bigger and thinner, and leaf area as a proportion of total plant biomass increased, but the proportion of above- to belowground biomass was similar across all light and soil moisture environments. In summary, although leaf characteristics were plastic, patterns of biomass allocation did not vary according to optimal partitioning models, and were not correlated with patterns of seedling survival. Thus, patterns of biomass allocation do not appear to contribute to invasion success in $B$. darwinii.
\end{abstract}

\section{Introduction}

Plasticity has long been considered a trait contributing to the success of weeds (Baker 1965; Baker 1974; Roy 1990), but few empirical data exist to support or refute this assertion (Kolar and Lodge 2001). Although plasticity is often considered at the level of genotype, it can be scaled up to the level of species (Ellsworth and Reich 1996; 
Weber and D'Antonio 1999; Filella and Penuelas 2003; Paz 2003). A species is said to be plastic if plants grown under different environmental conditions exhibit differences in morphological or physiological traits such as leaf characteristics (Popma et al. 1992; Ryser and Eek 2000; Valladares et al. 2000), photosynthesis (Björkman and Holmgren 1963; Björkman and Holmgren 1966; Boardman 1977; Ellsworth and Reich 1992; Thompson et al. 1992a), and overall patterns of biomass allocation (Grime et al. 1986; Rice and Bazzaz 1989; Chapin 1991; King 1991; Wang et al. 1994; Williams et al. 1995). This occurs to some extent in most plants, but a more plastic species may be better able to optimize its capacity to acquire the most limiting resource and hence maximize growth in a wider range of habitats than a less plastic species (Hirose 1987; Mooney et al. 1988; Robinson and Rorison 1988; Latham 1992; Schweitzer and Larson 1999; Valladares et al. 2000). While there are, presumably, costs associated with being plastic, this may be one way invasive species succeed over a wide range of environmental conditions and thus gain an advantage over native species (Williams et al. 1990; Schierenbeck et al. 1994; Williams et al. 1995; Fogarty and Facelli 1999; Schweitzer and Larson 1999; Baruch et al. 2000; Stratton and Goldstein 2001).

One of the primary factors affecting seedling plasticity and growth is likely to be light availability (Chazdon 1988; Kitajima 1996; Poorter 2001), although soil moisture (Williams et al. 1990; Veenendaal et al. 1995), nutrient supply (Rincón and Huante 1994; Müller et al. 2000), herbivory (Schierenbeck et al. 1994), and competition (Grime 1979; Thébaud et al. 1996; Fogarty and Facelli 1999) can also be important. Light is an extremely heterogeneous resource (Chazdon et al. 1996), particularly in disturbed sites which are often the point of entry for invasive species (Hobbs 1989; Rejmánek 1989; Hobbs and Huenneke 1992; Jesson et al. 2000; Lake and Leishman 2004), so it is an advantage for seedlings to be able to cope with a variety of light environments (Bazzaz 1996). Most species are able to acclimate to low light conditions by developing larger, thinner leaves and by increasing the ratio of total leaf area to total mass (Loach 1970; Givnish 1988; Popma and Bongers 1988; Walters et al. 1993; Lusk and Del Pozo 2002), but the link between shoot: root ratio and light environment is less consistent (Callaway 1992; Osunkoya et al. 1994; Pattison et al. 1998; Valladares et al. 2000), and may vary according to the shade tolerance of the species (Rao and Singh 1989; King 1991; Thompson et al. 1992b; Kobe 1997; 
Walters and Reich 2000). Optimal partitioning models suggest that plants can optimize growth in a variety of environments by shifting resource allocation to leaf and stem production in light-limited environments, and to root production in nutrientor water-limited environments (Brouwer 1962; Brouwer 1963; Thornley 1969; Thornley 1972; Bloom et al. 1985; Hirose 1987; Tilman 1988; Wilson 1988). Many studies support these models (Chapin 1991; King 1991; Mooney and Winner 1991; Wang et al. 1994; Canham et al. 1996; McConnaughay and Coleman 1999; Poorter and Nagel 2000; Ryser and Eek 2000), although few have looked specifically at invasive species (but see Pattison et al. 1998; Baruch et al. 2000; Longbrake and McCarthy 2001; Sanford et al. 2003).

In this study I examine the link between plasticity and invasiveness in the exotic species Berberis darwinii Hook. (Berberidaceae). Berberis darwinii is a woody, evergreen shrub up to $4 \mathrm{~m}$ high, native to southern Chile and Argentina. Initially brought to New Zealand as an attractive garden plant, it was first recorded naturalized in 1946 (Sykes 1982). It has since invaded many vegetation types throughout the country, including remnant forest stands, scrub, and along roadsides (Webb et al. 1988). It has high reproductive capacity and efficient seed dispersal by birds in New Zealand, and can form dense colonies that persist after overtopping by forest trees (Allen 1991). It is tolerant of drought and frost, and can occupy a wide range of soil types (Allen 1991; Timmins and Mackenzie 1995). Plants can vary in growth habit, from dense shrubs with interlaced branches in open environments, to lianoid-like small trees up to $10 \mathrm{~m}$ tall beneath the intact forest canopy (Webb et al. 1988; Allen 1991). It is this variable growth form and tolerance of a range of environmental conditions that suggests a highly plastic species. I hypothesised that plasticity in leaf characteristics and biomass allocation according to light environment contributes to this ability to establish in a wide range of habitat types. To test this I grew seedlings in a range of natural light environments in the field for seven months. I then asked three questions: 1) do leaf characteristics and patterns of biomass allocation vary across light environments, 2) do patterns of seedling mortality also vary, and 3) is there any correlation between 1) and 2)? 


\section{Methods}

\section{Study site}

I conducted this study within the Karori Wildlife Sanctuary, a 249-ha ecological restoration site in Wellington, New Zealand. See methods section of Chapter Two for detailed description of site.

\section{Environmental measures}

Canopy cover, soil moisture, and litter depth differed significantly among sites in Chapter Two (Table 2.1), so these data were also used for the analysis of growth and biomass allocation in the current chapter. See methods section of Chapter Two for more detail on these measures.

\section{Seedlings}

The $B$. darwinii seedlings used for this experiment were those grown from seed in five different light environments (full sun, edge, understorey, sycamore, and deep shade) as per Chapter Two. Three replicates of each light environment were located, giving a total of 15 sites. Within each of the 15 sites, three plots were prepared for seed-sowing, giving a total of 45 plots (see methods section of Chapter Two for more detail on light environments, plots, and seed sowing). Seeds were sown in March 2001, and most germination occurred in September 2001. In March 2002 I harvested three seedlings from each plot to measure growth and biomass allocation. Few seedlings had survived in the sycamore and deep shade light environments, so where possible I harvested naturally occurring, nearby seedlings that were obviously from the same cohort as the artificially sown seedlings. However, the total number of seedlings harvested did vary according to light environment: full sun, edge, and understorey: 45, sycamore: 44, and deep shade: 20. Following harvest, each seedling was cleaned, then divided into roots, stem, and leaves. Roots were sufficiently robust to withstand the harvest and cleaning process without damage, although fine hairs may have been lost. 


\section{Growth and biomass allocation measures}

I measured total fresh leaf area with a Licor 320 leaf area meter. Spines (modified leaves) were present at the base of leaf clusters on the stems of well-developed seedlings that had grown in the full sun. These were often very similar in shape, form and colour to leaves, so I included them in the leaf analyses, along with healthy cotyledons. I also measured stem length and number of leaves while the seedlings were still fresh. I then dried the plant material at $45^{\circ} \mathrm{C}$ for 7 days before calculating total biomass, leaf area ratio (LAR: total fresh leaf area/total seedling mass), leaf mass ratio (LMR: total leaf mass/total seedling mass), and root: shoot ratios (root mass/stem + leaf mass). I weighed 3 dried leaves of known (fresh) area per seedling in order to calculate the average specific leaf area (SLA: leaf area/leaf mass) of each seedling. These patterns of growth and biomass allocation were compared to patterns of seedling survival as measured in Chapter Two.

\section{Statistical analyses}

I analysed the data using S-Plus 4 (Mathsoft 1997) and SigmaStat 3.1 (SPSS 2004) statistical software. To identify the best way to transform the data, where necessary, I evaluated each variable for the best distribution of expected vs. actual residuals (Zar 1984). Stem length, root mass, leaf mass, total biomass, total number of leaves, and total leaf area data were log-transformed. Proportion of root, stem, and leaf data were arcsin-transformed. All other data met model assumptions untransformed. I used linear mixed effects models to test for differences among light environment, site (nested within light environment), and plot (nested within site) of stem length, root mass, stem mass, leaf mass, total biomass, root/shoot ratio, number of leaves, total leaf area, LAR, LMR, and SLA. Only results for light environment are presented, since site and plot were random effects. I made post-hoc comparisons using Sidaks tests. $P$-values from post-hoc comparisons were Bonferroni-corrected. I used multivariate analysis of variance to test for differences among light environment, site (nested within light environment), and plot (nested within site) of proportion of biomass allocated to root, stem, and leaf. In this situation, site and plot are treated as fixed effects. The effect of canopy openness, leaf litter depth, and soil moisture on seedling survival was examined in Chapter 2, but is also relevant to this chapter. 


\section{Results}

Canopy openness, litter depth, and soil moisture all differed significantly $(P<0.001)$ between sites as discussed in the results section of Chapter Two (also see Table 2.1 and Fig 2.3).

All growth, biomass allocation, and survival parameters exhibited significant differences between light environments (Table 3.1). Seedlings grown in full sun sites were at least 10 times greater in total biomass than seedlings grown in any other light environment (Fig 3.1). Seedlings grown in the three shadiest light environments were small, with no significant difference in their average total mass (Fig 3.1). Edge site seedlings were significantly different from all others; smaller than the seedlings grown in full sun but larger than the seedlings grown in the understorey, sycamore, and deep shade sites (Fig 3.1). Seedlings from full sun sites were also taller (Fig 3.2a), with more leaves (Fig 3.2b) and greater total leaf area (Fig 3.2c) than seedlings grown in any other light environment.

According to the optimal partitioning model, I had expected plants growing in low light to allocate a higher proportion of biomass to shoots, and plants growing in high light to allocate a higher proportion to roots. However, contrary to my expectations, B. darwinii did not vary biomass allocation in line with differences in light and soil moisture. Root: shoot ratios were similar across all sites, with no significant difference between even the two extremes of light environment, the full sun and deep shade sites (Fig. 3.3). Light environment did, however, have a significant effect on the proportion of biomass allocated to roots, stem, and leaves (Table 3.2). However, like most other parameters measured, it was only the seedlings grown in full sun sites that differed much (Fig. 3.4). Post-hoc comparisons indicated that full sun site seedlings allocated more biomass to leaf and less to stem than seedlings from the other four light environments. Proportions of biomass allocated to roots, stem, and leaves in the edge, understorey, sycamore, and deep shade light environments were similar.

As expected, specific leaf area increased consistently as shade increased, with significant differences between four of the five light environments (Fig 3.5a). Similarly, leaf area ratio increased consistently as canopy cover increased, although 
there was no significant difference between seedlings grown in the two shadiest sites (Fig 3.5b). Somewhat different was leaf mass as a proportion of total plant mass (leaf mass ratio). This was significantly different in seedlings grown in the full sun, but was similar in all other light environments, with only the understorey and sycamore sites significantly different from each other (Fig. 3.5c).

Average percent seedling survival was significantly higher in the two sunniest sites compared to the three shadiest sites (Fig 3.6). As per Chapter 2, multiple linear regression indicated that percent canopy openness was the strongest influence on seedling survival $(P<0.001)$, with litter depth $(P=0.196)$ and soil moisture $(P=0.866)$ less important. 
Table 3.1. ANOVA using linear mixed effects model of growth and biomass allocation parameters of Berberis darwinii seedlings by light environment, site (nested within light environment), and plot (nested within site). Site and plot were random effects, so only the results for the fixed effect (light environment) are presented. Summary table indicates degrees of freedom (df), residual degrees of freedom (res), variance ratios $(F)$ and $P$-values.

Growth and biomass

allocation parameters

df $\quad$ res $\quad F \quad P$

\begin{tabular}{llrrr}
\hline & & & & \\
Stem length & 4 & 194 & 80.71 & $<0.001$ \\
Root mass & 4 & 194 & 277.71 & $<0.001$ \\
Stem mass & 4 & 194 & 323.66 & $<0.001$ \\
Leaf mass & 4 & 194 & 273.50 & $<0.001$ \\
Total biomass & 4 & 194 & 390.88 & $<0.001$ \\
Root/shoot & 4 & 194 & 5.05 & $<0.001$ \\
Number of leaves & 4 & 194 & 203.04 & $<0.001$ \\
Total leaf area & 4 & 194 & 174.18 & $<0.001$ \\
Leaf area ratio & 4 & 194 & 54.50 & $<0.001$ \\
Leaf mass ratio & 4 & 194 & 26.34 & $<0.001$ \\
Specific leaf area & 4 & 194 & 49.41 & $<0.001$
\end{tabular}

Table 3.2. Multivariate analysis of variance of biomass proportions (root, stem, leaf) of Berberis darwinii seedlings by light environment, site (nested within light environment), and plot (nested within site). Summary table indicates degrees of freedom for Wilks lambda (df), Wilks lambda (Wilks), approximate $F$ value, numerator and denominator degrees of freedom, and $P$-values.

\begin{tabular}{lrrrrrr} 
Biomass proportion & df & Wilks & Approx $F$ & num df & den df & $P$ \\
\hline Light environment & 4 & 0.493 & 18.76 & 8 & 354 & $<0.001$ \\
Light environment: Site & 10 & 0.604 & 5.07 & 20 & 354 & $<0.001$ \\
Site: Plot & 6 & 0.940 & 0.94 & 12 & 354 & 0.514 \\
Residuals & 178 & & & & &
\end{tabular}




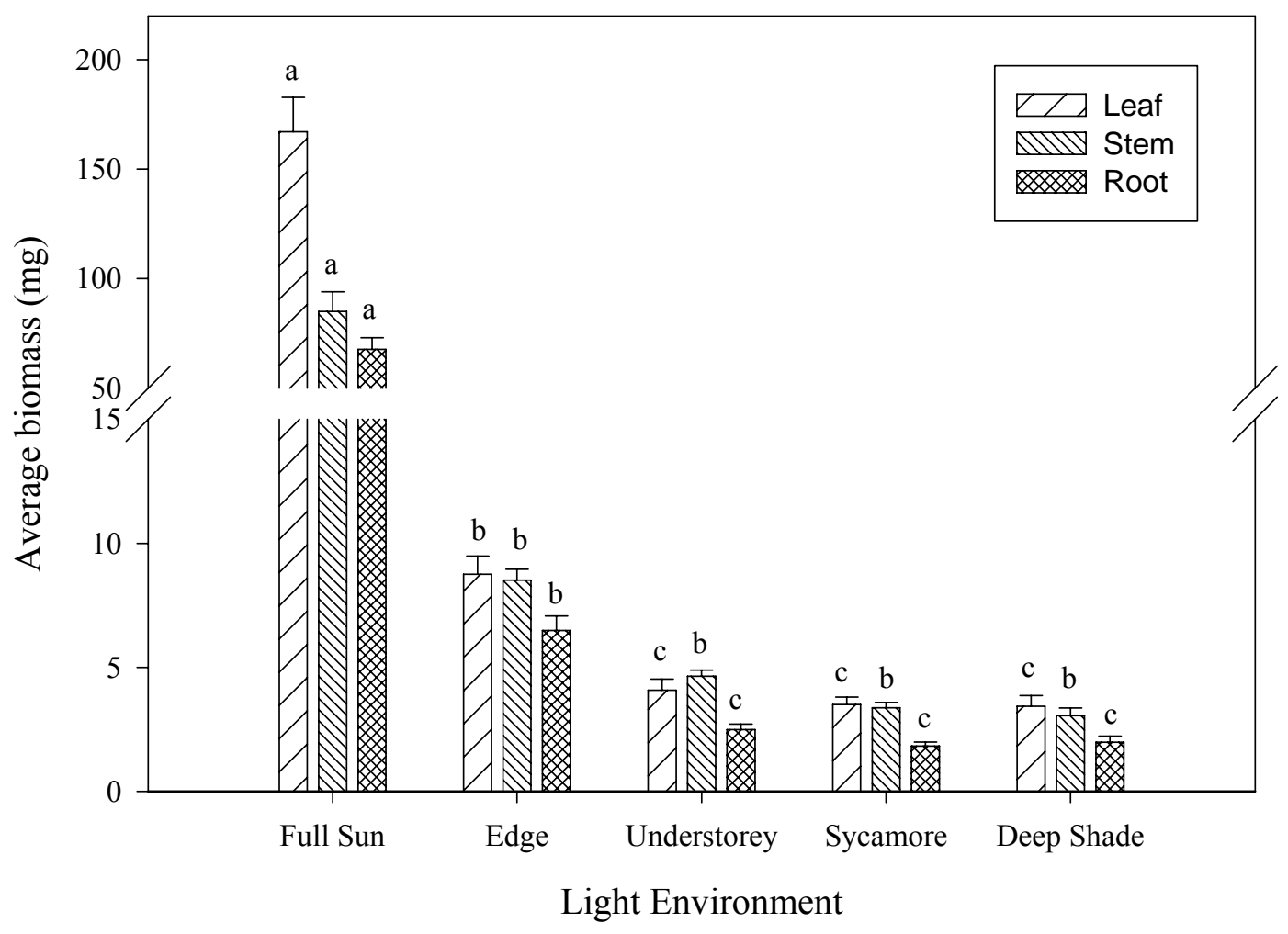

Fig. 3.1. Total leaf, stem, and root biomass of Berberis darwinii seedlings grown for 6 months in different light environments. Within each tissue type, bars that share the same letter are not significantly different from each other (Sidak posthoc contrasts $P<0.05$ ). Error bars are \pm 1 s.e. of the mean. 
a.

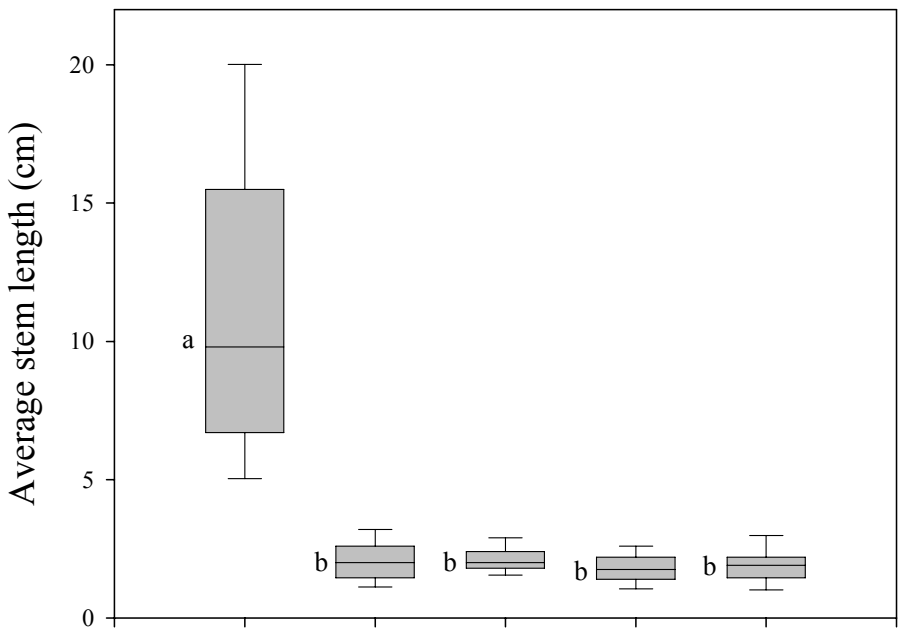

b.

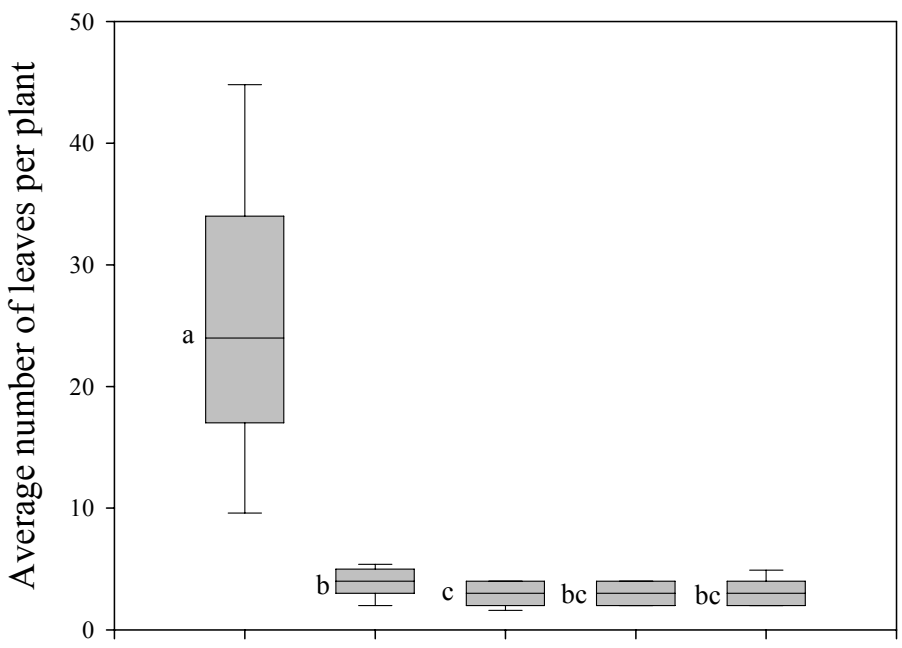

c.

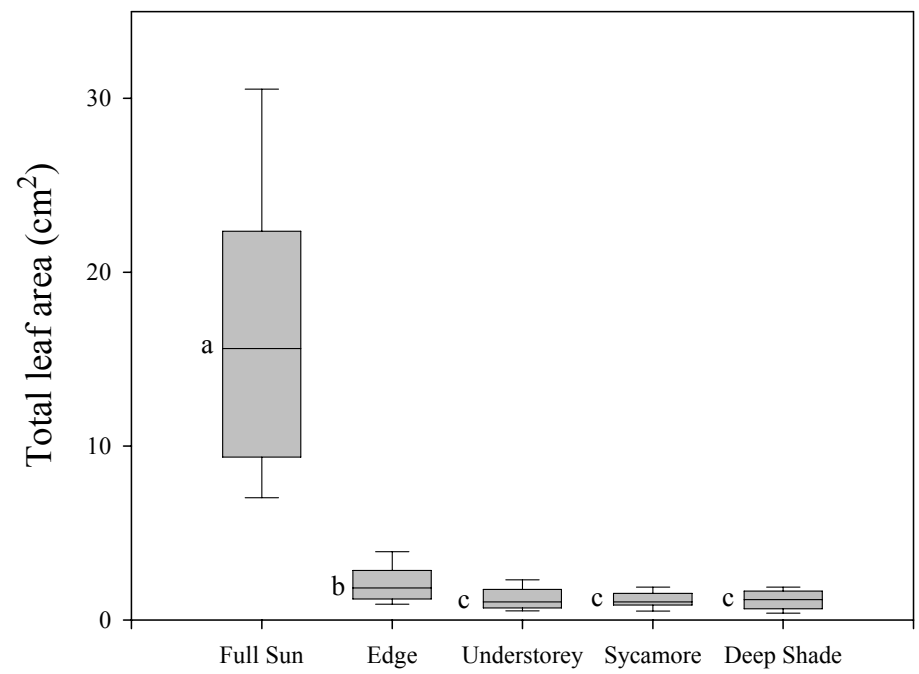

Light environment

Fig 3.2. Boxplots of leaf and stem measurements of Berberis darwinii seedlings grown for 6 months in different light environments: a) stem length, b) total number of leaves, and c) total leaf area. The line within each box-plot indicates the median value, the lower and upper side of the box the $25^{\text {th }}$ and $75^{\text {th }}$ percentiles, and the error bars the $10^{\text {th }}$ and $90^{\text {th }}$ percentiles. Within each graph, boxes that share the same letter/s are not significantly different (Sidak posthoc contrasts $P<0.05$ ). 


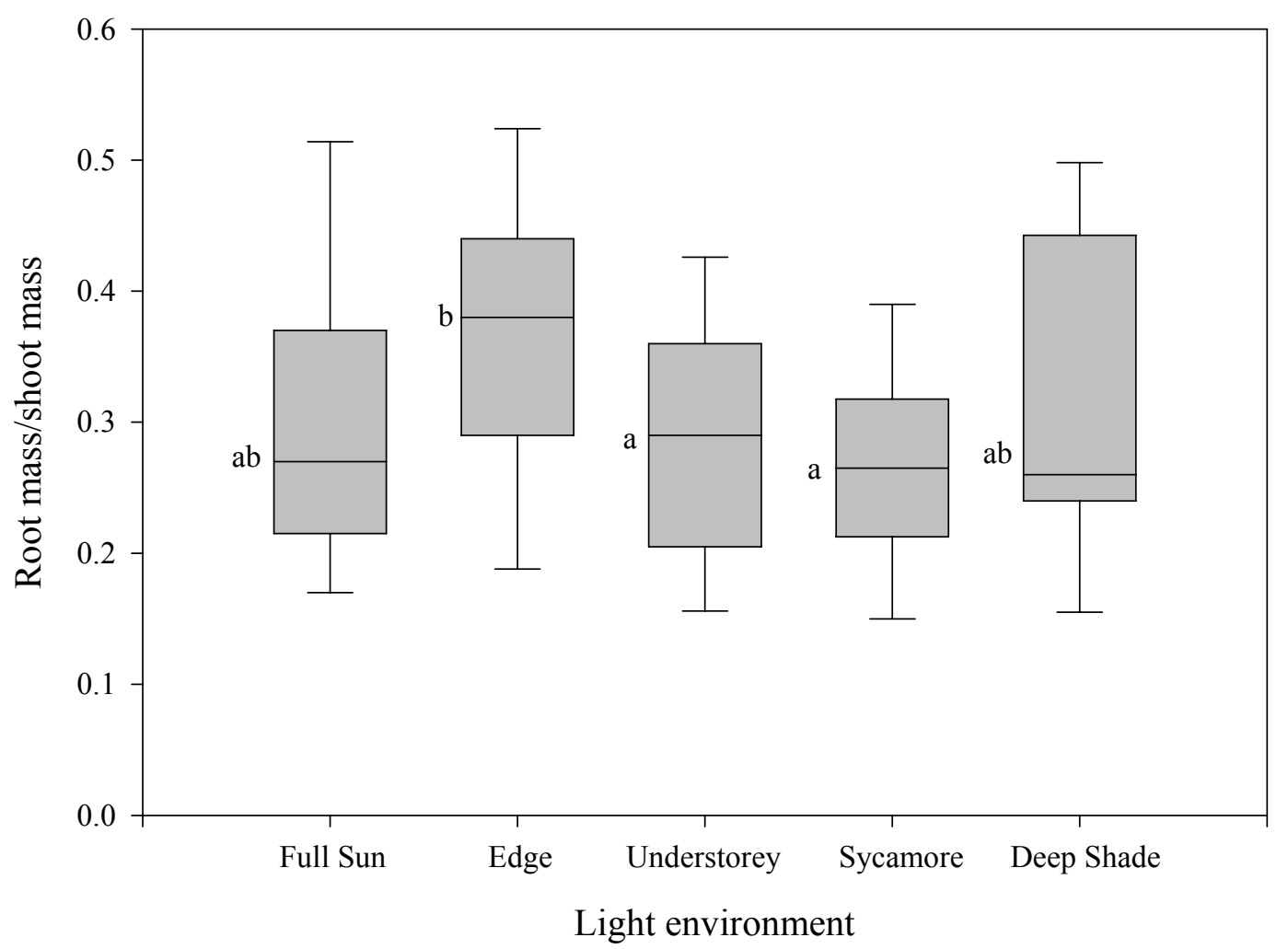

Fig. 3.3. Boxplots of root: shoot ratios of Berberis darwinii seedlings grown for 6 months in different light environments. The line within the box-plots indicates the median value, the lower and upper side of the box the $25^{\text {th }}$ and $75^{\text {th }}$ percentiles, and the error bars the $10^{\text {th }}$ and $90^{\text {th }}$ percentiles. Boxes that share the same letter/s are not significantly different from each other (Sidak posthoc contrasts $P<0.05)$. 
- Full sun

- Edge

$\nabla$ Understorey

$\nabla \quad$ Sycamore

- Deep shade

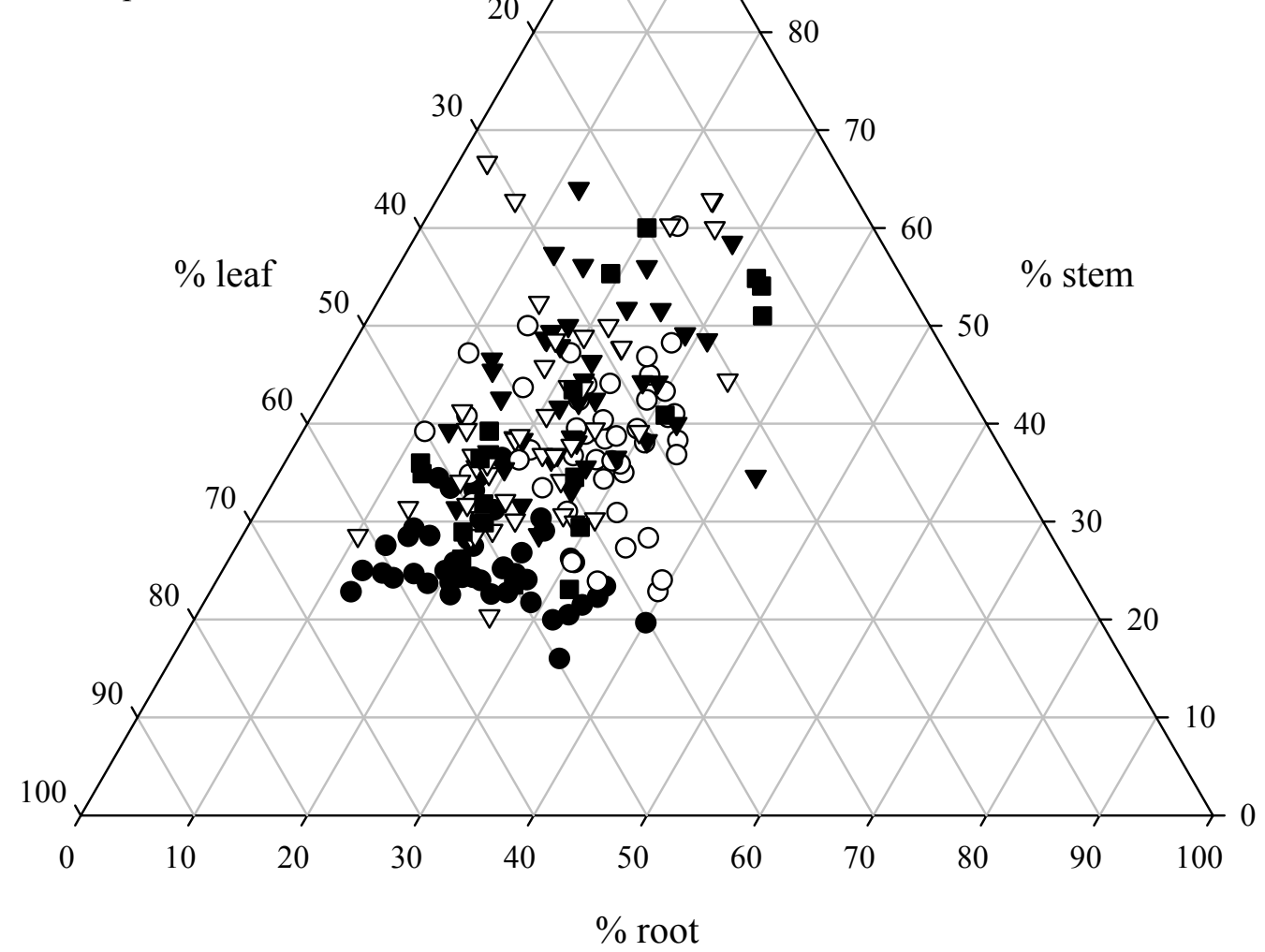

Fig. 3.4. Proportion of biomass allocated to root, stem, and leaf in Berberis darwinii seedlings grown for 6 months in different light environments. Each data point is an individual seedling collected from that light environment (full sun, edge, and understorey: $n=45$, sycamore: $n=44$, deep shade: $n=20$ ). 
a.

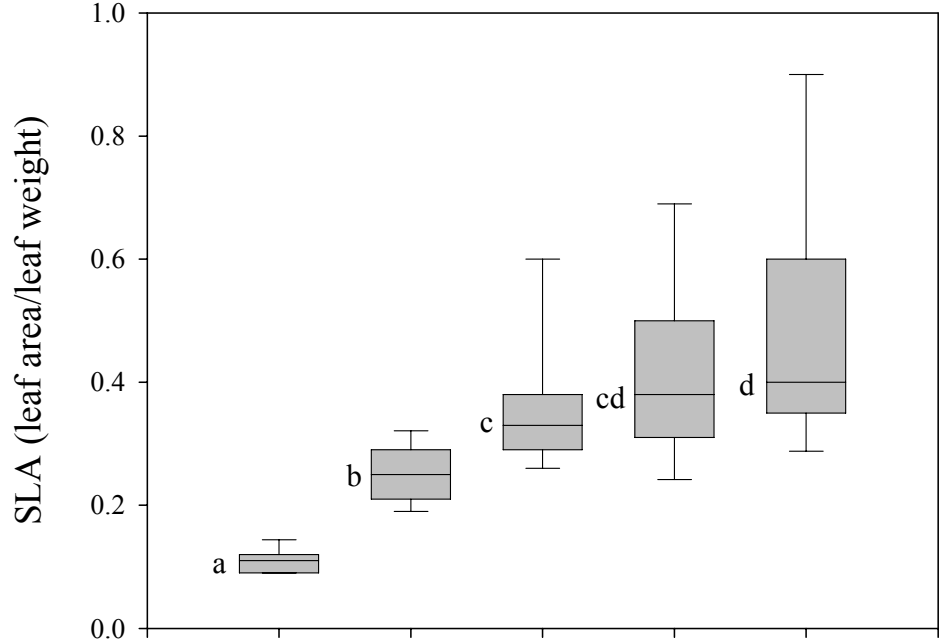

b.

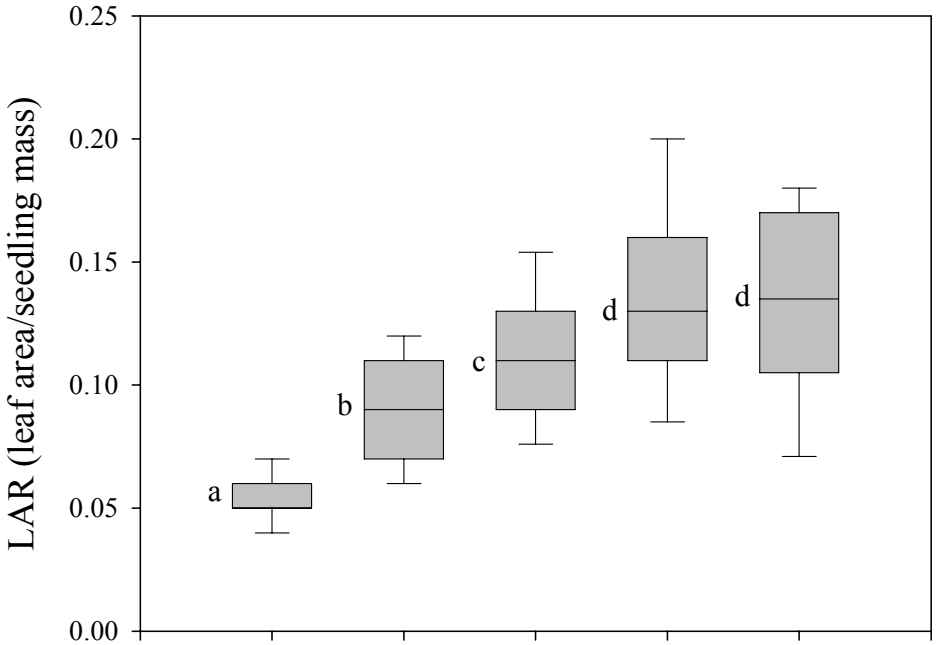

c.

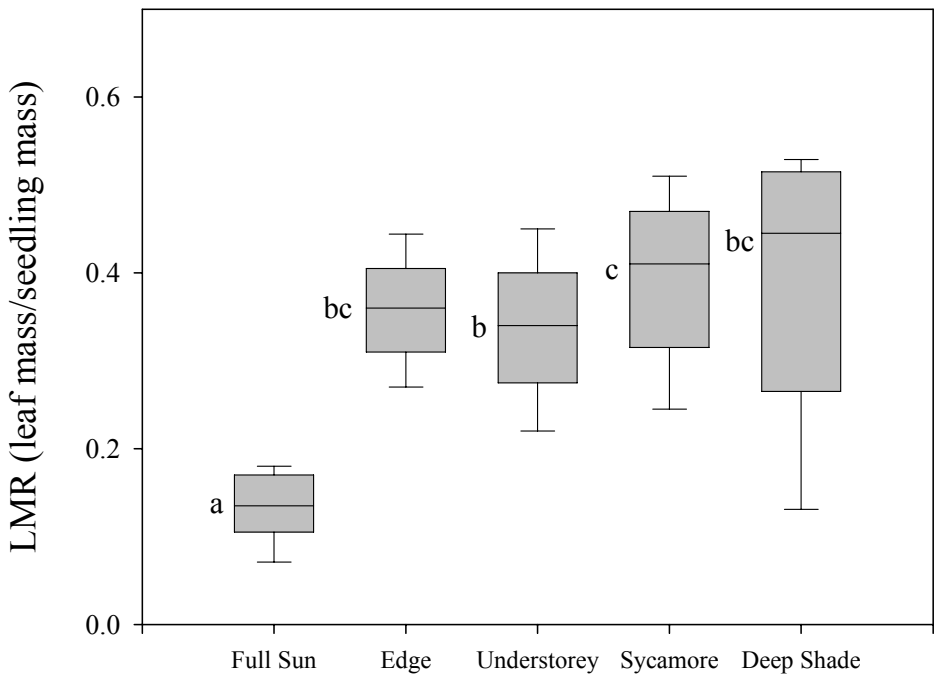

Light environment

Fig. 3.5. Boxplots of leaf characteristics of Berberis darwinii seedlings grown in different light environments: a) specific leaf area (SLA), b) leaf area ratio (LAR), and c) leaf mass ratio (LMR). The line within the box-plots indicates the median value, the lower and upper side of the box the $25^{\text {th }}$ and $75^{\text {th }}$ percentiles, and the error bars the $10^{\text {th }}$ and $90^{\text {th }}$ percentiles. Within each graph, boxes that share the same letter are not significantly different from each other (Sidak posthoc contrasts $P<0.05$ ). 


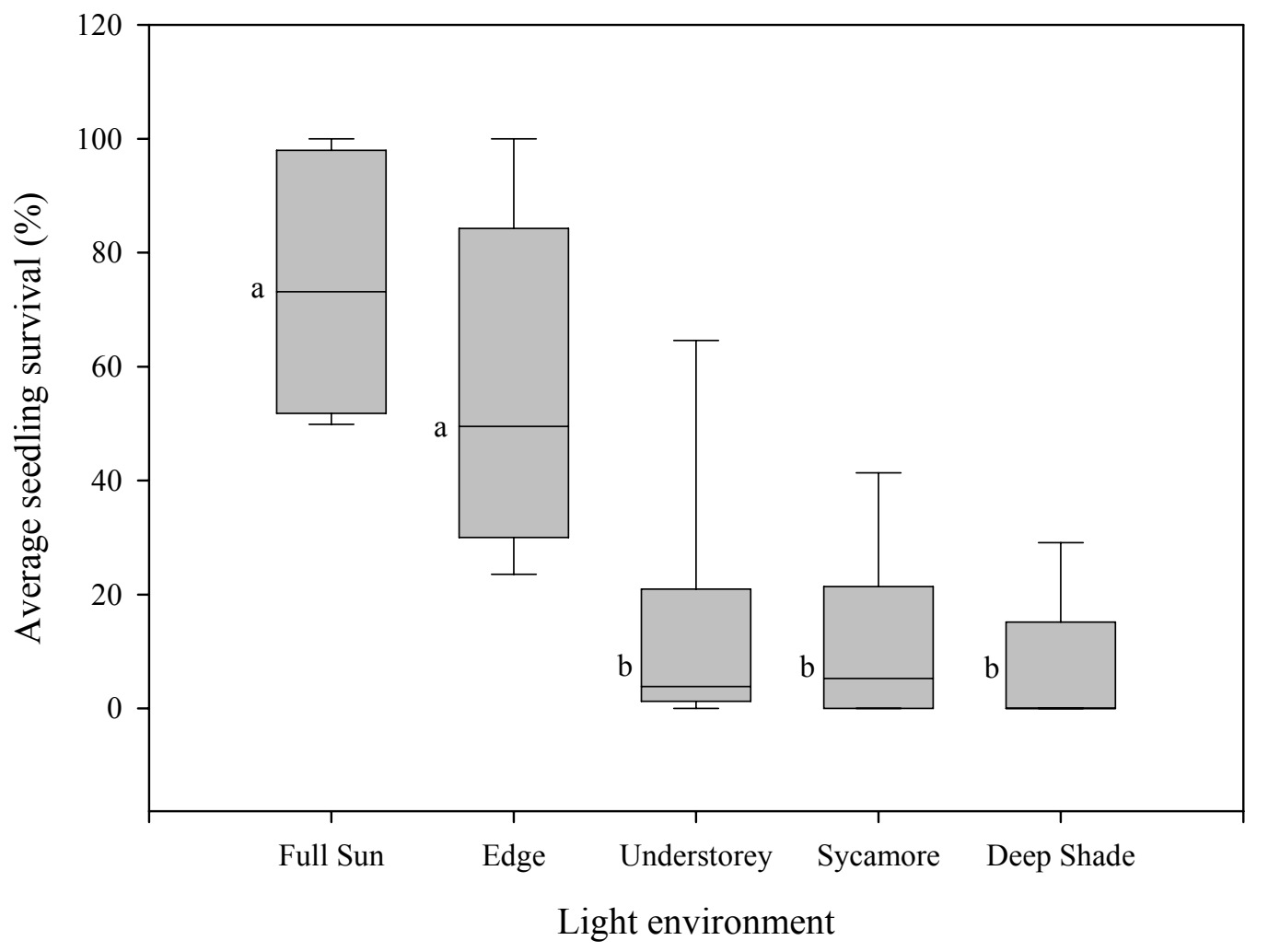

Fig. 3.6. Boxplots of percent survival of Berberis darwinii seedlings grown for 6 months in different light environments. The line within the box-plots indicates the median value, the lower and upper side of the box the $25^{\text {th }}$ and $75^{\text {th }}$ percentiles, and the error bars the $10^{\text {th }}$ and $90^{\text {th }}$ percentiles. Within each graph, boxes that share the same letter are not significantly different from each other (Sidak posthoc contrasts $P<0.05)$. 


\section{Discussion}

Differential microhabitat recruitment can be an important factor influencing adult plant spatial patterns (Jordano and Herrera 1995; Russell and Schupp 1998; Kobe 1999; Montgomery and Chazdon 2002; Radford et al. 2002). In this study seedling survival rates were high in the two sunniest sites, and low in the three shady sites, suggesting that seedlings are somewhat shade-intolerant. Interestingly, Allen (1991) surveyed existing $B$. darwini seedlings in a range of light environments and concluded that establishment was enhanced by shade. However, this discrepancy between our two studies might be due to the different ways we considered "shade". Allen's estimation of percent cover was restricted to plants less than 2 metres tall, so there may have still been significant light reaching the soil surface through such shortstature vegetation, depending on the density of canopy foliage. I measured percent canopy openness without regard to canopy height, but in most cases the canopy was approximately 5-8 metres tall, so only the full sun and edge sites received any direct light. In other words, Allen's shady sites may in fact be comparable to my edge sites, and in both cases survival was high. Furthermore, Allen (1991) found that seedling densities were significantly higher in open and edge vegetation classes than beneath young and old forest, which is also consistent with my findings.

While canopy openness was the strongest influence on seedling survival, this measurement alone may not account for all differences in light environment and hence seedling performance. Although edge and understorey sites were similar to each other in terms of canopy openness, the seedlings from these sites exhibited several significant differences: seedlings from edge sites had more leaves and lower specific leaf area than seedlings from understorey sites. This may be due to differences in the quality of light: the edges of forest gaps tend to receive more direct light than areas beneath the intact forest canopy, which tend to receive predominantly diffuse light (Chazdon and Fetcher 1984; Canham et al. 1990). Light beneath a canopy also has a different spectral composition and is strongly reduced in photosynthetically active radiation (Coombe 1957; Federer and Tanner 1966), and this too can impact on seedling growth and survival (e.g. Morgan and Smith 1981; Corré 1983; Kwesiga and Grace 1986; Schmitt and Wulff 1993; Tinoco-Ojanguren and Pearcy 1995). Similarly, the sycamore and deep shade sites had similar levels of 
canopy openness, resulting in similar amounts of seedling growth and survival, but in the long term plants might perform differently in the two sites because the sycamore canopy is deciduous and will therefore receive more light in winter. There are likely other factors beyond the scope of this study affecting seedling survival—for example seedlings in the crowded full sun sites might be further reduced by density-dependant mortality (Janzen 1970; Connell 1971; Harms et al. 2000; Peters 2003). However, in general these results suggest that the chances of a seedling surviving are highest within and around disturbed sites where light levels are relatively high.

High mortality of $B$. darwinii seedlings in the shade was unexpected, given that adult plants are shade tolerant (Allen 1991, pers. obs.). Other studies have shown shadetolerant tree and shrub species to suffer high mortality in the shade as seedlings, possibly due to an increased presence of pathogens (Augspurger and Kelly 1984; Augspurger 1984a; Augspurger 1984b; Grubb et al. 1996; Lusk and Del Pozo 2002; Sanford et al. 2003; Weber et al. 2003) or herbivores (Baraza et al. 2004), or because young seedlings cannot fix enough carbon at low light levels to resist these stressors and persist in the understorey (Kobe 1997; Kaelke et al. 2001; Weber et al. 2003). It is also possible that the shade-tolerance of $B$. darwinii increases as it ages, as has been suggested for other tree species (Clark and Clark 1992; Kobe 1999; Weber et al. 2003). Other invasive species of Berberis show a similar pattern of seedling growth and survival: $B$. thunbergii tolerates a wide range of soil and light conditions and persists under dense canopies, but seedlings are rarely found in very shady conditions (Ehrenfeld 1999; Silander and Klepeis 1999), and growth and survival of B. vulgaris seedlings is poor under low light conditions (Kollmann and Reiner 1996). Light availability may be a limiting factor for the growth and survival of seedlings for all these species.

Seedlings in sunny sites also exhibited significantly different growth patterns from those of seedlings grown in other sites. Sun-grown seedlings were an order of magnitude taller and heavier, and had five times as many leaves and a significantly higher leaf mass ratio than seedlings grown in other light environments. This general pattern is often characteristic of pioneer, or light-demanding species (Grime 1965; Bazzaz 1979; Veenendaal et al. 1996; Wright et al. 1998; Agyeman et al. 1999) — as is low seedling survival in the shade (Denslow 1987; Swaine and Whitmore 1988; 
Kitajima 1994). However, B. darwinii is shade tolerant, at least as an adult, and this trait is not generally associated with pioneer species (Grime 1977; Bazzaz 1979; Augspurger 1984b; Denslow 1987). Many species are able to regenerate in both highand low-light environments (Welden et al. 1991), and can grow fast both in the sun and in the shade, relative to other species (Augspurger 1984b; Popma and Bongers 1988; Kitajima 1994; Poorter 1999), so are not easily classified into successional status. Berberis darwinii seems to be one such species, with traits of both early and late successional status: seedlings are largely restricted to high light conditions, yet adults are extremely shade-tolerant.

Other growth parameters also varied across light environments: specific leaf area (SLA) and leaf area ratio (LAR) increased as light levels decreased. However, most plants respond in this way to low light levels (e.g. Loach 1970; Boardman 1977; Caldwell et al. 1981; Givnish 1988; Walters et al. 1993; Grubb et al. 1996; Pattison et al. 1998; Baruch et al. 2000; Longbrake and McCarthy 2001; Lusk and Del Pozo 2002), so this is unlikely to be the reason behind invasion success.

While there was some variation in biomass allocation across sites, this too was largely due to the fact that seedlings grown in full sun sites were so different from seedlings grown in the other four light environments. In general, proportional allocation to above- and below-ground biomass did not vary according to the optimal partitioning hypothesis, despite significant differences in the light and soil moisture environment. Several studies have found similar results for invasive species (Pattison et al. 1998; Schweitzer and Larson 1999), but others have not (Baruch et al. 2000; Longbrake and McCarthy 2001). Similarly, non-invasive species may or may not exhibit morphological plasticity in biomass allocation when grown along a light gradient (Messier 1992; Thompson et al. 1992b; Wang et al. 1994; Veneklaas and Poorter 1998; McConnaughay and Coleman 1999; Tani et al. 2001; Lusk and Del Pozo 2002; Montgomery 2004). It appears this trait is species-specific, and not necessarily linked to invasiveness per se. Furthermore, many phenotypic traits change during the life of a plant (Evans 1972; Poorter and Pothman 1992; Coleman et al. 1994; Gedroc et al. 1996; Veneklaas and Poorter 1998), so patterns of biomass allocation may be different —including more plastic_-later in life. 
In summary, the success of $B$. darwinii in a wide range of environments does not appear to be explained by plasticity in proportional biomass allocation at the seedling stage. Some leaf characteristics did vary consistently across light environment, but this is likely to be the case for native species too. First-year seedling survival was low in the shade, despite adult plants of $B$. darwinii commonly occurring beneath an intact forest canopy. These results have implications for the management and control of this invasive species, where it occurs in similar conditions. While adult plants may be found in almost any light environment, the main focus of seedling control should be in and around high light areas such as canopy gaps and other disturbed areas. The majority of first-year seedlings growing beneath the closed canopy will likely die off naturally, particularly if soil moisture levels are high. 


\title{
CHAPTER FOUR. PHOTOSYNTHESIS AND WATER USE EFFICIENCY: A COMPARISON BETWEEN INVASIVE AND NATIVE SPECIES
}

\begin{abstract}
Photosynthetic characteristics and water use efficiency were compared in wild and cultivated plants of the invasive species $B$. darwinii and four native species to examine how these traits might contribute to invasion success in New Zealand. Wild plants were selected from sunny and shady field sites, and cultivated plants were grown in three light environments created using varying levels of shade cloth. In sunny sites, the average maximum photosynthetic rate of $B$. darwinii was approximately double that of all native species. In shady sites, however, rates of photosynthesis were similar among all species. Values for quantum yield and dark respiration were also similar for all species. There was no significant difference between species in terms of water use efficiency, but $B$. darwinii and three of the four native species were more efficient in sunny sites than shady sites. The invasion success of $B$. darwinii may be partially explained by its ability to photosynthesis at higher rates in the sun and hence gain a rapid height and biomass advantage over native species. Greater water use efficiency does not appear to contribute to $B$. darwinii's competitive advantage, although this may be different when water is limiting.
\end{abstract}

\section{Introduction}

Invasive plant species can drastically alter ecosystem-level processes by changing community structure and dynamics, soil water and nutrient levels, substrate stability, rates and pathways of succession, and disturbance and fire regimes (Ramakrishnan and Vitousek 1989; Vitousek and Walker 1989; Hughes et al. 1991; D'Antonio and Vitousek 1992; Walker 1993; Cronk and Fuller 1995; Ehrenfeld et al. 2001). How and why this happens is a question that has long interested population ecologists (Mack 1985; Vitousek 1990), but is also of practical interest to managers dealing with 
invasive species (Allendorf and Lundquist 2003; Donlan et al. 2003). Successful invasive species can have life history and morphological traits that enable them to utilize available resources more effectively than native species, such as more prolific seed production and dispersal, longer flowering periods, higher rates of seedling recruitment, more efficient leaf arrangement, faster growth rates, better recovery from leaf loss, or greater phenotypic plasticity (Williams et al. 1995; Ehrenfeld 1999; Fogarty and Facelli 1999; Lavergne et al. 1999; Martin 1999; Durand and Goldstein 2001a).

Physiological attributes such as higher rates of photosynthesis also have the potential to confer an advantage to exotic species over natives, and hence contribute to invasion success. For example, in a study conducted in the USA, Kloeppel and Adams (1995) found that the invasive tree species Acer platanoides had greater carbon assimilation (i.e. higher net photosynthesis) than the native Acer saccharum. In Hawaii, the invasive grass Pennisetum setaceum was demonstrated to have higher net photosynthetic rates than the native grass Heteropogon contortus (Williams and Black 1994). Pattison et al. (1998) compared five invasive species with four natives, and found that all invasive species had higher rates of net photosynthesis than the native species. But how might a higher rate of photosynthesis contribute to invasion success? Plants with high photosynthetic capacity generally exhibit high rates of biomass accumulation and growth (Lambers and Poorter 1992), and therefore may be able to out-compete slower-growing species and rapidly colonize a large area (Grime and Hunt 1975). Specific leaf area (SLA, leaf area per unit leaf mass) is also a key component of a species' growth strategy, because it describes the light capture area deployed per unit leaf mass (Lambers and Poorter 1992; Reich et al. 1997; Wright and Westoby 2001). So if invasive species have higher maximum rates of photosynthesis and higher SLA than native species, they may be better able to capture and utilize light resources - particularly in high-light environments associated with disturbance that are often the entry point for invasive species (Drake et al. 1989; Hobbs 1989; Burke and Grime 1996; Paynter et al. 1998; Petryna et al. 2002).

Greater water use efficiency may confer a competitive advantage if an invasive species is able to use more of a limited water supply, or use it more efficiently. Plants might use more of a limited water supply by reducing above-ground biomass and thus 
reducing transpirational water loss, by increasing biomass allocation to root tissue, or by storing water in rhizomal or other tissue for later use (Busch and Smith 1995; Gordon et al. 1999; Li 1999). Water use efficiency can be defined as the amount of carbon gained per unit water transpired (Farquhar et al. 1989). In order to acquire more carbon, a plant must take up more $\mathrm{CO}_{2}$. To take up more $\mathrm{CO}_{2}$, a plant must open its stomata wider, but this in turn results in greater transpirational water-loss. To use water efficiently, therefore, plants must be able to acclimate to water stress and adjust stomatal conductance accordingly (Cowan 1982). While it is unlikely that any single trait or group of traits alone will completely explain the success of an invasive species, comparing ecologically similar, sympatric invasive and native taxa can help to identify factors contributing to invasion success (Mack 1996).

Berberis darwinii Hook. (Berberidaceae) is a woody, evergreen shrub up to approximately $4 \mathrm{~m}$ high, native to southern Chile and Argentina. It was originally brought to New Zealand for horticultural purposes, but has since invaded many vegetation types throughout the country (Webb et al. 1988). It forms dense, impenetrable stands that exclude natives and persist beneath the forest canopy (Allen 1991). I hypothesized that the more efficient use of light and water might give $B$. darwinii an advantage over native species, and thus contribute to invasion success. I tested this hypothesis by measuring gas exchange processes and water use efficiency in $B$. darwinii and four co-occurring, ecologically similar native plant species: Coprosma grandifolia (Rubiaceae), Melicytus ramiflorus (Violaceae), Pseudopanax arboreus (Araliaceae), and Shefflera digitata (Araliaceae). These species are all small trees c. 7-10 m tall, common in both sunny and shady conditions in lowland and montane forest throughout much of New Zealand (Allan 1961; Poole and Adams 1994).

\section{Methods}

\section{Study site}

I conducted this study within the Karori Wildlife Sanctuary, a 249-ha ecological restoration site in Wellington, New Zealand. See methods section of Chapter Two for detailed description of site. 


\section{Light environment}

To measure photosynthesis in plants from different light environments I selected wild plants growing in the full sun with no canopy cover, and in the shade with complete canopy cover. I quantified the degree of canopy cover at each plant using a crown densitometer (Forestry Suppliers, USA) to estimate canopy openness. This instrument is comprised of a spherical, convex mirror which reflects a large overhead area. A grid etched into the mirror is used to estimate the percentage of this overhead area covered by forest canopy (Lemmon 1957). I measured percent open sky overhead to the north, south, east and west and took the average of these four values. I took the readings from $10 \mathrm{~cm}$ directly above the leaf being measured for photosynthesis.

\section{Photosynthesis}

I measured photosynthesis within and around the Karori Wildlife Sanctuary between January and April 2003 using a portable open gas exchange system (LI-6400, Licor, Lincon, Nebraska, USA) with a blue-red LED light source (6400-02B, Licor). I selected 10 wild plants per species, a minimum of $50 \mathrm{~cm}$ and up to $4 \mathrm{~m}$ tall: 5 growing in full sun and 5 growing in shade beneath the native forest canopy. I chose one recently matured, fully expanded leaf per plant for the measurements, giving a total of 10 leaves measured per species. Leaf temperature was kept at approximately $19^{\circ} \mathrm{C}$ during all measurements, similar to daytime summer temperatures in the shade. Sample $\mathrm{CO}_{2}$ concentration was $370 \mu \mathrm{mol} \mathrm{mol}^{-1}$, and vapour pressure deficit was generally held between 1.0 and $1.5 \mathrm{kPa}$. To compare the steady-state photosynthetic performance in sun and shade of each species, a light response curve was generated for each leaf using the automated routine in the LI-6400. Prior to measurements, leaves were allowed to acclimate under a photosynthetic photon flux density (PPFD) of either $1500 \mu \mathrm{mol} \mathrm{m} \mathrm{s}^{-1}$ (for plants grown in sun) or $1000 \mu \mathrm{mol} \mathrm{m} \mathrm{m}^{-2}$ (for plants grown in shade). Once stable, leaves were exposed to a series of PPFDs decreasing from that initial level to darkness: 1500, 1000, 500, 200, 100, 50, 10, $0 \mu \mathrm{mol} \mathrm{m}^{-2} \mathrm{~s}^{-1}$. At each light level I allowed the photosynthetic rate to stabilise for two to four minutes before recording photosynthetic rate. Upon completion of the light response curve, I harvested the measured leaf for future calculation of specific leaf area (leaf 
area/leaf mass). Leaves were measured using a Licor 320 area meter, dried for 7 days at $45^{\circ} \mathrm{C}$, then weighed.

\section{Water use efficiency}

I measured water use efficiency on plants of a known age that had been grown under uniform, controlled conditions. To do this I collected seeds of all species and sowed them onto vermiculite in January (B. darwinii), February (P. arboreus and $M$. ramiflorus), March (C. grandifolia), and April (S. digitata) of 2001. All four native species germinated within 6 weeks, while $B$. darwinii took 5 months to germinate. I potted up seedlings within one month of germination using a commercially produced potting mix and c. 1.5 litre potting bags. Seedlings that died within 1 month were replaced.

I created three light environments in an outdoor area at Victoria University, Wellington, using shade boxes $80 \mathrm{~cm}$ high x $180 \mathrm{~cm}$ wide $\mathrm{x} 120 \mathrm{~cm}$ deep, covered with neutral-density shade cloth: full sun (no shade box), single shade (one layer of shade cloth), and double shade (two layers of shade cloth). There were two replications of each light treatment, giving a total of 6 sites. Photon flux ( $\mu \mathrm{mol} \mathrm{m} \mathrm{m}^{-2}$ ) of photosynthetically active radiation was used as a measure of irradiance under the light treatments to determine how much light was intercepted by the shade cloth. LICOR LI-190SA quantum sensors (LI-COR) were used to simultaneously measure irradiance in the full sun, beneath one layer of shade cloth, and beneath two layers of shade cloth. Five readings were taken over the course of 25 minutes to find an average measure for each light treatment. Relative to the full sun treatment, one layer of shade cloth reduced irradiance by $40.9 \pm 0.2 \%$, and two layers reduced it by $6.7 \pm 0.04 \%$ (values are means $\pm 1 \mathrm{SE}$ ). These light levels are likely to be similar to natural light environments within, or close to, a treefall gap and beneath the closed canopy respectively (McDonald and Norton 1992; Ebbett and Ogden 1998).

Ten seedlings of each species were randomly allocated to a light treatment site. To minimize effects of heterogeneity within the study site, seedlings were rotated randomly within light treatment several times during the experiment. Plants were kept moist with frequent watering, and fertilised with Scotts Osmocote controlled release 
plant food at 7 months of age. The cultivated plants were used for measuring water use efficiency when the plants were approximately two years old.

I measured carbon isotope composition in the leaves of the cultivated plants to compare photosynthetic water use efficiency (WUE) in the five study species. Carbon isotope composition (expressed as $\delta^{13} \mathrm{C}$ ) is calculated by comparing the ratio of ${ }^{13} \mathrm{C}$ to ${ }^{12} \mathrm{C}$ in a sample $\left(R_{\text {sample }}\right)$ to the ratio of the Pee Dee belemnite carbonate standard $\left(R_{\text {standard }}\right)($ Craig 1957):

$$
\delta^{13} C=\left(R_{\text {sample }} / R_{\text {standard }}-1\right) \times 1000
$$

In $\mathrm{C}_{3}$ plants $\delta^{13} \mathrm{C}$ varies with the ratio of intercellular to ambient $\mathrm{CO}_{2}$ (Farquhar et al. 1989). Carbon isotope discrimination is calculated from the carbon isotopic composition of the plant sample and the source air:

$$
\delta^{13} C_{\text {plant }}=\delta^{13} C_{a t m}-a-\left[(b-a) C_{i} / C_{a}\right]
$$

where $\delta^{13} \mathrm{C}_{\mathrm{atm}}$ is the isotopic composition of the source air $(\sim-8 \%$ in the present atmosphere), $a$ is the diffusional discrimination against ${ }^{13} \mathrm{CO}_{2}(-4.4 \%), b$ is the discrimination against ${ }^{13} \mathrm{CO}_{2}$ by Rubisco (-29\%), and $C_{i} / C_{a}$ is the ratio of intercellular to ambient $\mathrm{CO}_{2}$. During photosynthesis $\mathrm{C}_{3}$ plants preferentially assimilate ${ }^{12} \mathrm{C}$ and discriminate against ${ }^{13} \mathrm{C}$, so they contain a smaller ratio of ${ }^{13} \mathrm{C}$ to ${ }^{12} \mathrm{C}$ than does the $\mathrm{CO}_{2}$ of the source air. Carbon isotope discrimination in $\mathrm{C}_{3}$ plants is correlated with water use efficiency because both processes are related to $\mathrm{C}_{i}$ (Farquhar et al. 1989). This follows because WUE can be expressed as the molar ratio of photosynthesis $(A)$ to transpiration $(E)$ as:

$$
\begin{array}{ll}
\text { WUE }= & A / E=\left(\mathrm{c}_{\mathrm{a}}-\mathrm{c}_{\mathrm{i}}\right) /(1.6 \Delta w) \\
\text { where, } & A=\left[\left(\mathrm{c}_{\mathrm{a}}-\mathrm{c}_{\mathrm{i}}\right) g\right] / 1.6 \\
& E=\Delta w g
\end{array}
$$

where $g$ is leaf conductance to water vapour, 1.6 is the molar ratio of diffusion of water vapour and $\mathrm{CO}_{2}$ in the air, $\mathrm{c}_{\mathrm{a}}$ is ambient $\mathrm{CO}_{2}$ level, $\mathrm{c}_{\mathrm{i}}$ is intercellular $\mathrm{CO}_{2}$ level, 
and $\Delta w$ is leaf to air water vapour concentration gradient. Discrimination against ${ }^{13} \mathrm{C}$ will be least (and so the $\delta^{13} \mathrm{C}$ value will be more positive) in plants that fix the most carbon per unit amount of water transpired (Farquhar and Richards 1984).

I chose two healthy plants per species in each of the six plots (two replications of three light treatments), and harvested one recently expanded leaf per plant in June 2003. This gave a total of 12 leaves per species measured — 4 per light treatment. Each leaf was air dried at $45^{\circ} \mathrm{C}$ for 7 days, then finely ground $(<3 \mathrm{~mm})$ using an electric grinder. Samples were then sent to the Stable Isotope Unit at Waikato University, Hamilton, New Zealand, for analysis of $\delta^{13} \mathrm{C}$ ratios on a fully automated Europa Scientific 20/20 Isotope analyser.

\section{Statistical analyses}

I used a non-rectangular hyperbola as an empirical curve to approximate the response of photosynthesis to photosynthetic photon flux density (Ögren and Evans 1993; Lambers et al. 1998). Curve fitting was conducted in SigmaPlot, using the following equation:

$$
A=\frac{\phi I+A \max +r_{\mathrm{d}}-\sqrt{\left(\phi I+A_{\max }+r_{\mathrm{d}}\right)^{2}-4 \phi \theta I\left(A_{\max }+r_{\mathrm{d}}\right)}}{2 \theta}-r_{\mathrm{d}}
$$

where $A$ is the photosynthetic rate, $\phi$ is quantum yield (the initial slope of the light response curve, which is an indication of the apparent yield of photosynthesis), $A_{\max }$ is the photosynthetic capacity (asymptote of $A$ ), $r_{\mathrm{d}}$ is dark respiration ( $y$ intercept), and $\theta$ is a curvature parameter (see Ögren 1993 for a discussion of the biological meaning of $\theta)$.

I analysed the data using S-Plus 4 (Mathsoft 1997) and SigmaStat (SPSS 2004) statistical software. To identify the best way to transform the data I evaluated each variable for the best distribution of expected vs. actual residuals (Zar 1984). Quantum yield and specific leaf area data were log-transformed, but all other data met model assumptions untransformed. I used two-way ANOVA using linear mixed effects models to test for the main effects and interactions of species and light environment 
on photosynthetic and leaf characteristics of the wild plants growing in sun and shade. To measure water use efficiency on the cultivated plants, I used linear mixed effects models to test for the main effects and interactions of species and light environment, with site incorporated as a random variable. Post-hoc comparisons were made using either Tukey or Sidak tests, and resulting $P$-values were Bonferroni-corrected.

\section{Results}

\section{Light environment}

Percent canopy openness was significantly different between light environments $(F=$ 327.46, $\mathrm{df}=1$, residual $=48, P<0.001)$, averaging $24.73 \% \pm 1.71($ mean $\pm \mathrm{se})$ for plants growing in the sun, and $1.67 \% \pm 0.17$ for plants growing in the shade. Tukey posthoc contrasts indicated that there was no significant difference between species for light environment $(F=2.489, \mathrm{df}=4$, residual $=40, P=0.06)$. This means that, as was intended, all plants measured were growing in a similar degree of sun or shade, regardless of species.

\section{Photosynthesis}

The average light-saturated photosynthetic rate $\left(A_{\max }\right)$ differed by both light environment and species (Table 4.1). $A_{\max }$ of $B$. darwinii in the sun was approximately double that of the four native species, but in the shade average $A_{\max }$ was similar among all species (Fig. 4.1a). There was also an interaction between light environment and species, likely due to the fact that $B$. darwinii was different from all other species in the sun, but was only different to P. arboreus in the shade (Fig. 4.1). There were no significant differences between species for quantum yield or dark respiration (Table 4.1). However there were significant differences between light environments for both factors; in the sun, all species had a significantly lower quantum yield (Fig. 4.1b), and higher dark respiration (Fig. 4.1c) compared to the shade.

Light response curves differed between light environments in the same way for all species, in that leaves developed in shade had significantly lower light-saturated 
photosynthesis rates, and they saturated at lower PPFDs than sun leaves (Fig. 4.2, Table 4.1). However, in the sunny sites $B$. darwinii had a higher rate of photosynthesis than the native species across most PPFDs (Fig. 4.2). Light response curves in the shade were similar for all species (Fig. 4.2).

\section{Specific leaf area}

Specific leaf area (SLA) varied significantly among species and across light environments, and there was an interaction between the two (Table 4.1). As expected, SLA was higher (leaves were larger and thinner) in the shade for all species (Fig. 4.3). In the sun, SLA of $B$. darwinii was significantly lower than all native species, but in the shade SLA was less variable, with $B$. darwinii differing from only two of the native species (Fig. 4.3). The interaction is likely due to the fact that $B$. darwinii and S. digitata are different from all other species in the sun, but not in the shade (Fig. $4.3)$.

\section{Water use efficiency}

Mean $\delta^{13} \mathrm{C}$ values in the cultivated plants ranged from -33.12 to -28.08 (Fig 4.4). ANOVA indicated that there was a significant difference in $\delta^{13} \mathrm{C}$ between light environments and between species, but there was no interaction (Table 4.1). Within species, $\delta^{13} \mathrm{C}$ values were more positive (and so water use efficiency increased) as light increased, with all species except $S$. digitata significantly more efficient in full sun than in the double shade treatment (Fig. 4.4). 
a.

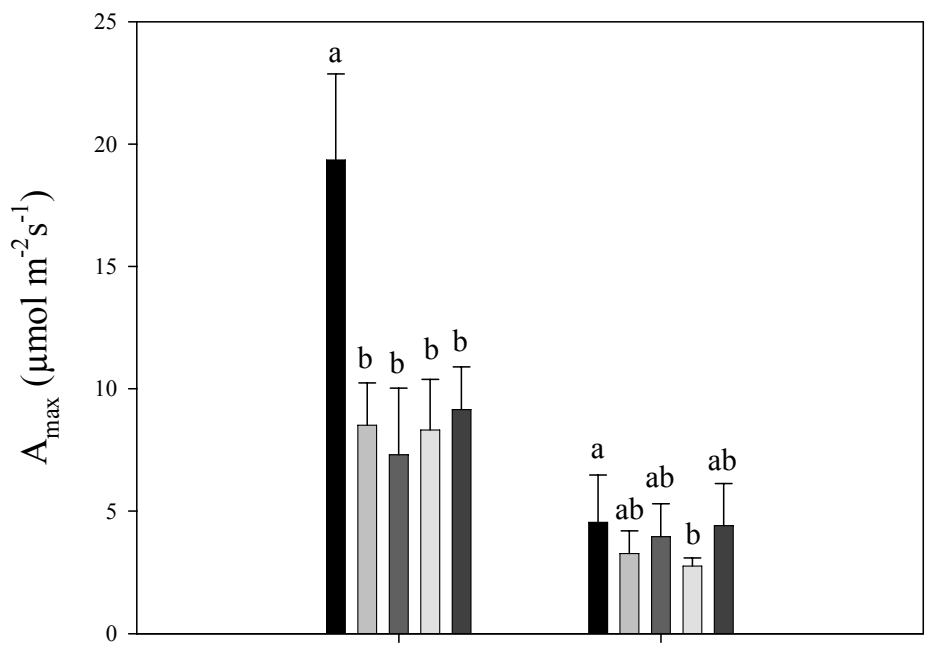

b.

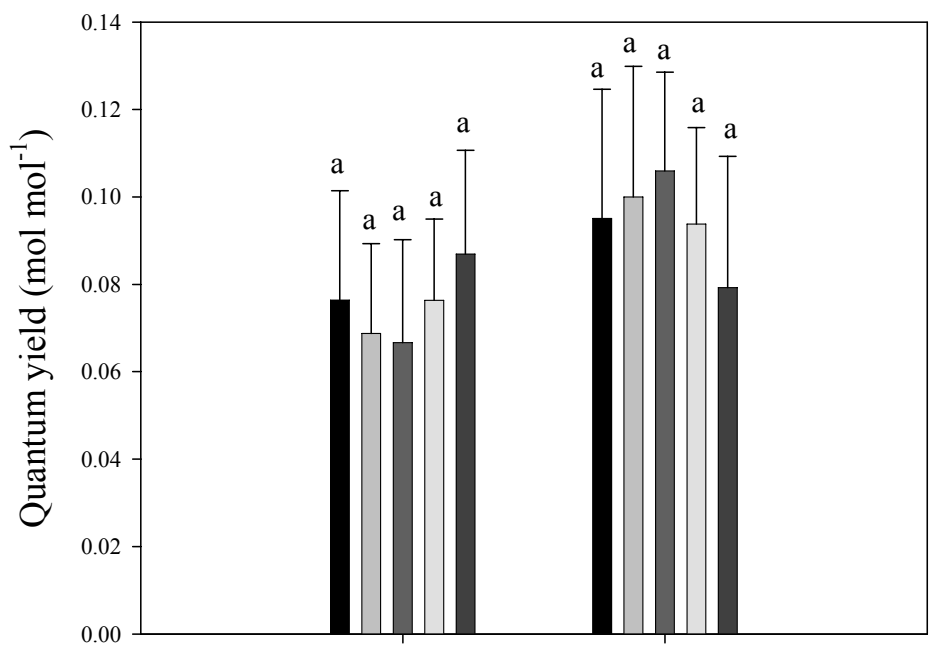

c.

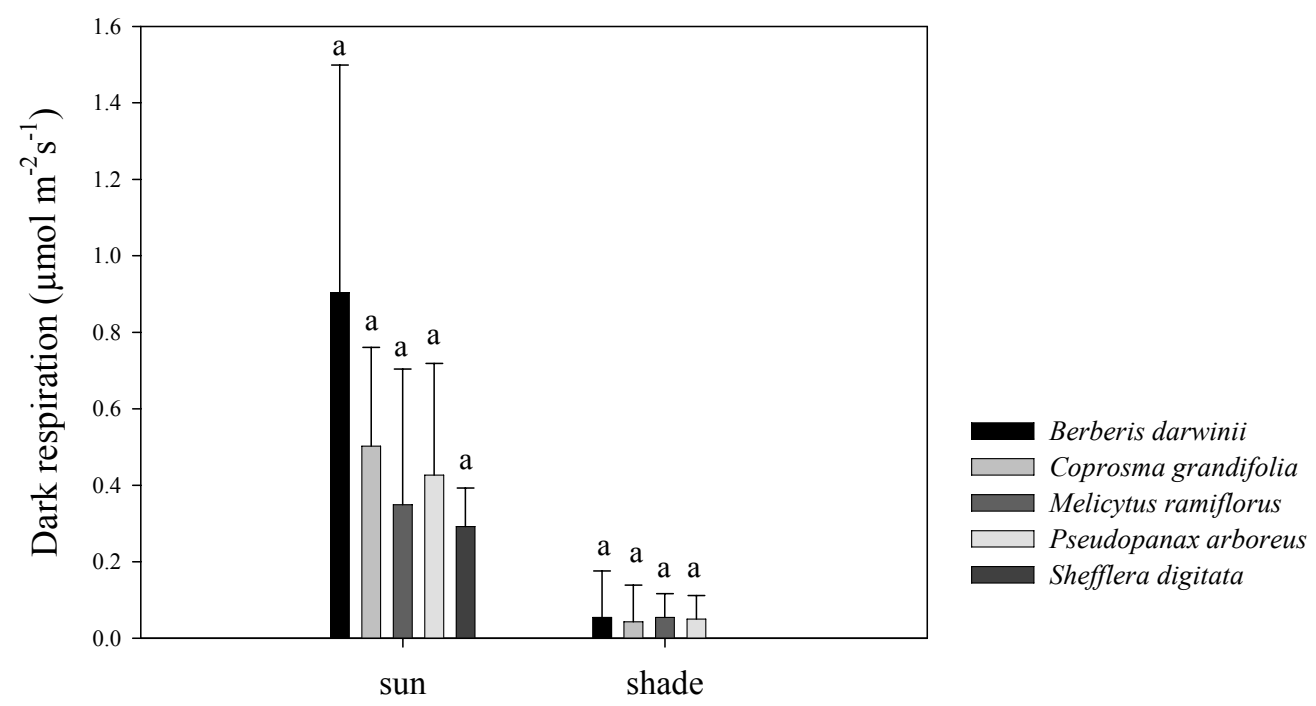

Light environment

Fig. 4.1. Photosynthetic measurements from wild plants growing in sun and shade: a) $\mathrm{A}_{\max }$, b) quantum yield, and c) dark respiration (see methods). Each bar indicates the average value \pm se from five leaves: one leaf from five plants per species. Within each light environment, bars that share the same letter/s are not significantly different from each other (Sidak posthoc contrasts $P<0.05$ ). 
Table 4.1. Generalized linear model of photosynthetic and leaf parameters by light environment and species (Berberis darwinii, Coprosma grandifolia, Melicytus ramiflorus, Pseudopanax arboreus, and Shefflera digitata), and linear mixed effects models of water use efficiency (WUE) by light environment and species. $\mathrm{A}_{\max }$, quantum yield, dark respiration, and specific leaf area measurements were conducted on wild plants growing in sun and shade. WUE measurements were conducted on cultivated plants growing in three artificially created light environments, with site nested within light environment (no deviance is reported for WUE because a linear mixed effects model was used). Site was a random effect, so only the results for the fixed effect (light environment) are presented. Summary table indicates degrees of freedom (df), deviance (dev), variance ratios $(F)$, and $P$-values $(P)$.

Photosynthetic and leaf parameters

df

dev

F

$P$

AMAX

Light environment

Species

Light environment $\mathrm{x}$ species

Residual

1

567.01

143.61

$<0.001$

$4 \quad 296.60$

18.78

$<0.001$

$4 \quad 210.49$

13.33

$<0.001$

40

QUANTUM YIELD

Light environment

Species

Light environment $\mathrm{x}$ species

Residual

$\begin{array}{rlll}1 & 0.69 & 7.30 & 0.010 \\ 4 & 0.01 & 0.03 & 0.998 \\ 4 & 0.54 & 1.42 & 0.244 \\ 40 & & & \end{array}$

\section{DARK RESPIRATION}

Light environment

Species

Light environment $\mathrm{x}$ species

Residual

$\begin{array}{rrrr}1 & 2.58 & 38.31 & <0.001 \\ 4 & 0.65 & 2.40 & 0.066 \\ 4 & 0.54 & 1.99 & 0.115 \\ 40 & & & \end{array}$

\section{SPECIFIC LEAF AREA}

Light environment

Species

Light environment $\mathrm{x}$ species

Residual

\section{WATER USE EFFICIENCY}

Light environment

Species

Light environment $\mathrm{x}$ species

Residual

$\begin{array}{rrr}11.85 & 553.93 & <0.001 \\ 4.65 & 54.36 & <0.001 \\ 1.50 & 17.48 & 2.28\end{array}$

$28.11<0.001$

$3.16 \quad 0.023$

$0.71 \quad 0.684$ 


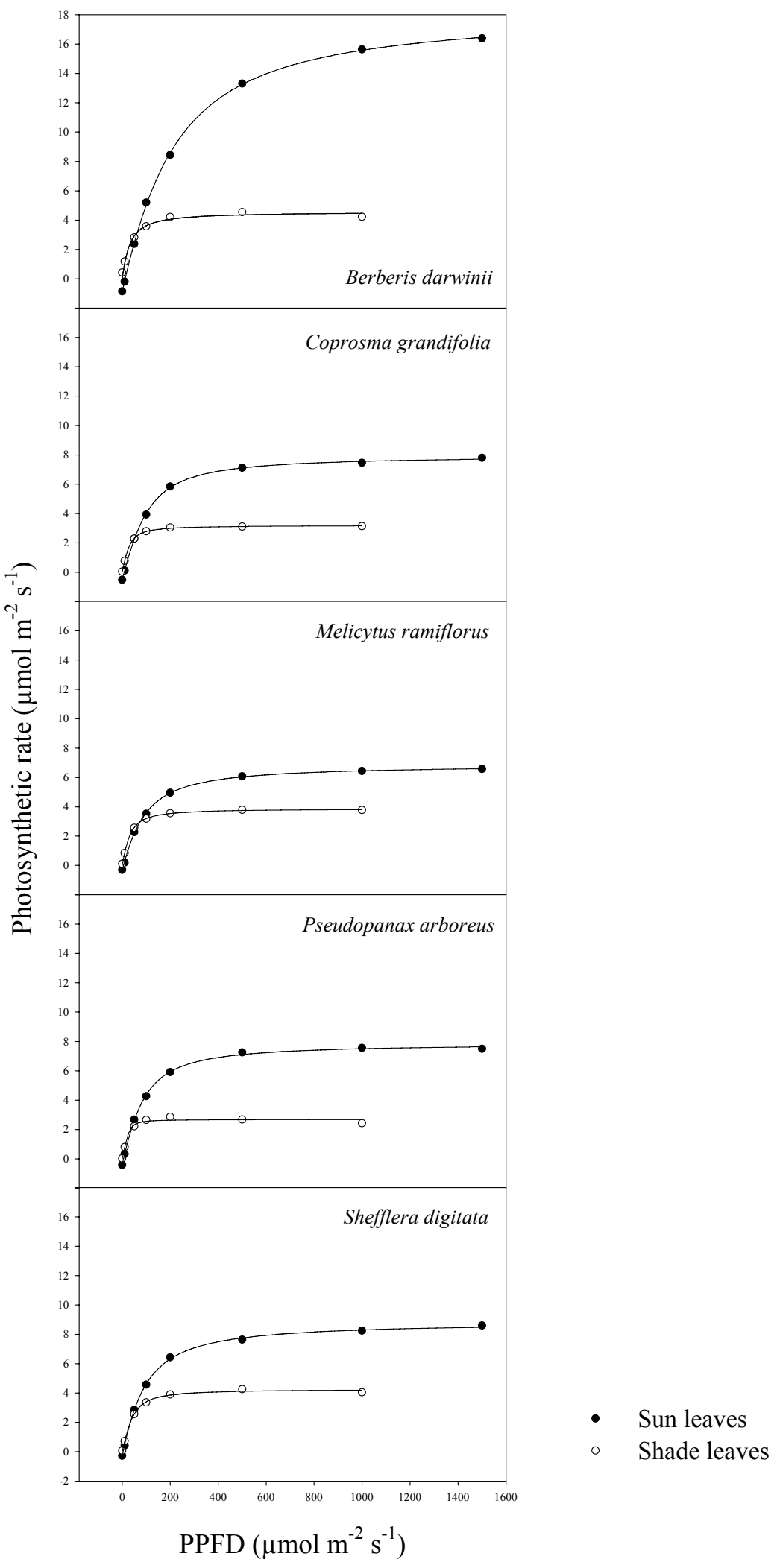

Fig. 4.2. Light response curves from wild plants growing in sun and shade. Each point represents the average photosynthetic rate of five leaves in the given light environment. Curves are non-rectangular hyperbolae (see statistical analysis section in methods for equation) fitted through mean values of photosynthesis recorded at each irradiance level. 


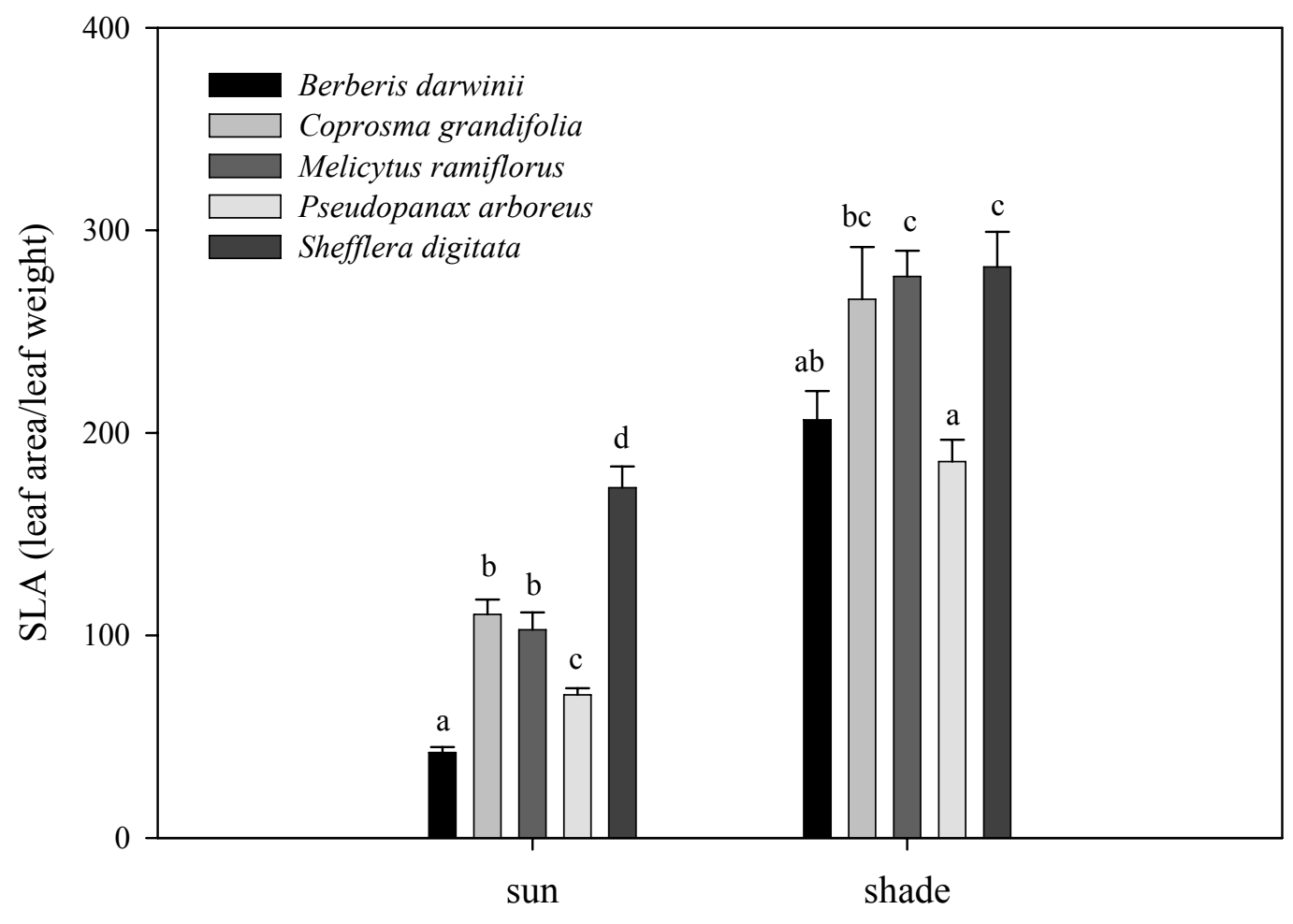

Light environment

Fig. 4.3. Specific leaf area (SLA) of leaves on which photosynthesis was measured. Each bar indicates the average SLA \pm se of five leaves: one leaf from five plants per species (see methods). Within each light environment, bars that share the same letter/s are not significantly different from each other (Sidak posthoc contrasts $P<0.05$ ). 


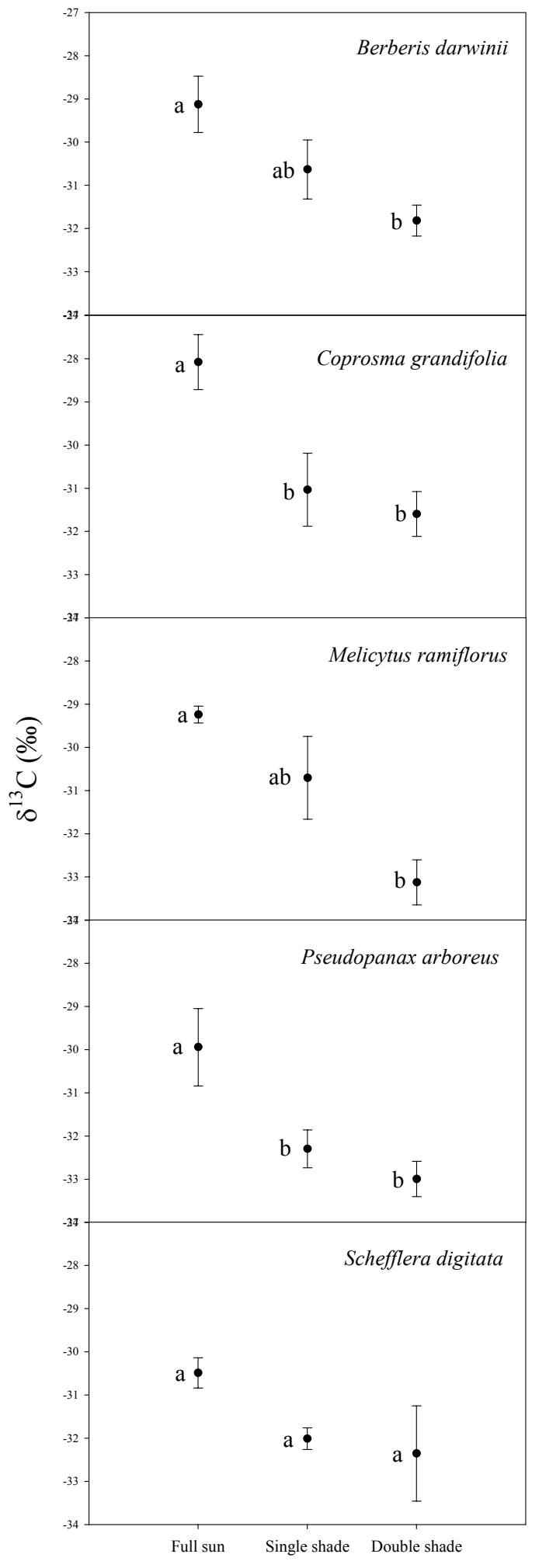

Light environment

Fig. 4.4. Carbon isotope composition $\left(\delta^{13} \mathrm{C}\right)$ as a measure of water use efficiency (see methods) of cultivated plants growing in three light environments. Each point represents the average $\delta^{13} \mathrm{C} \pm$ se of four leaves per light environment. Within each graph, points that share the same letter/s are not significantly different from each other (Tukey posthoc contrasts $P<0.05$ ). 


\section{Discussion}

Black (1969) suggested that it is the ability of certain plants to fix carbon at high rates that makes them successful weeds. Many studies have since found evidence that some invasive plants photosynthesize at higher rates than natives (Carter et al. 1989; Owens 1996; Pattison et al. 1998; Baruch and Goldstein 1999; Baruch et al. 2000; Stratton and Goldstein 2001; Durand and Goldstein 2001b; McDowell 2002), including the present study. In sun-grown plants, $B$. darwinii exhibited maximum rates of photosynthesis that were approximately double that of all four native species studied. Plants with higher photosynthetic capacity do not necessarily exhibit higher growth rates because there may be trade-offs in patterns of resource allocation (Poorter and Remkes 1990), but in the current study there does appear to be a positive correlation between growth rate and photosynthetic rate in $B$. darwinii. Plants growing in sunny sites not only had significantly higher $A_{\max }$ than plants growing in shade, they were also an order of magnitude larger, despite similar patterns of biomass allocation (see chapter 3 for growth data). I did not measure the growth of the native species in this study, largely because of extremely low seedling survival rates, but I did observe that 2 year-old seedlings of $B$. darwinii were at least twice as big as the 2 year-old seedlings of the four native species in sunny sites. These results suggest that, at least in high light environments, $B$. darwinii may be able to grow bigger and survive better than native species in the sun because it has a higher photosynthetic capacity under these conditions.

Interestingly, $B$. darwinii does not appear to have a similar advantage under shady conditions, despite being considered a shade-tolerant species (Allen 1991). Many species that can photosynthesise faster than other species in sunny conditions can also photosynthesise faster in shady conditions (e.g. Owens 1996; Pattison et al. 1998; Durand and Goldstein 2001b), but B. darwinii does not appear to be one of them. Maximum photosynthetic capacity in the shade was approximately four times lower than it was in the sun for B. darwinii, and was no higher than any of the native species. Furthermore, all other measured parameters were the same for all species in the shade. It appears that $B$. darwinii's photosynthetic advantage under high light conditions is nonexistent under low light conditions. Factors contributing to its 
persistence and competitive success in the shade may be related to other factors such as resistance to herbivory and pathogens, efficient seed dispersal, high rates of germination and seedling establishment, vegetative reproduction, phenotypic plasticity, or some combination of these factors.

Greater water use efficiency has previously been proposed as a factor contributing to invasion success, particularly when water is a limiting resource (Busch and Smith 1995; Kloeppel and Abrams 1995; Stratton and Goldstein 2001). In the current study, however, all species except $S$. digitata were more efficient as light increased, so this does not appear to be an area where $B$. darwinii gains a competitive advantage over the native species. Several studies have suggested that plants can afford to be less efficient in the shade, where water is more available (Toft et al. 1989; Gordon et al. 1999; Blicker et al. 2003), and that, in some cases, drought results in an increase in water-use efficiency (Garten and Taylor 1992; Meinzer et al. 1992; Högberg et al. 1993; Hubrick and Gibson 1993; Knight et al. 1994). In this study, water use efficiency measurements were done on plants grown in artificial conditions, which no doubt received more water than plants in the field. It is, therefore, possible that these results may have been different if water had been more limiting, as it would have been in the sunny sites in the field (see Chapter Two). Further research would clarify this aspect.

Other differences between field- and container- grown plants also support the assertion that water-use efficiencies may have been different in the two populations. Plants of all species growing in artificial conditions were much bigger than the fieldgrown plants, and survival rates were significantly higher (pers. obs.). Also, size differences between $B$. darwinii and natives reversed between field and artificial conditions: under sunny conditions in the field $B$. darwinii was significantly bigger than the natives, but under artificial conditions the reverse was true (pers. obs.). These observations suggest that $B$. darwinii seems to be more competitive under high light, low moisture field conditions, in part because of its ability to photosynthesise faster than the natives, but possibly also because of greater water use-efficiency under water-limiting conditions. On the other hand, drawing general conclusions solely from eco-physiological characters can be problematic. For example, in Australia the invasive species Chrysanthemoides monilifera subsp. rotundata has a lower per unit 
leaf area net assimilation rate and lesser drought tolerance than the native species Acacia longifolia, but $C$. monilifera subsp. rotundata can out-grow A. longifolia through a more effective arrangement of photosynthetic tissue (Weiss and Noble 1984). More research would elucidate the WUE relationships between these species.

In summary, the results of this study suggest that $B$. darwinii may have higher growth rates under high light conditions than the four native species studied because it has higher photosynthetic capacity. Greater water use efficiency does not appear to contribute to $B$. darwinii's competitive advantage, although this may be different under conditions where water is limiting. 


\section{CHAPTER FIVE. WHY IS BERBERIS DARWINII SUCH A SUCCESSFUL ENVIRONMENTAL WEED?}

Invasive species are, by definition, species that successfully recruit into new areas or environments, often to the detriment of naturally-occurring species and ecosystem processes (Mack 1997). Invasion biologists and conservation managers need to understand how that occurs. This knowledge helps them to predict which species are likely to become invasive, and manage or control those that already have. In most cases this requires an examination of all stages of seedling recruitment, from the time mature seeds are released from the parent plant to the time seedlings emerge and become photosynthetically self-sufficient (e.g. Gleadow 1982; Vitousek and Walker 1989; Silander and Klepeis 1999; Greenberg et al. 2001; Aragón and Groom 2003; Ellsworth et al. 2004). Seedling colonization is usually necessary for recruitment to take place, although some species do expand their territory largely via rhizome expansion and/or vegetative regeneration (e.g. Kelly and Skipworth 1984; Timmins and Williams 1987; e.g. Huffman and Tappeiner II 1997; Hertling and Lubke 2002), particularly aquatic or semi-aquatic species (Coffey and Clayton 1988; Lemon et al. 2001; Cecere et al. 2004). However, understanding the dynamics of seedling recruitment is no simple task, given the multitude of interacting factors that determine seed and seedling survival at any given site. The aim of this thesis was to (a) better understand the recruitment dynamics of Berberis darwinii, (b) identify factors that might give $B$. darwinii a competitive advantage over native species and thus contribute to invasion success, and (c) identify critical life-stages and/or situations when weed control is likely to be most effective.

Factors contributing to invasion success

The results of this study suggest that $B$. darwinii has several seed and seedling traits that may confer a competitive advantage over native species and thus contribute to invasion success. It produces large amounts of fruit earlier in the growing season than many co-occurring species, and those seeds are dispersed by birds many hundreds of metres from the parent plants (Fig. 2.5). Berberis darwinii seeds germinate in higher 
numbers and in a wider range of light environments than at least four of the common native species (Fig. 2.9), resulting in a virtual 'carpet' of seedlings that have the potential to expand the population. Survival of these new seedlings is significantly higher than that of the common native species (Fig. 2.9), potentially because $B$. darwinii photosynthesises at almost twice the rate of the natives under high light conditions (Fig. 4.1). Plasticity in biomass allocation and water use efficiency, however, do not appear to contribute to invasion success. These traits are discussed in more detail below.

\section{Effective seed dispersal}

Propagule pressure is one of the most important influences on invasion success: the more individuals introduced, and the greater the number of introductions, the more likely a non-indigenous species will become established (Kolar and Lodge 2001). Berberis darwinii exerts a significant propagule pressure on the surrounding environment, with vast quantities of viable seed dispersed over a large area on a yearly basis (Fig. 2.5). In effect, this ensures a constant supply of potential new recruits to the population, which likely serves to both extend the occupied territory and initiate new populations. This widespread dispersal may be enhanced further because $B$. darwinii fruits earlier in the year compared to many other species, when competition for dispersers is low (Allen and Lee 1992). Indeed, B. darwinii appears to be at least as effectively dispersed than native species, if the number of seedlings that were observed during the two years of this study is any indication. Following the period of peak germination, $B$. darwinii seedlings were present in significant numbers throughout the KWS, but the same phenomenon was not noted for the native species, despite fruiting adult plants of all species being widespread throughout the study area (pers. obs.). On the other hand, other native species may germinate at different times of the year, or have dormant seeds and only germinate when suitable conditions arise, so any advantage may be lost over the long term. However, an earlier study that found annual seedling establishment of $B$. darwinii far exceeded that of all native species sampled (Allen 1991) so it likely does have some advantage in this respect. Early fruiting and widespread dispersal may also allow $B$. darwinii to reach suitable sites ahead of competing species, thereby giving it a head start in the recruitment race at any particular site. This assertion is supported by a 13-year study into the recruitment dynamics of 314 species, which concluded that many sites were 'won' not by the best 
competitor for that site, but by the species that arrived first (Hubbell et al. 1999). However, this may vary among species depending on relative timing of germination, and whether suitable environmental conditions are available at that time.

Seed dispersal by birds appears to be important to $B$. darwinii recruitment for another reason: seeds that dropped to the ground and thus germinated beneath the parent canopy had virtually no chance of surviving as a seedling (Fig. 2.11). This result supports the escape hypothesis, which predicts that density-dependent seed and seedling mortality is highest beneath the parent canopy (Janzen 1970; Connell 1971). This is a common aspect of recruitment for many plants, but nevertheless is vital information for the management and control of this species: seedlings occurring beneath the undisturbed parent canopy will generally not be contributing to population expansion - and therefore will not require artificial control measures. Results also indicate that light environment plays a significant role in seedling survival, so seeds that are dispersed to treefall gaps or open areas are also more likely to establish. Whether light or density is the most important influence on survival may depend on the situation. Results seem to suggest that seedling density limits survival when density is high (possibly due to intense seedling competition), but at lower densities, light is the limiting factor. The fate of seedlings germinating at sites where B. darwinii had been controlled would be a useful addition to this research.

\section{Mass germination}

There are two main germination strategies common in nature: 'take-what-you-get' (relatively prompt germination, regardless of the environment), or 'sit-and-wait' (delayed germination, or dispersal in time) (sensu Figueroa and Armesto 2001). Berberis darwinii exhibits the former strategy: almost all seeds germinate in the spring following dispersal (Fig. 2.8), regardless of habitat or light environment (Fig. 2.9). This strategy, coupled with widespread dispersal results in a 'carpet' of seedlings that appear to have a good chance of surviving if they happen to occur in the right light conditions. As always, however, there are trade-offs associated with any particular strategy (Roff 1992). The main cost of the 'take-what-you-get' strategy is the risk that many seeds will germinate in sites unsuitable for seedling establishment (Egley 1994; Fenner and Thompson 2005). 'Sitting-and-waiting' for suitable conditions, however, means that seeds are exposed to the risk of death from seed 
predators and pathogens for a longer period of time (Crist and Friese 1993; Lonsdale 1993a; Dalling et al. 1998b; Leishman et al. 2000) or may lose viability before conditions become suitable (Baskin and Baskin 1998; Fenner and Thompson 2005). Thus, alternative regeneration strategies are likely to be attuned to a limited range of habitat conditions, so competitive superiority may vary from site to site.

In the current study, the 'take-what-you-get' strategy does appear to result in more newly-germinated $B$. darwinii seedlings, in a wider range of light environments, when compared to the native species (Fig. 2.9). However, this comparison is only valid if all species have the same germination strategy. If any of the native species had the 'sitand-wait' strategy, the low rate of native germination in the shade might be due to the fact that those seeds had become dormant, and would germinate at a later date when conditions became favourable. Given that few B. darwinii seedlings survive in the shade, and few seeds persist in the soil for more than one year, native species with persistent, dormant seeds might in fact have an advantage in those sites over the long term. However, a previous study of the same native species suggests that only Schefflera digitata has a persistent seedbank (Moles et al. 2000), so B. darwinii may have a real advantage at the germination stage over the other three species at least. More research into the germination strategies of all species, and the consequences of the different environmental conditions likely to be encountered over the long-term, would clarify this situation.

\section{High seedling growth rates and survival}

Berberis darwinii has high rates of seedling growth and survival in high light environments (Figs. 2.9 and 3.1), and this may be largely due to its ability to photosynthesis faster under these conditions (Fig. 4.1). A species that can photosynthesise faster than others can fix more carbon per quantum of light energy, and can thus accumulate biomass faster (Lambers and Poorter 1992). Accumulation of biomass is positively correlated with competitive ability and fitness in plants (Harper 1977), therefore $B$. darwinii's ability to photosynthesise rapidly likely contributes to its invasion success. However, there are costs and trade-offs associated with photosynthesising fast, so this trait alone does not guarantee competitive superiority. For example, high carbon gain can result in higher water loss, since carbon dioxide and water vapour diffuse in and out of a leaf along the same pathway; thus, a plant 
that is photosynthesising fast may also be losing water fast (Givnish 1986). However, $B$. darwinii was more efficient at using water in high light - where it photosynthesises fast - compared to low light (Fig. 4.4), suggesting that B. darwinii is compensating for this loss, perhaps by effective stomatal regulation. Leaves with high photosynthetic capacity can also be costly to construct and maintain, because they require large inputs of mineral nutrients to create the enzyme and pigment pools needed to sustain high rates of $\mathrm{CO}_{2}$ uptake (Field and Mooney 1986). Additionally, nutrient-rich leaves tend to be more attractive to herbivores, so they may require extra expenditure on defense mechanisms (Givnish 1988).

Nevertheless, if the costs of high photosynthetic capacity can be met, rapid growth can confer a significant advantage. Larger seedlings often survive better than small seedlings, possibly because they are able to capture limiting resources first, and have more resources with which to cope with biotic and abiotic challenges (Turner 1990; Simons and Johnston 2000). Other studies have also found invasive species to have higher rates of photosynthesis than natives, and have linked this to higher rates of growth, biomass accumulation, and subsequent invasion success (Baruch et al. 1985; Williams and Black 1994; Kloeppel and Abrams 1995; Pattison et al. 1998). High photosynthetic capacity has also been linked to enhanced utilization of sunflecks, the shafts of light that penetrate small openings in the forest canopy (Poorter and Oberbauer 1993; Naumberg and Ellsworth 2000; FitzJohn 2002). Sunflecks potentially comprise more than half of the daily photon flux density in the understorey, and may account for more $30-60 \%$ of carbon gain (Pearcy and Calkin 1983; Pearcy 1987; Chazdon 1988). Plants that can utilize sunflecks more efficiently may, therefore, have a competitive advantage over less efficient species in the shade. Thus, the high photosynthetic capacity of Berberis darwinii may also contribute to its ability to persist in the forest understorey as adult plants.

\section{Critical life-stage}

The critical stage of recruitment for Berberis darwinii appears to be first-year seedling establishment. Widespread dispersal and mass germination create a carpet of seedlings, but site-dependent mortality of seedlings strongly modifies recruitment

(Figs 2.5, 2.9, and 2.11). All potential sources of mortality were not identified in this 
study, but significant factors were density and light availability: first-year seedlings rarely survived in shady sites (Fig. 2.9) or in sites directly beneath the parent canopy where density was extremely high (Fig. 2.10, Fig 2.11). Thus, although B. darwinii is shade-tolerant as an adult (Allen 1991), seedling recruitment appears to be strongly limited by both density and light availability. Dispersal away from parent plants, to high light environments is critical to establishment.

This study makes a valuable contribution to the growing body of knowledge on invasive species. Shade-tolerant weeds are often considered to be of particular concern, due to their potential impact on natural, relatively intact ecosystems. However this study indicates that the light requirements of seedlings may be different to the light requirements of adult plants, so each stage should be considered separately in assessments of invasion risk and control options. Furthermore, while there is no universal group of traits that explains or predicts invasion success in general, the results of this study add to current evidence that invasion success is often due to- or at least accelerated by - high reproductive output, widespread seed dispersal, and higher rates of growth and survival than native species.

\section{Management implications}

This study provides a clear picture of the recruitment dynamics of $B$. darwinii and thus reveals critical information for the management of this invasive species. Knowledge of the critical life-stage of a species allows managers to concentrate control measures where and when they will be most effective and efficient. For example, since the critical life-stage of $B$. darwinii recruitment is seedling establishment, managers can effectively ignore seeds or newly-germinated seedlings, because most will not survive through the seedling establishment stage. Furthermore, knowing the conditions that create this bottleneck of recruitment allows managers to further focus control efforts within that critical stage; seedlings beneath the parent canopy and in other shady environments will largely die out naturally, so seedling control need only be done in sunny sites such as disturbed areas and tree-fall gaps.

Understanding the recruitment dynamics of a species also helps managers to predict where and when invasion is likely to occur - and re-occur following control. Berberis 
darwinii has widespread seed dispersal and comparatively high seedling survival in high light environments. Therefore, any forest patch within a minimum of four- to five-hundred metres of adult $B$. darwinii plants that is frequented by dispersers of $B$. darwinii seeds (e.g. silvereyes, thrushes and blackbirds) is likely to receive seed rain input each year - although the quantity may vary according to the size of the $B$. darwinii population. Seeds that are dispersed to high light environments such as treefall gaps and other disturbed areas are likely to out-compete native species, due to faster growth rates and better seedling survival. Furthermore, once seedlings get past a certain size, they may well cope with being overtopped and persist in the understorey. These understorey plants are unlikely to produce many flowers and thus fruit (Allen and Wilson 1992), but may still increase coverage via vegetative reproduction (Allen 1991). Furthermore, B. darwinii is likely to out-compete native species in the event of canopy disturbance, given its superior photosynthetic capacity in high light. It is unclear whether New Zealand native forest will eventually regenerate through a dominant stand of $B$. darwinii, but if tree-fall gaps and other disturbances continue to occur, B. darwinii will be a recurring problem. Where practical, managers should focus on the removal of existing plants, (particularly if they occur within approximately $500 \mathrm{~m}$ of favourable microsites and/or highly valued areas) and concentrate control efforts around gaps and other high-light areas for as long as the seed source remains. Seedlings should be removed before they reach sexual maturity, which can be as early as two years after germination.

\section{Summary}

Berberis darwinii appears to have several traits that have the potential to contribute to invasion success. Firstly, B. darwinii seedlings appear to be more numerous, and more widespread, than native seedlings, possibly due to the combination of effective seed dispersal and non-specific germination requirements. Secondly, B. darwinii seedlings survive better, and have the potential to grow more rapidly than native species under high light conditions due to higher photosynthetic capacity. The critical life-stage for B. darwinii is first-year seedling establishment, with both high density and low light being the main factors limiting recruitment. Invasion is thus most likely to occur in open and/or disturbed sites, so seedling control will be most efficient if concentrated in these areas. 


\section{REFERENCES}

Ackerman, J. D., A. Sabat and J. K. Zimmerman (1996). Seedling establishment in an epiphytic orchid: an experimental study of seed limitation. Oecologia 106: 192-198.

Adair, R. and R. H. Groves (1998). Impact of environmental weeds on biodiversity: a review and development of a methodology. Canberra, Environment Australia.

Agyeman, V. K., M. D. Swaine and J. Thompson (1999). Responses of tropical forest tree seedlings to irradiance and the derivation of a light response index. Journal of Ecology 87: 815-827.

Allan, H. H. (1961). Flora of New Zealand. Wellington, P. D. Hasselberg, Government Printer.

Allen, R. B. (1991). A preliminary assessment of the establishment and persistence of Berberis darwinii Hook., a naturalised shrub in secondary vegetation near Dunedin, New Zealand. New Zealand Journal of Botany 29: 353-360.

Allen, R. B. and W. G. Lee (1992). Fruit selection by birds in relation to fruit abundance and appearance in the naturalised shrub Berberis darwinii. New Zealand Journal of Botany 30: 121-124.

Allen, R. B. and W. G. Lee (2001). Woody weed dispersal by birds, wind and explosive dehiscence in New Zealand. New Zealand Plant Protection 54: 61-66.

Allen, R. B. and J. B. Wilson (1992). Fruit and seed production in Berberis darwinii Hook., a shrub recently naturalised in New Zealand. New Zealand Journal of Botany 30: 45-55.

Allendorf, F. W. and L. L. Lundquist (2003). Introduction: population biology, evolution, and control of invasive species. Conservation Biology 17: 24-30. 
Almasi, K. N. (2000). A non-native perennial invades a native forest. Biological Invasions 2: 219-230.

Alvarez-Buylla, E. and M. Martínez-Ramos (1990). Seed bank versus seed rain in the regeneration of a tropical pioneer tree. Oecologia 84: 314-325.

Amor, R. L. and C. M. Piggin (1977). Factors influencing the establishment and success of exotic plants in Australia. Proceedings of the Ecological Society of Australia 10: 15-26.

Aragón, R. and M. Groom (2003). Invasion by Ligustrum lucidum (Oleaceae) in NW Argentina: early stage characteristics in different habitat types. Revista De Biología Tropical 51: 59-70.

Augspurger, C. K. (1983a). Offspring recruitment around tropical trees: changes in cohort distance with time. Oikos 40: 189-196.

Augspurger, C. K. (1983b). Seed dispersal of the tropical tree, Platypodium elegans, and the escape of its seedlings from fungal pathogens. Journal of Ecology 71: 759771.

Augspurger, C. K. (1984a). Seedling survival of tropical tree species: interactions of dispersal distance, light-gaps, and pathogens. Ecology 65: 1705-1712.

Augspurger, C. K. (1984b). Light requirements of neotropical tree seedlings: a comparative study of growth and survival. Journal of Ecology 72: 777-795.

Augspurger, C. K. and C. K. Kelly (1984). Pathogen mortality of tropical tree seedlings: experimental studies of the effects of dispersal distance, seedling density, and light conditions. Oecologia (Berlin) 61: 211-217.

Baker, H. G. (1965). Characteristics and modes of origin of weeds. In: The genetics of colonising species. H. G. Baker and G. L. Stebbins. New York, Academic Press: 147168. 
Baker, H. G. (1974). The evolution of weeds. Annual Review of Ecology and Systematics 5: 1-24.

Baker, H. G. (1989). Some aspects of the natural history of seed banks. In: Ecology of soil seed banks. M. A. Leck, V. T. Parker and R. L. Simpson. San Diego, Academic Press Inc.: 9-21.

Bakker, J. P., P. Poschlod, R. J. Strykstra, R. M. Bekker and K. Thompson (1996). Seed banks and seed dispersal: important topics in restoration ecology. Acta Botanical Neerlands 45: 461-490.

Ballaré, C. L. (1994). Light gaps: sensing the light opportunities in highly dynamic canopy environments. In: Exploitation of environmental heterogeneity by plants: ecophysiological processes above and below ground. M. M. Caldwell and R. W. Pearcy. California, Academic Press: 73-110.

Baraza, E., J. M. Gómez, J. A. Hódar and R. Zamora (2004). Herbivory has a greater impact in shade than in sun: response of Quercus pyrenaica seedlings to multifactorial environmental variation. Canadian Journal of Botany 82: 357-364.

Barrett, S. C. H. and B. J. Richardson (1986). Genetic attributes of invading species. In: Ecology of biological invasions: an Australian perspective. R. H. Groves and J. J. Burdon. Canberra, Australian Academy of Science: 21-33.

Baruch, Z. and G. Goldstein (1999). Leaf construction cost, nutrient concentration, and net $\mathrm{CO}_{2}$ assimilation of native and invasive species in Hawaii. Oecologia 121: 183-192.

Baruch, Z., M. M. Ludlow and R. Davis (1985). Photosynthetic responses of native and introduced C4 grasses from Venezuelan savannas. Oecologia 67: 388-393. 
Baruch, Z., R. R. Pattison and G. Goldstein (2000). Responses to light and water availability of four invasive Melastomataceae in the Hawaiian islands. International Journal of Plant Science 161: 107-118.

Baskin, C. C. and J. M. Baskin (1998). Seeds: ecology, biogeography, and evolution of dormancy and germination. London, Academic Press.

Baskin, J. M. and C. C. Baskin (1989). Physiology of dormancy and germination in relation to seed bank ecology. In: Ecology of soil seed banks. M. A. Leck, V. T. Parker and R. L. Simpson. San Diego, Academic Press, Inc: 53-66.

Bazzaz, F. A. (1979). The physiological ecology of plant succession. Annual Review of Ecology and Systematics 10: 351-371.

Bazzaz, F. A. (1986). Life history of colonizing plants: some demographic, genetic, and physiological features. In: Ecology of biological invasions of North America and Hawaii. H. A. Mooney and J. A. Drake. New York, Springer-Verlag: 96-110.

Bazzaz, F. A. (1991). Habitat selection in plants. American Naturalist 137: s116-s130.

Bazzaz, F. A. (1996). Plants in changing environments: linking physiological, population, and community ecology. Cambridge, Cambridge University Press.

Bazzaz, F. A. and R. W. Carlson (1982). Photosynthetic acclimation to variability in the light environment of early and late successional plants. Oecologia (Berlin) 54 : 313-316.

Bazzaz, F. A. and S. T. A. Pickett (1980). Physiological ecology of tropical succession: a comparative review. Annual Review of Ecology and Systematics 11: 287-310.

Bazzaz, F. A. and P. M. Wayne (1994). Coping with environmental heterogeneity: the physiological ecology of tree seedling regeneration across the gap-understorey continuum. In: Exploitation of environmental heterogeneity by plants: 
ecophysiological processes above and below ground. M. M. Caldwell and R. W. Pearcy. San Diego, Academic Press: 350-390.

Bekker, R. M., J. P. Bakker, U. Grandin, R. Kalamees, P. Milberg, P. Poschlod, K. Thompson and J. H. Willems (1998). Seed size, shape and vertical distribution in the soil: indicators of seed longevity. Functional Ecology 12: 834-842.

Bellingham, P. J., D. A. Peltzer and L. R. Walker (2005). Contrasting impacts of a native and an invasive exotic shrub on flood-plain succession. Journal of Vegetation Science 16: 135-142.

Binggeli, P. (1996). A taxonomic, biogeographical and ecological overview of invasive woody plants. Journal of Vegetation Science 7: 121-124.

Björkman, O. and P. Holmgren (1963). Adaptability of the photosynthetic apparatus to light intensity in ecotypes from exposed and shaded habitats. Physiologia Plantarum 16: 889-914.

Björkman, O. and P. Holmgren (1966). Photosynthetic adaptation to light intensity in plants native to shaded and exposed habitats. Physiologia Plantarum 19: 854-859.

Black, C. C., T. M. Chen and R. H. Brown (1969). Biochemical basis for plant competition. Weed Science 17: 338-344.

Blicker, P. S., B. E. Olson and J. M. Wraith (2003). Water use and water-use efficiency of the invasive Centaurea maculosa and three native grasses. Plant and Soil 254: $371-381$.

Bloom, A. J., F. S. Chapin III and H. A. Mooney (1985). Resource limitation in plants - an economic analogy. Annual Review of Ecology and Systematics 16: 36392.

Boardman, N. K. (1977). Comparative photosynthesis of sun and shade plants. Annual Review of Plant Physiology 28: 355-377. 
Braithwaite, R. W. and W. M. Lonsdale (1987). The rarity of Sminthopsis virginiae in relationship to natural and unnatural habitats. Conservation Biology 1: 341-343.

Braithwaite, R. W., W. M. Lonsdale and J. A. Estbergs (1989). Alien vegetation and native biota in tropical Australia: the impact of Mimosa pigra. Biological Conservation 48: 189-210.

Braker, H. E. and R. L. Chazdon (1992). Ecological, behavioral, and nutritional factors influencing use of palms as host plants by a neotropical forest grasshopper. Journal of Tropical Ecology 9: 181-195.

Brokaw, N. V. L. (1985a). Gap-phase regeneration in a tropical forest. Ecology 66: 682-687.

Brokaw, N. V. L. (1985b). Treefalls, regrowth, and community structure in tropical forests. In: The ecology of natural disturbance and patch dynamics. S. T. A. Pickett and P. S. White. Orlando, Academic Press: 53-69.

Broncano, M. J., M. Riba and J. Retana (1998). Seed germination and seedling preformance of two Mediterranean tree species, holm oak (Quercus ilex L.) and Aleppo pine (Pinus halepensis Mill.): a multifactor experimental approach. Plant Ecology 138: 17-26.

Bronstein, J. L. and K. Hoffmann (1987). Spatial and temporal variation in frugivory at a Neotropical fig, Ficus pertusa. Oikos 49: 261-268.

Brothers, T. S. and A. Spingarn (1992). Forest fragmentation and alien plant invasion of central Indiana old-growth forests. Conservation Biology 6: 91-100.

Brouwer, R. (1962). Nutritive influences on the distribution of dry matter in the plant. Netherlands Journal of Agricultural Sciences 10: 361-376. 
Brouwer, R. (1963). Some aspects of the equilibrium between overground and underground plant parts. Jaarboek IBS Wageningen 1963: 31-39.

Burke, M. J. W. and J. P. Grime (1996). An experimental study of plant community invasibility. Ecology 77: 776-790.

Burns, J. H. and T. E. Miller (2004). Invasion of Chinese tallow (Sapium sebiferum) in the Lake Jackson area, northern Florida. American Midland Naturalist 152: 410417.

Burton, P. J. and F. A. Bazzaz (1991). Tree seedling emergence on interactive temperature and moisture gradients and in patches of old-field vegetation. American Journal of Botany 78: 131-149.

Busch, D. E. and S. D. Smith (1995). Mechanisms associated with decline of woody species in riparian ecosystems of the southwestern U.S. Ecological Monographs 65: 347-370.

Bush, J. K. and O. W. Van Auken (1991). Importance of time of germination and soil depth on growth of Prosopsis glandulosa (Leguminosae) seedlings in the presence of a C4 grass. American Journal of Botany 78: 1732-1739.

Cabin, R., D. Marshall and R. Mitchell (2000). The demographic role of soil seed banks. II. Investigations of the fate of experimental seeds of the desert mustard Lesquerella fendleri. Journal of Ecology 88: 293-302.

Cain, M. L., B. G. Milligan and A. E. Strand (2000). Long-distance seed dispersal in plant populations. American Journal of Botany 87: 1217-1227.

Caldwell, M. M., J. H. Richards, D. A. Johnson, R. S. Nowak and R. C. Dzurec (1981). Coping with herbivory: photosynthetic capacity and resource allocation in two semiarid Agropyron bunchgrasses. Oecologia 50: 14-24. 
Callaway, J. C. and M. N. Josselyn (1992). The introduction and spread of smooth cordgrass (Spartina alterniflora) in South San Francisco Bay. Estuaries 15: 218-226.

Callaway, R. M. (1992). Morphological and physiological responses of three Californian oak species to shade. International Journal of Plant Science 153: 434-441.

Canham, C. D., A. R. Berkowitz, V. R. Kelly, G. M. Lovett, S. V. Ollinger and J. Schnurr (1996). Biomass allocation and multiple resource limitation in tree seedlings. Canadian Journal of Forest Research 26: 1521-1530.

Canham, C. D., J. S. Denslow, W. J. Platt, J. R. Runkle, T. A. Spies and P. S. White (1990). Light regimes beneath closed canopy and tree-fall gaps in temperate and tropical forests. Canadian Journal of Forest Research 20: 620-631.

Carter, G. A., A. H. Teramura and I. N. Forseth (1989). Photosynthesis in an open field for exotic versus native vines of the southeastern United States. Canadian Journal of Botany 67: 443-446.

Case, C. M. and M. J. Crawley (2000). Effect of interspecific competition and herbivory on the recruitment of an invasive alien plant: Conyza sumatrensis. Biological Invasions 2: 103-110.

Cavers, P. B. (1983). Seed demography. Canadian Journal of Botany 61: 3578-3590.

Cecere, E., A. Petrocelli and M. Verlaque (2004). Morphology and vegetative reproduction of the introduced species Hypnea comuta (Rhodophyta, Gigartinales) in the Mar Piccolo of Taranto (Italy), Mediterranean Sea. Botanica Marina 47: 381-388.

Chapin, F. (1991). Effects of multiple environmental stresses on nutrient availability and use. In: Response of plants to multiple stresses. H. A. Mooney, W. E. Winner and E. J. Pell. New York, Academic Press: 67-88.

Charles-Dominique, P. (1986). Inter-relations between frugivorous vertebrates and pioneer plants: Cecropia, birds and bats in French Guyana. In: Frugivores and seed 
dispersal. A. Estrada and T. H. Fleming. Dordrecht, Netherlands, Dr. W. Junk Publishers: 119-135.

Chauvet, S., F. Feer and P. Forget (2004). Seed fate of two Sapotaceae species in a Guianan rain forest in the context of escape and satiation hypotheses. Journal of Tropical Ecology 20: 1-9.

Chavez-Ramirez, F. and R. D. Slack (1994). Effects of avian foraging and postforaging behaviour on seed dispersal patterns of Ashe juniper. Oikos 71: 40-46.

Chazdon, R. and N. Fetcher (1984). Light environments of tropical forests. In: Physiological ecology of plants of the wet tropics. E. Medina, H. A. Mooney and C. Vasquez-Yanes. Boston, Junk: 27-36.

Chazdon, R. L. (1988). Sunflecks and their importance to forest understorey plants. In: Advances in ecological research. M. Begon, A. H. Fitter, E. D. Ford and A. Macfadyen. London, Academic Press. 18: 2-54.

Chazdon, R. L., R. W. Pearcy, D. W. Lee and N. Fetcher (1996). Photosynthetic responses of tropical forest plants to contrasting light environments. In: Tropical forest plant ecophysiology. S. S. Mulkey, R. L. Chazdon and A. P. Smith. New York, Chapman Hall: 5-55.

Christian, C. E. and M. L. Stanton (2004). Cryptic consequences of a dispersal mutualism: seed burial, elaiosome removal, and seed-bank dynamics. Ecology 85: 1101-1110.

Clark, D. A. and D. B. Clark (1981). Effects of seed dispersal on the regeneration of Bursera graveolens (Burseraceae) on Santa Fe Island, Galapagos. Oecologia 49: 7375 .

Clark, D. A. and D. B. Clark (1984). Spacing dynamics of a tropical rain forest tree: evaluation of the Janzen-Connell model. The American Naturalist 124: 769-788. 
Clark, D. A. and D. B. Clark (1992). Life history diversity of canopy and emergent trees in a neotropical rain forest. Ecological Monographs 62: 315-344.

Clark, J. S., C. Fastie, G. Hurtt, S. T. Jackson, C. Johnson, G. A. King, M. Lewis, J. Lynch, S. Pacala, C. Prentice, E. W. Schupp, T. Webb III and P. Wyckoff (1998a). Reid's paradox of rapid plant migration: dispersal theory and interpretation of paleoecological records. BioScience 48: 13-24.

Clark, J. S., E. Macklin and L. Wood (1998b). Stages and spatial scales of recruitment limitation in southern Appalachian forests. Ecological Monographs 68: 213-235.

Clement, E. J. and M. C. Foster (1994). Alien plants of the British Isles. London, Botanical Society of the British Isles.

Coates-Estrada, R. and A. Estrada (1988). Frugivory and seed dispersal in Cymbopetalum baillonii (Annonaceae) at Los Tuxtlas, Mexico. Journal of Tropical Ecology 4: 157-172.

Coffey, B. T. and J. S. Clayton (1988). New Zealand waterplants: a guide to plants found in New Zealand freshwaters. Hamilton, Ruakura Agricultural Centre, MAFTech North.

Coleman, J. S., K. D. M. McConnaughay and D. D. Ackerly (1994). Interpreting phenotypic variation in plants. TREE 9: 187-191.

Connell, J. H. (1971). On the role of natural enemies in preventing competitive exclusion in some marine animals and in rain forest trees. In: Dynamics of Populations. P. J. den Boer and G. R. Gradwell. Wageningen, The Netherlands, Centre for Agricultural Publishing and Documentation: 298-312.

Connell, J. H. and R. O. Slatyer (1977). Mechanisms of succession in natural communities and their role in community stability and organization. The American Naturalist 111: 1119-1144. 
Coombe, D. E. (1957). The spectral distribution of shadelight in woodlands. Journal of Ecology 45: 823-830.

Corré, W. J. (1983). Growth and morphogenesis of sun and shade plants I. The influence of light quality. Acta Botanical Neerlands 32: 185-202.

Cowan, I. R. (1977). Stomatal behaviour and environment. Advances in Botanical Research 4: 1176-1227.

Cowan, I. R. (1982). Regulation of water use in relation to carbon gain in higher plants. In: Physiological plant ecology II. Water relations and carbon assimilation. Encyclopedia of Plant Physiology, Vol 12B. O. L. Lange, P. S. Nobel, C. B. Osmond and H. Ziegler. Berlin, Springer-Verlag: 589-613.

Cowan, I. R. and G. D. Farquhar (1977). Stomatal function in relation to leaf metabolism and environment. Symposia of the Society for Experimental Biology 31: 471-505.

Craig, H. (1957). Isotopic standards for carbon and oxygen and correction factors for mass-spectrometric analysis of carbon dioxide. Geochimica et Cosmochimica Acta 12: 133-149.

Crawley, M. J. (2000). Seed predators and plant population dynamics. In: Seeds: the ecology of regeneration in plant communities. M. Fenner. Wallingford, UK, CABI International: 167-182.

Crist, T. O. and C. F. Friese (1993). The impact of fungi on soil seeds: implications for plants and granivores in a semiarid shrub-steppe. Ecology 74: 2231-2239.

Cronk, Q. C. B. and J. L. Fuller (1995). Plant invaders. London, Chapman \& Hall.

Culver, D. C. and A. J. Beattie (1980). The fate of Viola seeds dispersed by ants. American Journal of Botany 67: 710-714. 
D'Antonio, C. M., T. L. Dudley and R. N. Mack (1999). Disturbance and biological invasions: direct effects and feedbacks. In: Ecosystems of disturbed ground. L. R. Walker. Amsterdam, NL, Elsevier: 413-452.

D'Antonio, C. M. and P. M. Vitousek (1992). Biological invasions by exotic grasses, the grass-fire cycle, and global change. Annual Review of Ecology and Systematics 23: 63-87.

Daehler, C. C. (2003). Performance comparisons of co-occurring native and alien invasive plants: implications for conservation and restoration. Annual Review of Ecology Evolution and Systematics 34: 183-211.

Dalling, J. W., S. P. Hubbell and K. Silvera (1998a). Seed dispersal, seedling establishment and gap partitioning among tropical pioneer trees. Journal of Ecology 86: 674-689.

Dalling, J. W., M. D. Swaine and N. C. Garwood (1998b). Dispersal patterns and seed bank dynamics of pioneer trees in moist tropical forest. Ecology 79: 564-578.

Davidar, P. (1983). Birds and Neotropical mistletoes: effects on seedling recruitment. Oecologia 60: 271-273.

Davis, M. A., K. J. Wrage, P. B. Reich, M. G. Tjoelker, T. Schaeffer and C. Muermann (1999). Survival, growth, and photosynthesis of tree seedlings competing with herbaceous vegetation along a water-light-nitrogen gradient. Plant Ecology 145: 341-350.

De Steven, D. (1991a). Experiments on mechanisms of tree establishment in old-field succession: seedling emergence. Ecology 72: 1066-1075.

De Steven, D. (1991b). Experiments on mechanisms of tree establishment in old-field succession: seedling survival and growth. Ecology 72: 1076-1088. 
Dean, W. R. J. and S. J. Milton (2000). Directed dispersal of Opuntia species in the Karoo, South Africa: are crows the responsible agents? Journal of Arid Environments 45: $305-314$.

Debussche, M. and P. Isenmann (1994). Bird-dispersed seed rain and seedling establishment in patchy Mediterranean vegetation. Oikos 69: 414-426.

Denslow, J. S. (1987). Tropical rainforest gaps and tree species diversity. Annual Review of Ecology and Systematics 18: 431-451.

Dirr, M. A. and C. W. Heuser (1987). The reference manual of woody plant propogation: from seed to tissue culture. Athens, GA, Varsity Press, Inc.

Dirzo, R. and C. A. Domìnguez (1986). Seed shadows, seed predation and the advantage of dispersal. In: Frugivores and seed dispersal. A. Estrada and T. H. Fleming. Dordrecht, Dr W. Junk Publishers: 237-249.

Donlan, C. J., B. R. Tershey, K. Campbell and F. Cruz (2003). Research for requiems: the need for more collaborative action in eradication of invasive species. Conservation Biology 17: 1850-1851.

Drake, D. R. and L. W. Pratt (2001). Seedling mortality in Hawaiian rain forest: the role of small-scale physical disturbance. Biotropica 33: 319-323.

Drake, J. A., H. A. Mooney, F. di Castri, R. H. Groves, F. J. Kruger, M. Rejmánek and M. Williamson (1989). Biological invasions: a global perspective. Scope 37. Chichester, UK, John Wiley \& Sons.

Durand, L. Z. and G. Goldstein (2001a). Growth, leaf characteristics, and spore production in native and invasive tree ferns in Hawaii. American Fern Journal 91: 2535 . 
Durand, L. Z. and G. Goldstein (2001b). Photosynthesis, photoinhibition, and nitrogen use efficiency in native and invasive tree ferns in Hawaii. Oecologia 126: 345-354.

Dzwonko, Z. and S. Gawroński (2002). Influence of litter and weather on seedling recruitment in a mixed oak-pine woodland. Annals of Botany 90: 245-251.

Ebbett, R. L. and J. Ogden (1998). Comparative seedling growth of five endemic New Zealand podocarp species under different light regimes. New Zealand Journal of Botany 36: 189-201.

Egley, G. H. (1994). Seed germination in soil: dormancy cycles. In: Seed development and germination. J. Kigel and G. Galili. New York, Marcel Dekker Inc.: $529-543$.

Ehrenfeld, J. G. (1997). Invasion of deciduous forest preserves in the New York metropolitan region by Japanese barberry (Berberis thunbergii DC.). Journal of the Torrey Botanical Society 124: 210-215.

Ehrenfeld, J. G. (1999). Structure and dynamics of populations of Japanese barberry (Berberis thunbergii DC.) in deciduous forests of New Jersey. Biological Invasions 1: 203-213

Ehrenfeld, J. G., P. Kourtev and W. Huang (2001). Changes in soil functions following invasions of exotic understory plants in deciduous forests. Ecological Applications 11: 1287-1300.

Ehrlén, J. and O. Eriksson (2000). Dispersal limitation and patch occupancy in forest herbs. Ecology 81: 1667-1674.

Ellison, A. M. and J. N. Parker (2002). Seed dispersal and seedling establishment of Sarracenia purpurea (Sarraceniaceae). American Journal of Botany 89: 1024-1026. 
Ellsworth, D. S. and P. B. Reich (1992). Leaf mass per area, nitrogen content and photosynthetic carbon gain in Acer saccharum seedlings in contrasting forest light environments. Functional Ecology 6: 423-435.

Ellsworth, D. S. and P. B. Reich (1996). Photosynthesis and leaf nitrogen in five Amazonian tree species during early secondary succession. Ecology 77: 581-594.

Ellsworth, J. W., R. A. Harrington and J. H. Fownes (2004). Seedling emergence, growth, and allocation of Oriental bittersweet: effects of seed input, seed bank, and forest floor litter. Forest Ecology and Management 190: 255-264.

Evans, G. C. (1972). The quantitative analysis of plant growth. Berkely, CA, University of California Press.

Farquhar, G. D., J. Ehleringer and K. T. Hubick (1989). Carbon isotope discrimination and photosynthesis. Annual Review of Plant Physiology and Plant Molecular Biology 40: 503-537.

Farquhar, G. D. and R. A. Richards (1984). Isotopic composition of plant carbon correlates with water-use efficiency of wheat genotypes. Australian Journal of Plant Physiology 11: 539-552.

Federer, C. A. and C. B. Tanner (1966). Spectral distribution of light in the forest. Ecology 47: 555-560.

Fenner, M. (1985). Seed ecology. London, Chapman and Hall.

Fenner, M. (1987). Seed characteristics in relation to succession. In: Colonization, sucession and stability. A. Gray, M. Crawley and P. Edwards. Oxford, Blackwell Scientific Publications: 103-114.

Fenner, M. (1987). Seedlings. New Phytologist 106: 35-47. 
Fenner, M. (1994). Ecology of seed banks. In: Seed development and germination. J. Kigel and G. Galili. New York, Marcel Dekker Inc.: 507-528.

Fenner, M. and K. Thompson (2005). The ecology of seeds. Cambridge, Cambridge University Press.

Ferguson, R. H. and D. R. Drake (1999). Influence of vegetation structure on spatial patterns of seed deposition by birds. New Zealand Journal of Botany 37: 671-677.

Field, C. and H. A. Mooney (1986). The photosynthesis-nitrogen relationship in wild plants. In: On the economy of plant form and function. T. J. Givnish. Cambridge, Cambridge University Press: 25-55.

Figueroa, J. A. (2003). Seed germination in temperate rain forest species of southern Chile: chilling and gap dependency germination. Plant Ecology 166: 227-240.

Figueroa, J. A. and J. J. Armesto (2001). Community-wide germination strategies in a temperate rainforest of Southern Chile: ecological and evolutionary correlates. Australian Journal of Botany 49: 411-425.

Figueroa, J. A. and C. H. Lusk (2001). Germination requirements and seedling shade tolerance are not correlated in a Chilean temperate rain forest. New Phytologist 152: 483-489.

Filella, I. and J. Penuelas (2003). Partitioning of water and nitrogen in co-occurring Mediterranean woody shrub species of different evolutionary history. Oecologia 137: $51-61$.

Fischer, R. A. and N. C. Turner (1978). Plant productivity in the arid and semiarid zones. Annual Review of Plant Physiology 29: 277-317.

FitzJohn, R. G. (2002). Sunfleck ultisation and shade tolerance. MSc thesis. Wellington, Victoria University of Wellington. 
Fleming, T. H. and E. R. Heithaus (1981). Frugivorous bats, seed shadows and the structure of tropical forests. Biotropica (Supplement) 13: 45-53.

Fogarty, G. and J. M. Facelli (1999). Growth and competition of Cytisus scoparius, an invasive shrub, and Australian native shrubs. Plant Ecology 144: 27-35.

Frazer, G. W., C. D. Canham and K. P. Lertzman (1999). Gap Light Analyser (GLA), Version 2.0. Imaging software to extract canopy structure and gap light transmission indices from true-colour fisheye photographs, users manual and documentation. Millbrook, New York, Simon Fraser University, Burnaby, British Columbia, and the Institute of Ecosystem Studies.

Friedman, J. (1994). Allelopathy, autotoxicity, and germination. In: Seed development and germination. J. Kigel and G. Galili. New York, Marcel Dekker Inc.: $507-528$

Garrido, J. L., P. J. Rey and C. M. Herrera (2005). Pre- and post-germination determinants of spatial variation in recruitment in the perennial herb Helleborus foetidus L. (Ranunculaceae). Journal of Ecology 93: 60-66.

Garten, C. T. and G. E. Taylor (1992). Foliar $\Delta 13 \mathrm{C}$ within a temperate deciduous forest: spatial, temporal, and species sources of variation. Oecologia 90: 1-7.

Gedroc, J. J., K. D. M. McConnaughay and J. S. Coleman (1996). Plasticity in root/shoot partitioning: optimal, ontogenetic, or both? Functional Ecology 10: 44-50.

Givnish, T. J. (1986). The economics of gas exchange. In: On the economy of plant form and function. T. J. Givnish. Cambridge, Cambridge University Press: 11-21.

Givnish, T. J. (1988). Adaptation to sun and shade: a whole plant perspective. Australian Journal of Plant Physiology 15: 63-92. 
Gleadow, R. M. (1982). Invasion by Pittosporum undulatum of the forests of central Victoria. II. Dispersal, germination and establishment. Australian Journal of Botany 30: 185-198.

Glyphis, J. P., S. J. Milton and W. R. Siegfried (1981). Dispersal of Acacia cyclops by birds. Oecologia (Berlin) 48: 138-141.

Goergen, E. and C. C. Daehler (2001). Inflorescence damage by insects and fungi in native pili grass (Heteropogon contortus) versus alien fountain grass (Pennisetum setaceum) in Hawai'i. Pacific Science 55: 129-136.

Gorchov, D. L., F. Cornejo, C. Ascorra and M. Jaramillo (1993). The role of seed dispersal in the natural regeneration of rain forest after strip-cutting in the Peruvian Amazon. Vegetatio 107/108: 339-349.

Gordon, C., S. J. Woodin, C. E. Mullins and I. J. Alexander (1999). Effects of environmental change, including drought, on water use by competing Calluna vulgaris (heather) and Pteridium aquilinum (bracken). Functional Ecology 13(S1): 96-106.

Greater Wellington Regional Council (2005). Rainfall data recorded at Karori Wildlife Sanctuary 1879-2004, Laura Watts, Greater Wellington Regional Council.

Greenberg, C. H., L. M. Smith and D. J. Levey (2001). Fruit fate, seed germination and growth of an invasive vine - an experimental test of 'sit and wait' strategy. Biological Invasions 3: 363-372.

Grime, J. P. (1965). Shade tolerance in flowering plants. Nature 208: 161-163.

Grime, J. P. (1977). Evidence for the existence of three primary strategies in plants and its relevance to ecological and evolutionary theory. The American Naturalist 111: 1169-1194.

Grime, J. P. (1979). Plant strategies and vegetation processes. New York, John Wiley. 
Grime, J. P. (1989). Seed banks in ecological perspective. In: Ecology of soil seed banks. M. A. Leck, V. T. Parker and R. L. Simpson. San Diego, Academic Press, Inc: xv-xxii.

Grime, J. P., J. C. Crick and J. E. Rincon (1986). The ecological significance of plasticity. Symposia of the Society for Experimental Biology 40: 5-19.

Grime, J. P. and S. H. Hillier (1992). The contribution of seedling regeneration to the structure and dynamics of plant communities and larger units of landscape. In: Seeds: the ecology of regeneration in plant communities. M. Fenner. Oxon, CAB International: 349-364.

Grime, J. P. and R. Hunt (1975). Relative growth-rate: its range and adaptive significance in a local flora. Journal of Ecology 63: 393-422.

Grubb, P. (1987). Some generalizing ideas about colonization and succession in green plants and fungi. In: Colonization, succession and stability. A. Gray, M. Crawley and P. Edwards. Oxford, Blackwell Scientific Publications: 81-102.

Grubb, P. J., W. G. Lee, J. Kollmann and J. B. Wilson (1996). Interaction of irradiance and soil nutrient supply on growth of seedlings of ten European tall-shrub species and Fagus sylvatica. Journal of Ecology 84: 827-840.

Guevara, S. and J. Laborde (1993). Monitoring seed dispersal at isolated standing trees in tropical pastures: consequences for local species availability. Vegetatio 107/108: 319-338.

Harms, K. E., S. J. Wright, O. Calderón, A. Hernández and E. A. Herre (2000). Pervasive density-dependent recruitment enhances seedling diversity in a tropical forest. Nature 404: 493-495.

Harper, J. L. (1977). Population biology of plants. London, Academic Press. 
Hengeveld, R. (1989). Dynamics of biological invasions. London, UK, Chapman and Hall.

Herrera, C., P. Jordano, L. López-Soria and J. Amat (1994). Recruitment of a mastfruiting, bird-dispersed tree: bridging frugivore activity and seedling establishment. Ecological Monographs 64: 315-344.

Herrera, C. M. (1995). Plant-vertebrate seed dispersal systems in the Mediterranean: ecological, evolutionary, and historical determinants. Annual Review of Ecology and Systematics 26: 705-727.

Herrera, C. M. (1998). Long-term dynamics of Mediterranean frugivorous birds and fleshy fruits: a 12-year study. Ecological Monographs 68: 511-538.

Hertling, U. M. and R. A. Lubke (2002). Assessing the potential for biological invasion: The case of Ammophila arenaria in South Africa. South African Journal of Science 96: 520-527.

Heywood, V. H. (1989). Patterns, extents and modes of invasions by terrestrial plants. In: Biological invasions: a global perspective. J. A. Drake, H. A. Mooney, F. di Castriet al. Chichester, UK, John Wiley: 31-60.

Hille Ris Lambers, J. and J. S. Clark (2003). Effects of dispersal, shrubs, and densitydependent mortality on seed and seedling distributions in temperate forests. Canadian Journal of Forest Research 33: 783-795.

Hille Ris Lambers, J., J. S. Clark and M. Lavine (2005). Implications of seed banking for recruitment of southern Appalachian woody species. Ecology 86: 85-95.

Hirose, T. (1987). A vegetative plant growth model: adaptive significance of phenotypic plasticity in matter partitioning. Functional Ecology 1: 195-202. 
Hobbs, R. J. (1989). The nature and effects of disturbance relative to invasions. In: Biological Invasions: a global perspective. J. A. Drake, H. A. Mooney, F. diCastroet al. New York, John Wiley \& Sons: 389-405.

Hobbs, R. J. and L. K. Huenneke (1992). Disturbance, diversity and invasion: implications for conservation. Conservation Biology 6: 324-338.

Hobbs, R. J. and H. A. Mooney (1986). Community changes following shrub invasion of grassland. Oecologia 70: 508-513.

Högberg, P., C. Johannisson and J. E. Hällgren (1993). Studies of the ${ }^{13} \mathrm{C}$ in the foliage reveal interactions between nutrients and water in forest fertilisation experiments. Plant and Soil 153: 207-214.

Honig, M. A., R. M. Cowling and D. M. Richardson (1992). The invasive potential of Australian banksias in South African fynbos: a comparison of the reproductive potential of Banksia ericifolia and Leucadendron laureolum. Australian Journal of Ecology 17: 305-314.

Hoppes, W. G. (1988). Seedfall pattern of several species of bird-dispersed plants in an Illinois woodland. Ecology 69: 320-329.

Horvitz, C. C. and D. W. Schemske (1994). Effects of dispersers, gaps, and predators on dormancy and seedling emergence in a tropical herb. Ecology 75: 1949-1958.

Hoshizaki, K., W. Suzuki and T. Nakashizuka (1999). Evaluation of secondary dispersal in a large-seeded tree Aesculus turbinata: a test of directed dispersal. Plant Ecology 144: 167-176.

Houle, G. (1992). Spatial relationship between seed and seedling abundance and mortality in a deciduous forest of north-eastern North America. Journal of Ecology 80: 99-108. 
Houle, G. (1994). Spatiotemporal patterns in the components of regeneration of four sympatric tree species-Acer rubrum, A. saccharum, Betula alleghaniensis and Fagus grandifolia. Journal of Ecology 82: 39-53.

Houle, G. (1995). Seed dispersal and seedling recruitment: the missing link(s).

Ecoscience 2: 238-244.

Houle, G. (1996). Environmental filters and seedling recruitment on a coastal dune in subarctic Quebec (Canada). Canadian Journal of Botany 74: 1507-1513.

Houle, G. (1998). Seed dispersal and seedling recruitment of Betula alleghaniensis: spatial inconsistency in time. Ecology 79: 807-818.

Howe, H. F. (1986). Seed dispersal by fruit-eating birds and mammals. In: Seed dispersal. D. R. Murray. Australia, Academic Press: 123-189.

Howe, H. F. (1989). Scatter- and clump-dispersal and seedling demography: hypothesis and implications. Oecologia 79: 417-426.

Howe, H. F. (1990). Seed dispersal by birds and mammals: implications for seedling demography. In: Reproductive ecology of tropical forest plants. K. S. Bawa and M. Hadley. Paris, UK, USA, UNESCO and The Parthenon Publishing Group Ltd: 191218.

Howe, H. F. (1993). Aspects of variation in a neotropical seed dispersal system. Vegetatio 107/108: 149-162.

Howe, H. F. and R. B. Primack (1975). Differential seed dispersal by birds of the tree Casearia nitida (Flacoutiaceae). Biotropica 7: 278-283.

Howe, H. F., E. W. Schupp and L. C. Westley (1985). Early consequences of seed dispersal for a neotropical tree (Virola surinamensis). Ecology 66: 781-791. 
Howe, H. F. and J. Smallwood (1982). Ecology of seed dispersal. Annual Review of Ecology and Systematics 13: 201-228.

Hubbell, S. P. (1979). Tree dispersion, abundance, and diversity in a tropical dry forest. Science 203: 1299-1309.

Hubbell, S. P. (1980). Seed predation and the coexistence of tree species in tropical forests. Oikos 35: 214-229.

Hubbell, S. P., R. B. Foster, S. T. O'Brien, K. E. Harms, R. Condit, B. Wechsler, S. J. Wright and S. Loo de Lao (1999). Light-gap disturbances, recruitment limitation, and tree diversity in a neotropical forest. Science 283: 554-557.

Hubrick, K. T. and A. Gibson (1993). Diversity in the relationship between carbon isotope discrimination and transpiration efficiency when water is limited: an isotopic perspective. In: Stable isotopes in plant carbon-water relations. J. Ehleringer, A. E. Hall and G. D. Farquhar. London, Academic Press: 311-326.

Huffman, D. W. and J. C. Tappeiner II (1997). Clonal expansion and seedling recruitment of Oregon grape (Berberis nervosa) in Douglas-fir (Pseudotsuga menziesii) forests: comparisons with salal (Gaultheria shallon). Canadian Journal of Forest Research 27: 1788-1793.

Hughes, F., P. M. Vitousek and T. Tunison (1991). Alien grass invasion and fire in the seasonal submontane zone of Hawaii. Ecology 72: 743-746.

Hulme, P. E. (1998). Post-dispersal seed predation: consequences for plant demography and evolution. Perspectives in Plant Ecology, Evolution and Systematics 1: 32-46.

Hurlbert, S. H. (1984). Pseudoreplication and the design of ecological field experiments. Ecological Monographs 54: 187-211. 
Janzen, D. H. (1970). Herbivores and the number of tree species in tropical forests. American Naturalist 104: 501-528.

Jesson, L., D. Kelly and A. Sparrow (2000). The importance of dispersal, disturbance, and competition for exotic plant invasions in Arthur's Pass National Park, New Zealand. New Zealand Journal of Botany 38: 451-468.

Jones, R. H., B. P. Allen and R. R. Sharitz (1997). Why do early-emerging tree seedlings have survival advantages? A test using Acer rubrum (Aceraceae). American Journal of Botany 84: 1714-1718.

Jones, R. H. and K. W. McLeod (1990). Growth and photosynthetic responses to a range of light environments in Chinese tallowtree and Carolina ash seedlings. Forest Science 36: 851-862.

Jones, R. H. and R. R. Sharitz (1998). Survival and growth of woody plant seedlings in the understorey of floodplain forests in South Carolina. Journal of Ecology 86: 574587.

Jordano, P. (1987). Avian fruit removal: effects of fruit variation, crop size, and insect damage. Ecology 68: 1711-1723.

Jordano, P. and C. M. Herrera (1995). Shuffling the offspring: uncoupling and spatial discordance of multiple stages in vertebrate seed dispersal. Ecoscience 2: 230-237.

Kaelke, C. M., E. L. Kruger and P. B. Reich (2001). Trade-offs in seedling survival, growth, and physiology among hardwood species of contrasting successional status along a light-availability gradient. Canadian Journal of Forest Research 31: 16021616.

Kelly, D. and J. P. Skipworth (1984). Tradescantia fluminensis in a Manawatu (New Zealand) forest: I. Growth and effects on regeneration. New Zealand Journal of Botany 22: 393-397. 
King, D. A. (1991). Correlations between biomass allocation, relative growth rate and light environment in tropical forest seedlings. Functional Ecology 5: 485-492.

Kitajima, K. (1994). Relative importance of photosynthetic traits and allocation patterns as correlates of seedling shade tolerance of 13 tropical trees. Oecologia 98: 419-428.

Kitajima, K. (1996). Ecophysiology of tropical tree seedlings. In: Tropical forest plant ecophysiology. S. S. Mulkey, R. L. Chazdon and A. P. Smith. New York, Chapman Hall: 559-596.

Kitajima, K. and M. Fenner (2000). Ecology of seedling regeneration. In: Seeds: the ecology of regeneration in plant communities. M. Fenner. Wallingford, UK, CABI Publishing: 331-359.

Kitamura, S., T. Yumoto, P. Poonswad, N. Noma, P. Chuailua, K. Plongmai, T. Maruhashi and C. Suckasam (2004). Pattern and impact of hornbill seed dispersal at nest trees in a moist evergreen forest in Thailand. Journal of Tropical Ecology 20: $545-553$.

Kloeppel, B. D. and M. D. Abrams (1995). Ecophysiological attributes of the native Acer saccharum and the exotic Acer platanoides in urban oak forests in Pennsylvania, USA. Tree Physiology 15: 739-746.

Knight, J. D., N. J. Livingston and C. Van Kessel (1994). Carbon isotope discrimination and water-use efficiency of six crops grown under wet and dryland conditions. Plant, Cell and Environment 17: 174-179.

Kobe, R. K. (1997). Carbohydrate allocation to storage as a basis of interspecific variation in sapling survivorship and growth. Oikos 80: 226-233.

Kobe, R. K. (1999). Light gradient partitioning among tropical tree species through differential seedling mortality and growth. Ecology 80: 187-201. 
Kolar, C. S. and D. M. Lodge (2001). Progress in invasion biology: predicting invaders. TREE 16: 199-204.

Kollmann, J. and S. A. Reiner (1996). Light demands of shrub seedlings and their establishment within scrublands. Flora 191: 191-200.

Kornberg, H. and M. H. Williamson (1986). Quantitative aspects of the ecology of biological invasions. Philosophical Transactions of the Royal Society of London (B) 314: 501-746.

Kot, M., M. A. Lewis and P. ven den Driessche (1996). Dispersal data and the spread of invading organisms. Ecology 77: 2027-2042.

Kwesiga, F. and J. Grace (1986). The role of the red/far-red ratio in the response of tropical tree seedlings to shade. Annals of Botany 57: 283-290.

Lake, J. C. and M. R. Leishman (2004). Invasion success of exotic plants in natural ecosystems: the role of disturbance, plant attributes and freedom from herbivores. Biological Conservation 117: 215-226.

Laman, T. G. (1996). Ficus seed shadows in a Bornean rain forest. Oecologia 107: 347-355.

Lambers, H., F. S. Chapin III and T. L. Pons (1998). Plant physiological ecology. New York, Springer-Verlag New York Inc.

Lambers, H. and H. Poorter (1992). Inherent variation in growth rate between higher plants: a search for physiological causes and ecological consequences. Advances in Ecological Research 23: 188-261.

Lamont, B. B., E. T. F. Witkowski and N. J. Enright (1993). Post-fire litter microsites: safe for seeds, unsafe for seedlings. Ecology 74: 501-512. 
Landrum, L. R. (1999). Revision of Berberis (Berberidaceae) in Chile and adjacent southern Argentina. Annals of the Missouri Botanical Garden 86: 793-834.

Latham, R. E. (1992). Co-occurring tree species change rank in seedling performance with resources varied experimentally. Ecology 73: 2129-2144.

Lavergne, C., J. Rameau and J. Figier (1999). The invasive woody weed Ligustrum robustrum subsp. walkeri threatens native forests on La Réunion. Biological Invasions 1: 377-392.

Leck, M. A., V. T. Parker and R. L. Simpson (1989). Ecology of soil seed banks. San Diego, Academic Press, Inc.

Leishman, M. R., G. J. Masters, I. P. Clarke and V. K. Brown (2000). Seed bank dynamics: the role of fungal pathogens and climate change. Functional Ecology 14: 293-299.

Lemmon, P. E. (1957). A new instrument for measuring forest overstory density. Journal of Forestry 55: 667-668.

Lemon, G. D., U. Posluszny and B. C. Husband (2001). Potential and realized rates of vegetative reproduction in Spirodela polyrhiza, Lemna minor, and Wolffia borealis. Aquatic Botany 70: 79-87.

Levey, D. J., T. C. Moermond and J. S. Denslow (1984). Fruit choice in neotropical birds: the effect of distance between fruits on preference patterns. Ecology 65: 844850.

LI-COR. 4421 Superior Street, PO Box 4425, Lincoln, NE 68504, USA.

Li, C. (1999). Carbon-isotope composition, water-use efficiency and biomass productivity of Eucalyptus microtheca populations under different water supplies. Plant Soil 214: 165-171. 
Livingston, R. B. (1972). Influence of birds, stones and soil on the establishment of pasture juniper, Juniperus communis, and red cedar, J. virginiana, in New England pastures. Ecology 53: 1141-1147.

Loach, K. (1970). Shade tolerance in tree seedlings. II. Growth analysis of plants raised under artificial shade. New Phytologist 69: 273-286.

Lodge, D. M. (1993a). Biological invasions: lessons for ecology. TREE 8: 133-137.

Lodge, D. M. (1993b). Species invasions and deletions. In: Biotic interactions and global change. P. M. Kareiva, J. G. Kingsolver and R. B. Huey. Sunderland, Massachusetts, USA, Sinauer: 367-387.

Longbrake, A. C. W. and B. McCarthy (2001). Biomass allocation and resprouting ability of princess tree (Paulownia tomentosa: Scrophulariaceae) across a light gradient. American Midland Naturalist 146: 388-403.

Lonsdale, W. M. (1993a). Losses from the seed bank of Mimosa pigra: soil microorganisms vs. temperature fluctuations. Journal of Applied Ecology 30: 654-660.

Lonsdale, W. M. (1993b). Rates of spread of an invading species: Mimosa pigra in northern Australia. Journal of Ecology 81: 513-521.

Louda, S. M. (1989). Predation in the dynamics of seed regeneration. In: Ecology of soil seed banks. M. A. Leck, V. T. Parker and R. L. Simpson. San Diego, Academic Press, Inc: 53-66.

Loyn, R. H. and K. French (1991). Birds and environmental weeds in south-eastern Australia. Plant Protection Quarterly 6: 137-149.

Luken, J. O. and J. W. Thieret (1997). Assessment and management of plant invasions. New York, USA, Springer-Verlag. 
Lusk, C. H. and A. Del Pozo (2002). Survival and growth of seedlings of 12 Chilean rainforest trees in two light environments: gas exchange and biomass distribution correlates. Austral Ecology 27: 173-182.

Mack, R. N. (1985). Invading plants: their potential contribution to population biology. In: Studies on plant demography: a festschrift for John Harper. J. White. London, Academic Press: 127-142.

Mack, R. N. (1996). Predicting the identity and fate of plant invaders: emergent and emerging approaches. Biological Conservation 78: 107-121.

Mack, R. N. (1997). Plant invasions: early and continuing expressions of global change. In: Past and future rapid environment changes: the spatial and evolutionary responses of terrestrial biota. Vol 47. NATO ASI Series I: Global Environmental Change. B. Huntley, W. Cramer, A. V. Morgan, H. C. Prentice and J. R. M. Allen. Berlin, Springer-Verlag: 205-216.

Mandák, B. (2003). Germination requirements of invasive and non-invasive Atriplex species: a comparative study. Flora 198: 45-54.

Martin, P. H. (1999). Norway maple (Acer platanoides) invasion of a natural forest stand: understory consequence and regeneration pattern. Biological Invasions 1: 215222.

Masaki, T., Y. Kominami and T. Nakashizuka (1994). Spatial and seasonal patterns of seed dissemination of Cornus controversa in a temperate forest. Ecology 75: 19031910.

Mathsoft (1997). S-Plus 4 guide to statistics. Seattle, Washington, USA, Data Analysis Software Division, Mathsoft.

McAlpine, K. G. and D. R. Drake (2003). The effects of small-scale environmental heterogeneity on seed germination in experimental treefall gaps in New Zealand. Plant Ecology 165: 207-215. 
McClanahan, T. R. and R. W. Wolfe (1993). Accelerating forest succession in a fragmented landscape: the role of birds and perches. Conservation Biology 7: 279288.

McConnaughay, K. D. M. and J. S. Coleman (1999). Biomass allocation in plants: ontogeny or optimality? A test along three resource gradients. Ecology 80: 25812593.

McDonald, D. and D. A. Norton (1992). Light environments in temperate New Zealand podocarp rainforests. New Zealand Journal of Ecology 16: 15-22.

McDonnell, M. J. (1986). Old vegetation height and the dispersal pattern of birddisseminated woody plants. Bulletin of the Torrey Botanical Club 113: 6-11.

McDonnell, M. J. and E. W. Stiles (1983). The structural complexity of old field vegetation and the recruitment of bird-dispersed plant species. Oecologia (Berlin) 56: 109-116.

McDowell, S. C. L. (2002). Photosynthetic characteristics of invasive and noninvasive species of Rubus (Rosaceae). American Journal of Botany 89: 14311438.

McEvoy, P. B. and C. S. Cox (1987). Wind dispersal distances in dimorphic achenes of ragwort, Senecio jacobaea. Ecology 68: 2006-2015.

Meinzer, F. C., P. W. Goldstein and M. R. Sharifi (1992). Carbon isotope composition in relation to leaf gas exchange and environmental conditions in Hawaiian Metrosideros polymorpha populations. Oecologia 91: 305-311.

Messier, C. (1992). Effects of neutral shade and growing media on growth, biomass allocation, and competitive ability of Gaultheria shallon. Canadian Journal of Botany 70: 2271-2276. 
Mickelson, J. A. and R. N. Stougaard (2003). Assessment of soil sampling methods to estimate wild oat (Avena fatua) seed bank populations. Weed Science 51: 226-230.

Milberg, P., B. B. Lamont and M. A. Pérez-Fernández (1999). Survival and growth of native and exotic composites in response to a nutrient gradient. Plant Ecology 145: 125-132.

Miller, T. M., A. A. Winn and D. W. Shemske (1994). The effects of density and spatial distribution on selection for emergence time in Prunella vulgaris (Lamiaceae). American Journal of Botany 81: 1-6.

Mitchell, C. E. and A. G. Power (2003). Release of invasive plants from fungal and viral pathogens. Nature 421: 625-627.

Moles, A. T., D. W. Hodson and C. J. Webb (2000). Seed size and shape and persistence in the soil in the New Zealand flora. Oikos 89: 541-545.

Montgomery, R. (2004). Relative importance of photosynthetic physiology and biomass allocation for tree seedling growth across a broad light gradient. Tree Physiology 24: 155-167.

Montgomery, R. and R. Chazdon (2002). Light gradient partitioning by tropical tree seedlings in the absence of canopy gaps. Oecologia 131: 165-174.

Moody, M. E. and R. N. Mack (1988). Controlling the spread of plant invasions: the importance of nascent foci. Journal of Applied Ecology 25: 1009-1021.

Mooney, H. A., M. Küppers, G. W. Koch, J. Gorham, C. C. Chu and W. E. Winner (1988). Compensating effects to growth or carbon partitioning changes in response to $\mathrm{SO}_{2}$-induced photosynthetic reduction in radish. Oecologia 72: 502-506.

Mooney, H. A. and W. E. Winner (1991). Partitioning response of plants to stress. In: Responses of plants to multiple stresses. H. A. Mooney, W. E. Winner and E. J. Pell. California, Academic Press: 129-141. 
Moore, L. A. and M. F. Willson (1982). The effect of micro-habitat, spatial distribution, and display size on dispersal of Lindera benzoin by avian frugivores. Canadian Journal of Botany 60: 557-560.

Morgan, D. C. and H. Smith (1981). Control of development in Chenopodium album L. by shadelight: the effect of light quantity (total fluence rate) and light quality (red: far-red ratio). New Phytologist 88: 239-248.

Morgan, J. W. (1995). Ecological studies of the endangered Rutidosis leptorrhynchoides. I. Seed production, soil seed bank dynamics, population density and their effects on recruitment. Australian Journal of Botany 43: 1-11.

Müller, I., B. Schmid and J. Weiner (2000). The effect of nutrient availability on biomass allocation patterns in 27 species of herbaceous plants. Perspectives in Plant Ecology, Evolution and Systematics 3: 115-127.

Murray, K. G. (1988). Avian seed dispersal of three neotropical gap-dependent plants. Ecological Monographs 58: 271-298.

National Institute of Water and Atmospheric Research. (2005). "National Climate Centre database." New Zealand.

Naumberg, E. and D. S. Ellsworth (2000). Photosynthetic sunfleck utilization potential of understory saplings growing under elevated $\mathrm{CO}_{2}$ in $\mathrm{FACE}$. Oecologia 122: $163-174$.

Newsome, A. E. and I. R. Noble (1986). Ecology and physiological characters of invading species. In: Ecology of biological invasions. R. H. Groves and J. J. Burdon. Cambridge, Cambridge University Press: 1-19.

Niinemets, Ü., F. Valladares and R. Ceulemans (2003). Leaf-level phenotypic variability and plasticity of invasive Rhododendron ponticum and non-invasive Ilex 
aquifolium co-ocurring at two contrasting European sites. Plant, Cell and Environment 26: 941-956.

Ögren, E. (1993). Convexity of the photosynthetic light-response curve in relation to intensity and direction of light during growth. Plant Physiology 101: 1013-1019.

Ögren, E. and J. R. Evans (1993). Photosynthetic light-response curves. Planta 189: 182-190.

Osunkoya, O. O., J. E. Ash, M. S. Hopkins and A. W. Graham (1994). Influence of seed size and seedling ecological attributes on shade-tolerance of rain-forest tree species in northern Queensland. Journal of Ecology 82: 149-163.

Owens, M. K. (1996). The role of leaf and canopy-level gas exchange in the replacement of Quercus virginiana (Fagaceae) by Juniperus ashei (Cupressaceae) in semiarid savannas. American Journal of Botany 83: 617-623.

Packer, A. and K. Clay (2000). Soil pathogens and spatial patterns of seedling mortality in a temperate tree. Nature 404: 278-281.

Panetta, F. D. (2004). Seed banks: the bane of the weed eradicator. Proceedings of the Fourteenth Australian Weeds Conference 2004, Wagga Wagga: pp. 523-526.

Panetta, F. D. and J. McKee (1997). Recruitment of the invasive ornamental, Schinus terebinthifolius, is dependent upon frugivores. Australian Journal of Ecology 22: 432438.

Panetta, F. D. and E. C. Sparkes (2001). Reinvasion of a riparian forest community by an animal-dispersed tree weed following control measures. Biological Invasions 3: 75-88.

Panetta, F. D. and S. Timmins (2004). Evaluating the feasibility of eradication for terrestrial weed incursions. Plant Protection Quarterly 19: 5-11. 
Parendes, L. A. and J. A. Jones (2000). Role of light availability and dispersal in exotic plant invasion along roads and streams in the HJ Andrews experimental forest, Oregon. Conservation Biology 14: 64-75.

Parker, V. T., R. L. Simpson and M. A. Leck (1989). Pattern and process in the dynamics of seed banks. In: Ecology of soil seed banks. M. A. Leck, V. T. Parker and R. L. Simpson. San Diego, Academic Press, Inc: 367-384.

Pattison, R. R., G. Goldstein and A. Ares (1998). Growth, biomass allocation and photosynthesis of invasive and native Hawaiian rainforest species. Oecologia 117: 449-459.

Paynter, Q., S. V. Fowler, J. Memmott and A. W. Sheppard (1998). Factors affecting the establishment of Cytisus scoparius in southern France: implications for managing both native and exotic populations. Journal of Applied Ecology 35: 582-595.

Paz, H. (2003). Root/shoot allocation and root architecture in seedlings: variation among forest sites, microhabitats, and ecological groups. Biotropica 35: 318-332.

Pearcy, R. W. (1987). Photosynthetic gas exchange responses of Australian tropical forest trees in canopy, gap and understory micro-environments. Functional Ecology 1: 169-178.

Pearcy, R. W. and H. Calkin (1983). Carbon dioxide exchange of $\mathrm{C}_{3}$ and $\mathrm{C}_{4}$ tree species in the understory of a Hawaiian forest. Oecologia 58: 26-32.

Peters, H. A. (2003). Neighbour-regulated mortality: The influence of positive and negative density dependence on tree populations in species-rich tropical forests. Ecology Letters 6: 757-765.

Petryna, L., M. Moora, C. O. Nunes, J. J. Cantero and M. Zobel (2002). Are invaders disturbance-limited? Conservation of mountain grasslands in Central Argentina. Applied Vegetation Science 5: 195-202. 
Platt, M. J. (1976). The natural history of a fugitive prairie plant (Mirabilis hirsuta (Pursh) MacM.). Oecologia 22: 399-409.

Poole, A. L. and N. M. Adams (1994). Trees and shrubs of New Zealand. Lincoln, Canterbury, Manaaki Whenua Press.

Poorter, H. and O. Nagel (2000). The role of biomass allocation in the growth response of plants to different levels of light, $\mathrm{CO}_{2}$, nutrients and water: a quantitative review. Australian Journal of Plant Physiology 27: 595-607.

Poorter, H. and P. Pothman (1992). Growth and carbon economy of a fast-growing and a slow-growing grass species as dependent on ontogeny. New Phytologist 120: 159-166.

Poorter, H. and C. Remkes (1990). Leaf area ratio and net assimilation rate of 24 wild species differing in relative growth rate. Oecologia 83: 553-559.

Poorter, L. (1999). Growth responses of 15 rain-forest tree species to a light gradient: the relative importance of morphological and physiological traits. Functional Ecology 13: $396-410$.

Poorter, L. (2001). Light-dependent changes in biomass allocation and their importance for growth of rain forest tree species. Functional Ecology 15: 113-123.

Poorter, L. and S. F. Oberbauer (1993). Photosynthetic induction responses of two rainforest tree species in relation to light environment. Oecologia 96: 193-199.

Popma, J. and F. Bongers (1988). The effect of canopy gaps on growth and morphology of seedlings of rain forest species. Oecologia (Berlin) 75: 625-632.

Popma, J., F. Bongers, M. Martínez-Ramos and E. Veneklaas (1988). Pioneer species distribution in treefall gaps in Neotropical rain forest; a gap definition and its consequences. Journal of Tropical Ecology 4: 77-88. 
Popma, J., F. Bongers and M. J. A. Werger (1992). Gap-dependence and leaf characteristics of trees in a tropical lowland rain forest in Mexico. Oikos 63: 207-214.

Radford, I. J., D. M. Nicholas, J. R. Brown and D. J. Kriticos (2001). Paddock-scale patterns of seed production and dispersal in the invasive shrub Acacia nilotica (Mimosaceae) in northern Australian rangelands. Austral Ecology 26: 338-348.

Radford, I. J., M. Nicholas, F. Tiver, J. Brown and D. Kriticos (2002). Seedling establishment, mortality, tree growth rates and vigour of Acacia nilotica in different Astrebla grassland habitats: implications for invasion. Austral Ecology 27: 258-268.

Ramakrishnan, P. S. and P. M. Vitousek (1989). Ecosystem-level processes and the consequences of biological invasions. In: Biological Invasions: a global perspective. J. A. Drake, H. A. Mooney, F. diCastroet al. New York, John Wiley \& Sons: 281300.

Rao, P. B. and S. P. Singh (1989). Effect of shade on Central Himalayan species from a successional gradient. Acta Oecologia 10: 21-33.

Reich, P. B., M. B. Walters and D. S. Ellsworth (1997). From tropics to tundra: global convergence in plant functioning. Proceedings of The National Academy of Sciences 94: 13730-13734.

Rejmánek, M. (1989). Invasibility of plant communities. In: Biological Invasions: a global perspective. J. A. Drake, H. A. Mooney, F. diCastroet al. New York, John Wiley \& Sons: 369-388.

Rejmánek, M. (1995). What makes a species invasive? In: Plant invasions: general aspects and special problems. P. Pyšek, K. Prach, M. Rejmánek and M. Wade. Amsterdam, SPB Academic Publishing: 3-13.

Rejmánek, M. (1996). A theory of seed plant invasiveness: the first sketch. Biological Conservation 78: 171-181. 
Restrepo, C., N. Gomez and S. Heredia (1999). Anthropogenic edges, treefall gaps, and fruit-frugivore interactions in a neotropical montane forest. Ecology 80: 668-685.

Rey, P. J. and J. M. Alcàntara (2000). Recruitment dynamics of a fleshy-fruited plant (Olea europaea): connecting patterns of seed dispersal to seedling establishment. Journal of Ecology 88: 622-633.

Rice, E. L. (1983). Allelopathy. New York, Academic Press.

Rice, S. A. and F. A. Bazzaz (1989). Quantification of plasticity of plant traits in response to light intensity: comparing phenotypes at a common weight. Oecologia 78 : 502-507.

Richardson, D. M., N. Allsopp, C. M. D'Antonio, S. J. Milton and M. Rejmánek (2000a). Plant invasions - the role of mutualisms. Biological Reviews 75: 65-93.

Richardson, D. M., P. Pyšek, M. Rejmánek, M. G. Barbour, F. D. Panetta and C. J. West (2000b). Naturalization and invasion of alien plants: concepts and definitions. Diversity and Distributions 6: 93-107.

Richardson, D. M., B. W. Van Wilgen and D. T. Mitchell (1987). Aspects of the reproductive ecology of four Australian Hakea species Proteaceae in South Africa. Oecologia 71: 345-354.

Rincón, E. and P. Huante (1994). Influence of mineral nutrient availability on growth of tree seedlings from the tropical deciduous forest. Structure and Function of Trees 9: 93-97.

Robinson, D. and I. Rorison (1988). Plasticity in grass species in relation to nitrogen supply. Functional Ecology 2: 249-257.

Roff, D. A. (1992). The evolution of life histories: theory and analysis. New York, Chapman and Hall. 
Ross, M. A. and J. L. Harper (1972). Occupation of biological space during seedling establishment. Journal of Ecology 60: 77-88.

Roy, J. (1990). In search of the characteristics of plant invaders. In: Biological invasions in Europe and the Mediterranean Basin. F. di Castro, A. J. Hansen and M. Debussche. Dordrecht, Kluwer Academic Publishers: 335-352.

Russell, S. K. and E. W. Schupp (1998). Effects of microhabitat patchiness on patterns of seed dispersal and seed predation on Cercocarpus ledifolius (Rosaceae). Oikos 81: 434-443.

Russo, S. E. and C. K. Augspurger (2004). Aggregated seed dispersal by spider monkeys limits recruitment to clumped patterns in Virola calophylla. Ecology Letters 7: 1058-1067.

Ryser, P. and L. Eek (2000). Consequences of phenotypic plasticity vs interspecific differences in leaf and root traits for acquisition of aboveground and belowground resources. American Journal of Botany 87: 402-411.

Sallabanks, R. (1993). Fruiting plant attractiveness to avian seed dispersers: native vs. invasive Crataegus in western Oregon. Madroño 40: 108-116.

Salmonson, M. G. (1978). Adaptations for animal dispersal of one-seed juniper seeds. Oecologia 32: 333-339.

Sanford, N. L., R. A. Harrington and J. H. Fownes (2003). Survival and growth of native and alien woody seedlings in open and understorey environments. Forest Ecology and Management 183: 377-385.

Schierenbeck, K. A., R. N. Mack and R. R. Sharitz (1994). Effects of herbivory on growth and biomass allocation in native and introduced species of Lonicera. Ecology 75: 1661-1672. 
Schmidt, K. A. and C. J. Whelan (1999). Effects of exotic Lonicera and Rhamnus on songbird nest predation. Conservation Biology 13: 1502-1506.

Schmitt, J. and R. D. Wulff (1993). Light spectral quality, phytochrome and plant competition. TREE 8: 47-51.

Schmitz, D. C., D. Simberloff, R. H. Hofstetter, W. Haller and D. Sutton (1997). The ecological impact of nonindigenous plants. In: Strangers in paradise: impact and management of nonindigenous species in Florida. D. Simberloff, D. C. Schmitz and T. C. Brown. Washington, D. C., USA, Island Press: 39-61.

Schupp, E. W. (1988a). Factors affecting post-dispersal seed survival in a tropical forest. Oecologia 76: 525-530.

Schupp, E. W. (1988b). Seed and early seedling predation in the forest understory and in treefall gaps. Oikos 51: 71-78.

Schupp, E. W. (1990). Annual variation in seedfall, postdispersal predation, and recruitment of a neotropical tree. Ecology 71: 504-515.

Schupp, E. W. (1995). Seed-seedling conflicts, habitat choice, and patterns of plant recruitment. American Journal of Botany 82: 399-409.

Schupp, E. W. and M. Fuentes (1995). Spatial patterns of seed dispersal and the unification of plant population ecology. Ecoscience 2: 267-275.

Schweitzer, J. A. and K. C. Larson (1999). Greater morphological plasticity of exotic honeysuckle species may make them better invaders than native species. Journal of the Torrey Botanical Society 126: 15-23.

Seiwa, K. (1997). Variable regeneration behaviour of Ulmus davidiana var. japonica in response to disturbance regime for risk spreading. Seed Science Research 7: $195-$ 207. 
Seiwa, K. (1998). Advantages of early germination for growth and survival of seedlings of Acer mono under different overstorey phenologies in deciduous broadleaved forests. Journal of Ecology 86: 219-28.

Shibata, M. and T. Nakashizuka (1995). Seed and seedling demography of four cooccurring Carpinus species in a temperate deciduous forest. Ecology 76: 1099-1108.

Shimizu, Y. and H. Tabata (1985). Invasion of Pinus lutchuensis and its influence on the native forest on a Pacific island. Journal of Biogeography 12: 195-297.

Silander, J. A. (1978). Density-dependent control of reproductive success in Cassia biflora. Biotropica 10: 292-296.

Silander, J. A. and D. M. Klepeis (1999). The invasion ecology of Japanese barberry (Berberis thunbergii) in the New England landscape. Biological Invasions 1: 189-201.

Silvertown, J. (1982). Introduction to plant population biology. London, Longman.

Simons, A. M. and M. O. Johnston (2000). Variation in seed traits of Lobelia inflata (Campanulaceae): sources and fitness consequences. American Journal of Botany 87: 124-132.

Simpson, J. D., B. S. P. Wang and B. I. Daigle (2004). Long-term seed storage of various Canadian hardwoods and conifers. Seed Science and Technology 32: 561572.

Simpson, R. L., M. A. Leck and V. T. Parker (1989). Seed banks: general concepts and methodological issues. In: Ecology of soil seed banks. M. A. Leck, V. T. Parker and R. L. Simpson. New York, Academic Press: 3-8.

Slocum, M. G. and C. C. Horvitz (2000). Seed arrival under different genera of trees in a neotropical pasture. Plant Ecology 149: 51-62. 
Smith, M. D. and A. K. Knapp (2001). Physiological and morphological traits of exotic, invasive exotic, and native plant species in tallgrass prairie. International Journal of Plant Science 162: 785-792.

SPSS (2004). SigmaStat statistical software. Point Richmond, California, Systat Software, Inc.

Stanley, M. C. and A. Lill (2002). Avian fruit consumption and seed dispersal in a temperate Australian woodland. Austral Ecology 27: 137-148.

Stansbury, C. D. (1996). Observations of birds feeding on bridal creeper (Asparagus asparagoides) fruits within Yanchep National Park, western Australia. Plant Protection Quarterly 11: 59-60.

Stansbury, C. D. (2001). Dispersal of the environmental weed bridal creeper, Asparagus asparagoides, by silvereyes, Zosterops lateralis, in south-western Australia. Emu 101: 39-45.

Stapanian, M. A. and C. C. Smith (1978). A model for scatter-hoarding: coevolution of fox squirrels and black walnuts. Ecology 59: 884-96.

Stiles, E. W. and D. W. White (1986). Seed deposition patterns: influence of season, nutrients, and vegetation structure. In: Frugivores and seed dispersal. A. Estrada and T. H. Fleming. Dordrecht, DR W Junk Publishers: 45-54.

Stone, C. P., C. W. Smith and J. T. Tunisson, Eds. (1992). Alien plant invasions in native ecosystems of Hawaii. Honolulu, University of Hawaii Cooperative National Park Resources Studies Unit, and Hawaii University Press.

Stratton, L. C. and G. Goldstein (2001). Carbon uptake, growth and resource-use efficiency in one invasive and six native Hawaiian dry forest tree species. Tree Physiology 21: 1327-1334. 
Strauss-Debenedetti, S. and F. A. Bazzaz (1991). Plasticity and acclimation to light in tropical Moraceae of different successional positions. Oecologia 87: 377-387.

Streng, D., J. Glitzenstein and P. Harcombe (1989). Woody seedling dynamics in an East Texas floodplain forest. Ecological Monographs 59: 177-204.

Swaine, M. D. and T. C. Whitmore (1988). On the definition of ecological species groups in tropical rain forests. Vegetatio 75: 81-86.

Sykes, W. R. (1982). Checklist of dicotyledons naturalised in New Zealand 15. Annonales, Berberidales, Cactales, Fagales, some Geraniales, Juglandales, Laurales, Rutales, Salicales, Sapindales, Tiliales, Nyctaginaceae, and Zygophyllaceae. New Zealand Journal of Botany 20: 333-341.

Tani, T., H. Kudoh and N. Kachi (2001). Responses of photosynthesis and biomass allocation of an understorey herb, Pteridophyllum racemosum, to gradual increases in irradiance. Annals of Botany 88: 393-402.

Thébaud, C., A. C. Finzi, L. Affre, M. Debussche and J. Escarre (1996). Assessing why two introduced Conyza differ in their ability to invade Mediterranean old fields. Ecology 77: 791-804.

Thomas, D. W., D. Cloutier, M. Provencher and C. Houle (1988). The shape of birdand bat-generated seed shadows around a tropical fruiting tree. Biotropica 20: 347348.

Thompson, J. N. and M. F. Willson (1978). Disturbance and the dispersal of fleshy fruits. Science 200: 1161-1163.

Thompson, K. (2000). The functional ecology of soil seed banks. In: Seeds: the ecology of regeneration in plant communities. M. Fenner. Wallingford, UK, CABI Publishing: 215-235. 
Thompson, K., J. P. Bakker and R. M. Bekker (1997). The soil seed banks of north west Europe: methodology, density and longevity. Cambridge, Cambridge University Press.

Thompson, K., R. M. Ceriani, J. P. Bakker and R. M. Bekker (2003). Are seed dormancy and persistence in soil related? Seed Science Research 13: 97-100.

Thompson, K. and J. P. Grime (1979). Seasonal variation in the seed banks of herbaceous species in ten contrasting habitats. Journal of Ecology 67: 893-921.

Thompson, K., J. G. Hodgson and T. C. G. Rich (1995). Native and alien plants: more of the same? Ecography 18: 390-402.

Thompson, W. A., L. K. Huang and P. E. Kriedemann (1992a). Photosynthetic response to light and nutrients in sun-tolerant and shade-tolerant rainforest trees. II. Leaf gas exchange and component processes of photosynthesis. Australian Journal of Plant Physiology 19: 19-42.

Thompson, W. A., P. E. Kriedemann and I. E. Craig (1992b). Growth and photosynthetic response to light and nutrients in sun-tolerant and shade-tolerant rainforest trees. I. Growth, leaf anatomy and nutrient content. Australian Journal of Plant Physiology 19: 1-18.

Thornley, J. H. M. (1969). A model to describe the partitioning of photosynthate during vegetative plant growth. Annals of Botany 33: 419-430.

Thornley, J. H. M. (1972). A balanced quantitative model for root: shoot ratios in vegetative plants. Annals of Botany 36: 431-441.

Tilman, D. (1988). Plant strategies and the dynamics and structure of plant communities. Princeton, Princeton University Press.

Tilman, D. (1997). Community invasibility, recruitment limitation, and grassland biodiversity. Ecology 78: 81-92. 
Timmins, S. M. and I. W. Mackenzie (1995). Weeds in New Zealand protected natural areas database. Wellington, Department of Conservation.

Timmins, S. M. and P. A. Williams (1987). Characteristics of problem weeds in New Zealand's protected natural areas. In: Nature conservation: the role of remnants of native vegetation. D. A. Saunders, G. W. Arnold, A. A. Burbidge and A. J. M. Hopkins. NSW, Surrey Beatty and Sons Pty Limited: 241-247.

Tinoco-Ojanguren, C. and R. W. Pearcy (1995). A comparison of light quality and quantity effects on the growth and steady-state and dynamic photosynthetic characteristics of three tropical tree species. Functional Ecology 9: 222-230.

Toft, N. L., J. E. Anderson and R. S. Nowak (1989). Water-use efficiency and carbonisotope composition of plants in a cold desert environment. Oecologia 80: 11-18.

Toh, I., M. Gillespies and D. Lamb (1999). The role of isolated trees in facilitating tree seedling recruitment at a degraded sub-tropical rainforest site. Restoration Ecology 7: 288-297.

Traveset, A., J. Gulias, N. Riera and M. Mus (2003). Transition probabilities from pollination to establishment in a rare dioecious shrub species (Rhamnus ludovicisalvatoris) in two habitats. Journal of Ecology 91: 427-437.

Turner, I. M. (1990). Tree seedling growth and survival in a Malaysian rain forest. Biotropica 22: 146-154.

Uhl, C., K. Clark, N. Dezzeo and P. Maquirrino (1988). Vegetation dynamics in Amazonian treefall gaps. Ecology 69: 751-763.

Valladares, F., S. J. Wright, E. Lasso, K. Kitajima and R. W. Pearcy (2000). Plastic phenotypic response to light of 16 congeneric shrubs from a Panamanian rainforest. Ecology 81: 1925-1936. 
Vázquez-Yanes, C. and A. Orozco-Segovia (1984). Ecophysiology of seed germination in the tropical humid tropics of the world: a review. In: Physiological ecology of plants of the wet tropics. E. Medina, H. A. Mooney and C. VázquezYanes. Dordrecht, The Netherlands, Dr. W. Junk: 37-50.

Vázquez-Yanes, C. and A. Orozco-Segovia (1993). Patterns of seed longevity and germination in the tropical rainforest. Annual Review of Ecology and Systematics 24: 69-87.

Veenendaal, E. M., M. D. Swaine, V. K. Agyeman, D. Blay, I. K. Abebrese and C. E. Mullins (1995). Differences in plant and soil water relations in and around a forest gap in West Africa during the dry season may influence seedling establishment and survival. Journal of Ecology 83: 83-90.

Veenendaal, E. M., M. D. Swaine, R. T. Lecha, M. F. Walsh, I. K. Abebrese and K. Owusu-Afriyie (1996). Responses of West African forest tree seedlings to irradiance and soil fertility. Functional Ecology 10: 501-511.

Venable, D. L. and L. Lawlor (1980). Delayed germination and dispersal in desert annuals: escape in space and time. Oecologia 46: 272-282.

Veneklaas, E. J. and L. Poorter (1998). Growth and carbon partitioning of tropical tree seedlings in contrasting light environments. In: Inherent variation in plant growth: physiological mechanisms and ecological consequences. H. Lambers, H. Poorter and M. M. I. V. Vuren. Leiden, Backhuys Publishers: 337-361.

Verdú, M. and P. García-Fayos (1996). Nucleation processes in a Mediterranean birddispersed plant. Functional Ecology 10: 275-280.

Vilà, M. and C. M. D'Antonio (1998). Fruit choice and seed dispersal of invasive vs. noninvasive Carprobrotus (Aizoaceae) in coastal California. Ecology 79: 1053-1060.

Vitousek, P. M. (1990). Biological invasions and ecosystem processes: towards an integration of population biology and ecosystem studies. Oikos 57: 7-13. 
Vitousek, P. M. and J. S. Denslow (1986). Nitrogen and phosphorous availability in treefall gaps of a lowland tropical forest. Journal of Ecology 74: 1167-1178.

Vitousek, P. M. and L. R. Walker (1989). Biological invasion by Myrica faya in Hawai'i: plant demography, nitrogen fixation, ecosystem effects. Ecological Monographs 59: 247-265.

Vitousek, P. M., L. R. Walker, L. D. Whiteaker, D. Mueller-Dombois and P. A. Matson (1987). Biological invasion by Myrica faya alters ecosystem development in Hawaii. Science 238: 802-804.

Walker, L. R. (1993). Nitrogen fixers and species replacements in primary succession. In: Primary succession on land. J. Miles and D. H. Walton. Oxford, Blackwell: 249272.

Walters, M. B., E. L. Kruger and P. B. Reich (1993). Growth, biomass distribution and $\mathrm{CO}_{2}$ exchange of northern hardwood seedlings in high and low light: relationships with successional status and shade tolerance. Oecologia 94: 7-16.

Walters, M. B. and P. B. Reich (1996). Are shade tolerance, survival, and growth linked? Low light and nitrogen effects on hardwood seedlings. Ecology 77: 841-853.

Walters, M. B. and P. B. Reich (2000). Seed size, nitrogen supply, and growth rate affect tree seedling survival in deep shade. Ecology 81: 1887-1901.

Wang, G. G., H. Qian and K. Klinka (1994). Growth of Thuja plicata seedlings along a light gradient. Canadian Journal of Botany 72: 1749-1757.

Webb, C. J. and M. J. A. Simpson (2001). Seeds of New Zealand gymnosperms and dicotyledons. Christchurch, New Zealand, Manuka Press. 
Webb, C. J., W. R. Sykes and P. J. Garnock-Jones (1988). Flora of New Zealand Volume IV. Naturalised pteridophytes, gymnosperms, dicotyledons. Christchurch, Botany Division DSIR.

Weber, A., B. Gilbert, J. P. Kimmins and C. E. Prescott (2003). Factors limiting the early survivorship of Thuja plicata on northern Vancouver Island, British Columbia. Canadian Journal of Forest Research 33: 854-861.

Weber, E. and C. M. D'Antonio (1999). Phenotypic plasticity in hybridizing Carpobrotus spp. (Aizoaceae) from coastal California and its role in plant invasion. Canadian Journal of Botany 77: 1411-1418.

Weiss, P. W. and I. R. Noble (1984). Interactions between seedlings of Chrysanthemoides monilifera and Acacia longifolia. Australian Journal of Ecology 9: 107-115.

Welden, C. W., S. W. Hewett, S. P. Hubbell and R. B. Foster (1991). Sapling survival, growth and recruitment: relationship to canopy height in a neotropical forest. Ecology 72: 35-50.

Wenny, D. G. (2000). Seed dispersal, seed predation, and seedling recruitment of a neotropical montane tree. Ecological Monographs 70: 331-351.

Wenny, D. G. (2001). Advantages of seed dispersal: a re-evaluation of directed dispersal. Evolutionary Ecology Research 3: 51-74.

Wenny, D. G. and D. J. Levey (1998). Directed seed dispersal by bellbirds in a tropical cloud forest. Proceedings of The National Academy of Sciences 95: 62046207.

Wheelwright, N. T. and G. H. Orians (1982). Seed dispersal by animals: contrasts with pollen dispersal, problems of terminology, and constraints on coevolution. The American Naturalist 119: 402-413. 
Whelan, C. J., M. F. Willson, C. A. Tuma and I. Souza-Pinto (1991). Spatial and temporal patterns of post-dispersal seed predation. Canadian Journal of Botany 69: 428-436.

Williams, C. E., M. V. Lipscomb, W. C. Johnson and E. T. Nilsen (1990). Influence of leaf litter and soil moisture regime on early establishment of Pinus pungens. American Midland Naturalist 124: 142-152.

Williams, D. G. and R. A. Black (1994). Drought response of a native and introduced Hawaiian grass. Oecologia 97: 512-519.

Williams, D. G., R. N. Mack and R. A. Black (1995). Ecophysiology of introduced Pennisetum setaceum on Hawaii: the role of phenotypic plasticity. Ecology 76: 15691580 .

Williams, P. A. and B. J. Karl (1996). Fleshy fruits of indigenous and adventive plants in the diets of birds in forest remnants, Nelson, New Zealand. New Zealand Journal of Ecology 20: 127-145.

Willson, M. F. (1993). Dispersal mode, seed shadows, and colonization patterns. Vegetatio 107/108: 261-280.

Willson, M. F. and F. H. J. Crome (1989). Patterns of seed rain at the edge of a tropical Queensland rainforest. Journal of Tropical Ecology 5: 301-308.

Willson, M. F. and C. J. Whelan (1990). Variation in postdispersal survival of vertebrate-dispersed seeds: effects of density, habitat, location, season, and species. Oikos 57: 191-198.

Wilson, J. B. (1988). A review of evidence on the control of shoot: root ratio, in relation to models. Annals of Botany 61: 433-449. 
Wilson, R. G. (1988). Biology of weed seeds in the soil. In: Weed management in agroecosystems: ecological approaches. M. A. Altieri and M. Liebman. Boca Raton, Florida, CRC Press, Inc.: 25-39.

Wiser, S. K., R. B. Allen, P. W. Clinton and K. H. Platt (1998). Community structure and forest invasion by an exotic herb over 23 years. Ecology 79: 2071-2081.

Woitke, M. and H. Dietz (2002). Shifts in dominance of native and invasive plants in experimental patches of vegetation. Perspectives in Plant Ecology, Evolution and Systematics 5: 165-184.

Wright, E. F., K. D. Coates, C. D. Canham and P. Bartemucci (1998). Species variability in growth response to light across climatic regions in northwestern British Columbia. Canadian Journal of Forest Research 28: 871-886.

Wright, I. J. and M. Westoby (2001). Understanding seedling growth relationships through specific leaf area and leaf nitrogen concentration: generalisations across growth forms and growth irradiance. Oecologia 127: 21-29.

Yamashita, N., N. Tanaka, Y. Hoshi, H. Kushima and K. Kamo (2003). Seed and seedling demography of invasive and native trees of subtropical Pacific islands. Journal of Vegetation Science 14: 15-24.

Zangaro, W., S. M. A. Nisizaki, J. C. B. Domingos and E. M. Nakano (2003).

Mycorrhizal response and successional status in 80 woody species from south Brazil. Journal of Tropical Ecology 19: 315-324.

Zar, J. H. (1984). Biostatistical analysis. New Jersey, Prentice-Hall.

Zipperlen, S. W. and M. C. Press (1996). Photosynthesis in relation to growth and seedling ecology of two dipterocarp rain forest tree species. Journal of Ecology 84: 863-876. 
